\title{
Impact of Highest Maximum Sustained Wind Speed and Its Duration on Storm Surges and Hydrodynamics Along Krishna-Godavari Coast
}

Maneesha Sebastian ( $\square$ maneeshasebastian@gmail.com )

Indian Institute of Technology Bombay https://orcid.org/0000-0002-6602-4473

Manasa Ranjan Behera

Indian Institute of Technology Bombay

\section{Research Article}

Keywords: Tropical Cyclone, Rapid intensification, Gradual intensification, Duration of Intensification, Storm Surge, Hydrodynamics

Posted Date: May 10th, 2021

DOI: https://doi.org/10.21203/rs.3.rs-241625/v1

License: (c) (i) This work is licensed under a Creative Commons Attribution 4.0 International License.

Read Full License

Version of Record: A version of this preprint was published at Climate Dynamics on February 19th, 2022. See the published version at https://doi.org/10.1007/s00382-022-06173-9. 
1 Impact of highest maximum sustained wind speed and its duration on storm surges and 2 hydrodynamics along Krishna-Godavari coast

3 Maneesha Sebastian $^{1, *}$, Manasa Ranjan Behera ${ }^{1,2}$

$4{ }^{1}$ Department of Civil Engineering, Indian Institute of Technology Bombay, Mumbai, 5 Maharashtra 400076, India,

6 2 Interdisciplinary Program in Climate Studies, Indian Institute of Technology Bombay, 7 Mumbai 400076, India, 8

9 *Corresponding author:

10 Dr. Maneesha Sebastian

11 Department of Civil Engineering,

12 Indian Institute of Technology Bombay,

13 Powai, Mumbai - 400076, India.

14 Email id: maneeshasebastian@gmail.com

15 orcid: https://orcid.org/0000-0002-6602-4473

16

17

18

19

20

21

22 
24 The storm surge and hydrodynamics along the Krishna-Godavari (K-G) basin are examined based on numerical experiments designed from assessing the landfalling cyclones in Bay of Bengal $(\mathrm{BoB})$ over the past 38 years with respect to its highest maximum sustained wind speed and its duration. The model is validated with the observed water levels at the tide gauge stations at Visakhapatnam during Helen (2013) and Hudhud (2014). Effect of gradual and rapid intensification of cyclones on the peak water levels and depth average currents are examined and the vulnerable locations are identified. The duration of intensification of a rapidly intensifying cyclone over the continental shelf contributed to about 10-18\% increase in the peak water levels, whereas for the gradually intensifying cyclone the effect is trivial. The inclusion of the wave-setup increased the peak water levels up to $39 \%$ compared to those without wave-setup. In the deep water region, only rapidly intensifying cyclones affected the peak MWEs. Intensification over the continental slope region significantly increases the currents along the shelf region and coast. The effect on peak maximum depth averaged current extends up to $400 \mathrm{~km}$ from the landfall location. Thus, it is necessary to consider the effect of various combinations of the highest cyclone intensity and duration of intensification for identifying the worst scenarios for impact assessment of coastal processes and sediment transport. The study is quite useful in improving the storm surge prediction, in preparedness, risk evaluation, and vulnerability assessment of the coastal regions in the present changing climate.

Keywords: Tropical Cyclone, Rapid intensification, Gradual intensification, Duration of

\section{Intensification, Storm Surge, Hydrodynamics}

\section{Declarations}

\section{Funding}

Industrial Research \& Consultancy Centre (07IR001) and Department of Civil Engineering (DF/1111020) at Indian Institute of Technology (IIT) Bombay.

\section{Conflicts of interest/Competing interests}

The authors declare that they have no known conflicts of interest/competing interests. 


\section{Introduction}

Indian ocean is warming at a rapid pace giving rise to increased tropical cyclone (TC) activities under the changing climate (Singh and Roxy 2020). Storm surge is one of deadliest and frequently occurring extreme events associated with TCs that affect the coastal community. TC induced storm surge in the Bay of Bengal $(\mathrm{BoB})$ is reported to be the most destructive in nature as it affects the socio-economics of the densely populated coastal community India, Bangladesh, Sri Lanka and Myanmar. The life of a cyclone starts as a tropical disturbance with lower wind speed that intensifies based on its favourable condition while ends with the cyclone decaying. A TC is categorised based on upper bound of the highest maximum sustained wind speed during its life cycle. The improvement in the track and the intensity prediction have resulted in improvement in the surge prediction accuracy as well. But the abrupt variation in the storm parameters such as cyclone intensity, pressure drop, duration, translation speed, cyclone track during the life of a TC make the storm surge prediction further challenging in a changing climate.

Cyclone intensity is measured in terms of the maximum sustained wind speed measured for duration of 1 or 3 or 10 minute over an unobstructed height of $10 \mathrm{~m}$. Table 1 , shows the cyclone category based on the India Meteorological Department (IMD), with the maximum sustained wind speed measured for a duration of 3 minutes. Intensification rate of a cyclone is computed by forward differencing the maximum sustained surface wind speed in time, usually at a 6hour interval (Mei et al. 2012). A rapidly intensifying cyclone refers to those cyclones whose wind speed escalates by $15 \mathrm{~m} / \mathrm{s}$ or more within a period of 24 hours, while those intensified by less than $15 \mathrm{~m} / \mathrm{s}$ are referred to as gradually intensifying cyclones. A cyclone undergoes abrupt variation in the intensity along its path of propagation leading to forecast errors that can affect the surge response at the coast. The destructive nature of the cyclone wind intensity makes it practically impossible to measure it directly. In the absences of observations from the surface ships or instrumented ocean buoys, Dvorak technique (Dvorak 1975) estimates the cyclone intensity from Infrared and/or satellite imagery based on their appearances, temperature, and apparent motion of cloud features over time and are represented as Current Intensity (C.I) or $\mathrm{T}$-number, where $\mathrm{T}$ refers to the TC. The minimum T-number of different cyclone category is shown in Table 1.

The extreme sea level rise caused by TC storm surge pose major catastrophic damage to life and property as a result of coastal inundation, and create an imbalance to the existing coastal 
ecosystem. Knapp \& Kruk (2010) reported variations in the best track information provided by different agencies that include IMD and JTWC. Their study reports that there exist variations in the maximum sustained wind speed as well as the temporal scale of the maximum sustained wind speed. Recent investigations on the cyclone activities under the changing climate, (Elsner et al. 2008; Balaguru et al. 2014, 2018; Sebastian and Behera 2015; Bhatia et al. 2019; IPCC 2019; Albert and Bhaskaran 2020; Wu et al. 2020) have revealed an increase in the cyclone intensity, duration, intensifying rate, etc. especially in the Atlantic Ocean and North Indian Ocean (NIO) regions. Underestimation/overestimation of the cyclone intensity during a TC event impact the storm surge prediction accuracy. Many researchers (Mcinnes et al. 2003; Irish et al. 2008; Rego and Li 2009; Resio et al. 2013; Cyriac et al. 2018; Sahoo and Bhaskaran 2018; Sebastian et al. 2019; Thomas et al. 2019; Li et al. 2020; Poulose et al. 2020) have quantified the impact of storm surge with changing intensity, storm size, speed of the storm, approach angles but the impact of duration of the highest cyclone intensity on the storm surge has not been addressed yet. Though they are expected to result in higher storm surge, the coastal geometry can alter the storm surge characteristics (Resio and Westerink 2008; Sebastian et al. 2014, 2019). Here an attempt is made to understand the effect of the highest maximum sustained wind speed of a cyclone and its duration on the storm surge and hydrodynamics.

\section{Study Area}

Compared to the TCs in the world, only $7 \%$ of them occur in NIO but consequences of one cyclone striking the Indian subcontinent is higher than elsewhere. Storm surge is one of the known threats associated with TC landfall causing a rise/fall in surface water level near the coastal area resulting in inland flooding/grounding of vessels. NIO is divided into two basins, Arabian Sea towards the west and BoB towards the east of the Indian subcontinent. Figure 1 shows the cumulative tracks of the landfalling cyclones from 1970-2019 in NIO. Therefore, storm surge related vulnerability regions are more along the east coast than the west coast.

For the present study, a low lying coast of Andhra Pradesh on the east coast of India, between Bapatla and Kakinada, holding estuaries of the two major rivers Krishna and Godavari (shown in Figure 2) is selected for the study. This region belongs to a Very High Risk Zone (VHRZ) (INCOIS, 2020; Keim et al., 2020; Rao et al., 2007) as per the storm potential vulnerability.

13 The deltaic plain formed by the two rivers Krishna and Godavari, also widely known as 14 Krishna-Godavari $(\mathrm{K}-\mathrm{G})$ basin is a proven petroliferous basin of continental margin located on the east coast of India. The K-G basin has a coastline of approximately $300 \mathrm{~km}$ and extends 
116 offshore up to 1000m isobaths. Directorate General of Hydrocarbon (DGH) of India reports K-

117 G Basin as an established hydrocarbon province with an oil and gas resource of about 1130

118 MMT (Million Metric Tons), along both onshore and offshore locations (DGH 2015). About

$119555 \mathrm{MMT}$ are assessed for the offshore region up to $200 \mathrm{~m}$ isobaths.

120 The Cyclone eAtlas-IMD (2020), reports 24 CS or more intense storms along the Andhra 121 Pradesh coast from 1982-2020 out of which 8 made landfall along the coast of K-G basin. The 122 coastal region of K-G basin consists of complex geomorphologic units like upland plains, 123 coastal plains, recent flood and delta plains that are low lying and with gentle slope (DGH 124 2015) making storm surge prediction challenging in this region. For offshore platform 125 constructions, the American Petroleum Institute (API 2003) recommends design criteria based 126 on a 100 year return period storm event. The design water level is a combination of tide, storm surge and wave set up due to a 100-year return period storm event. But before designing the water level, it is necessary to define worst-case scenarios during risk evaluation or impact assessment studies. Previous studies carried out along the K-G basin includes, the impact of rising sea level along the low lying region of the K-G basin (Rao et al., 2008), storm surge inundation studies resulting from 1989 Kavali Cyclone and 1996 Andhra Cyclone (Rao et al., 2013), shoreline changes due to change in climate over the K-G basin (Kallepalli et al. 2017).

133 Previous studies (Jain et al., 2010; Sindhu \& Unnikrishnan, 2012) that computed the expected 134 total water level with a return period of 50 years along the east coast of India found the low135 lying area of the Krishna River prone to expected total water level of $6.0 \pm 0.4 \mathrm{~m}$. The K-G 136 basin is a micro-tidal region with a tidal range less than $1.5 \mathrm{~m}$ and significant wave height less 137 than $2 \mathrm{~m}$ (Rao et al., 2008). Sebastian \& Behera (2018) studied the storm surge and current 138 response along the K-G basin due to SCS events Laila (2010) and Helen (2013), approaching 139 at two different angles making landfall closer to each other, reportedly generating a maximum 140 storm surge height of $1 \mathrm{~m}$ and maximum currents of $1.2 \mathrm{~m} / \mathrm{s}$ along the coast.

\section{3. Data and Methodology}

142 Based on the IMD and JTWC best track archives of TC, a preliminary assessment of 143 concerning highest cyclone intensity, duration sustained and their distance to the landfall of 144 BoB cyclones is carried out. The JTWC provides the best track of cyclones in NIO from 1945 145 to 2018 (JTWC 2020), whereas the best tracks of cyclone from IMD are available only from 146 1982. Thus, on comparing the frequency cyclone events in BoB from 1982-2018, it could be 147 identified that JTWC reported 6 cyclones less when compared to the IMD. On investigating 
further, it could be found that two of them belong to ESCS, and originated in the Gulf of

149 Thailand and belonged to the JTWC best track archives of Western North Pacific Ocean. The

150 highest cyclone intensity and its durations of the landfalling cyclones, formed in BoB from

151 IMD and JTWC best track archives are shown in Figure 3. Variation in the intensity and

152 duration of the maximum sustained wind speed from the two different agencies can be

153 explicitly observed from Figure 3. This instigates a need to understand the effect of highest

154 cyclone intensity and duration on the storm surge behavior.

155 Figure 4(a) represents the highest cyclone intensity, duration sustained and its closeness to the

156 landfall time of TCs from 1982-2020 obtained from IMD best tracks. It is observed that 34

$157(\sim 38 \%)$ TC events made landfall with their highest cyclone intensity, $46(\sim 52 \%)$ TCs dissipated

158 within 24 hours to landfall. Similar to the sustained duration, the distance travelled by highest

159 cyclone intensity and their closeness to the landfall location estimated from the best tracks of

160 IMD from 1982-2020 (up to May) is shown in Figure 4(b). On examining Figure 4(b), it could

161 be found that about $80 \%$ of cyclones' highest intensity decays within $200 \mathrm{~km}$ to landfall

162 location. In Figure 4(a) the circles represent the cyclones with their highest intensity only at a

163 given time (22 such events reported from 1982-2020). Similarly, the circles in Figure 4(b)

164 represent the cyclone highest intensity at a given time (22 TCs) as well as those intensified

165 over a duration but remained stationary ( 5 TCs) for some duration but reduced their intensity

166 as they move towards the land.

167 In the present study, we have only considered the impact of cyclones with maximum sustained

168 wind speed higher than $33 \mathrm{~m} / \mathrm{s}$ during its lifetime. On inspecting the historical cyclone tracks

169 we come to an understanding that about $90 \%$ of the cyclones intensify and dissipate within 24

170 hours to the landfall time. Hence, for the numerical experiments the cyclone intensities are

171 increased at 24 hours or lesser duration to the landfall time. To quantify the effect of cyclone

172 intensity and its duration a single cyclone track is only considered for the present study. For

173 understanding the impact caused by the change in the cyclone intensity and duration, a cyclone

174 track from the best tracks is selected and the maximum sustained wind speed of the cyclone

175 are increased by $2.57 \mathrm{~m} / \mathrm{s}(5$ knots $), 5.14 \mathrm{~m} / \mathrm{s}(10$ knots $), 7.71 \mathrm{~m} / \mathrm{s}(15 \mathrm{knots}), 15.4 \mathrm{~m} / \mathrm{s}(30 \mathrm{knots})$

176 and $30.86 \mathrm{~m} / \mathrm{s}(60 \mathrm{knots})$ for 10 different test scenarios for which the cyclone intensities are

177 increased for varying durations as shown in Figure 5. The central pressure values were also

178 updated corresponding to the increased maximum sustained wind speed according to the

179 information available from the best tracks. The experiments were conducted using Laila

180 Cyclone that made landfall as a SCS at Bapatla, on May $20^{\text {th }}, 2010,1200$ UTC. The increased 
cyclone intensity resulted in changes in the maximum sustained wind speed, minimum central pressure and the radius of the maximum winds. Table 2 shows the total numerical experiments conducted for the analysis.

\section{$3.2 \quad$ Numerical Model}

\subsubsection{ADCIRC}

186 ADCIRC solves the shallow water equations (SWE) on unstructured meshes using continuous-

187 Galerkin finite element method with linear $\mathrm{C}_{0}$ triangular elements, allowing localized refinement in the region where the solution gradients are largest. The time derivative for the continuity equation is discretised over three levels such that the future water level requires information on the present and past water levels. In the case of momentum equation, the temporal discretization is explicit for all terms except the Coriolis, which uses an average of present and future velocities. ADCIRC solves for the water level and two components of currents at every mesh node at each time step over the simulation duration.

194 ADCIRC computes the water level from the solution of Generalized Wave Continuity Equation (GWCE) that is a combined form of the continuity and momentum equations, whereas the currents are computed from the solution of the vertically integrated momentum equations.

197 The generalized wave continuity equation is

$$
\frac{\partial^{2} \zeta}{\partial t^{2}}+\tau_{0} \frac{\partial \zeta}{\partial t}+S_{p} \frac{\partial \tilde{J}_{\lambda}}{\partial \lambda}+\frac{\partial \tilde{J}_{\phi}}{\partial \phi}-S_{p} \mathrm{UH} \frac{\partial \tau_{0}}{\partial \lambda}-\mathrm{VH} \frac{\partial \tau_{0}}{\partial \phi}=0
$$

where,

$$
\begin{gathered}
\tilde{J}_{\lambda}=S_{p} Q_{\lambda} \frac{\partial U}{\partial \lambda}-Q_{\phi} \frac{\partial U}{\partial \phi}+f Q_{\phi}-\frac{g}{2} S_{p} \frac{\partial \zeta^{2}}{\partial \lambda}-g S_{p} H \frac{\partial}{\partial \lambda}\left[\frac{P_{s}}{g \rho_{0}}-\alpha \eta\right]+\frac{\tau_{s \lambda, \text { winds }}+\tau_{s \lambda, \text { waves }}-\tau_{b \lambda}}{\rho_{0}} \\
+\left(M_{\lambda}-D_{\lambda}\right)+U \frac{\partial \zeta}{\partial t}+\tau_{0} Q_{\lambda}-g S_{p} H \frac{\partial \zeta}{\partial \lambda} \\
\tilde{J}_{\phi}=S_{p} Q_{\lambda} \frac{\partial V}{\partial \lambda}-Q_{\phi} \frac{\partial V}{\partial \phi}+f Q_{\lambda}-\frac{g}{2} \frac{\partial \zeta^{2}}{\partial \phi}-g H \frac{\partial}{\partial \phi}\left[\frac{P_{s}}{g \rho_{0}}-\alpha \eta\right]+\frac{\tau_{s \lambda, \text { winds }}+\tau_{s \lambda, \text { waves }}-\tau_{b \phi}}{\rho_{0}} \\
+\left(M_{\phi}-D_{\phi}\right)+V \frac{\partial \zeta}{\partial t}+\tau_{0} Q_{\phi}-g H \frac{\partial \zeta}{\partial \phi}
\end{gathered}
$$

198 The vertically integrated momentum equations are 


$$
\begin{aligned}
\frac{\partial U}{\partial t}+S_{p} U \frac{\partial U}{\partial \lambda}+ & V \frac{\partial U}{\partial \phi}-f V \\
& =-g S_{p} \frac{\partial}{\partial \lambda}\left[\frac{p_{s}}{g \rho_{0}}+\zeta-\alpha \eta\right]+\frac{\tau_{s \lambda, \text { winds }}+\tau_{s \lambda, \text { waves }}-\tau_{b \lambda}}{\rho_{0} H} \\
& +\frac{M_{\lambda}-D_{\lambda}}{H} \\
\frac{\partial V}{\partial t}+S_{p} U \frac{\partial V}{\partial \lambda}+ & V \frac{\partial V}{\partial \phi}-f U \\
& =-g \frac{\partial}{\partial \phi}\left[\frac{p_{s}}{g \rho_{0}}+\zeta-\alpha \eta\right]+\frac{\tau_{s \phi, w i n d s}+\tau_{s \phi, \text { waves }}-\tau_{b \phi}}{\rho_{0} H} \\
& +\frac{M_{\phi}-D_{\phi}}{H}
\end{aligned}
$$

199 where, $\mathrm{t}=$ time

$200 H=\zeta+h=$ the total water depth,

$201 \zeta=$ the deviation of the water surface from the mean water level,

$202 h$ = bathymetric depth;

$203 \lambda=$ degrees longitude (east of Greenwich is positive) and

$204 \phi=$ degrees latitude (north of equator is positive)

$205 S_{p}=\cos \phi_{0} / \phi$, is a spherical co-ordinate conversion factor and $\phi_{0}$ is a reference latitude.

$206 U, V=$ the depth-averaged horizontal velocities in $\mathrm{x}$ - and $\mathrm{y}$-directions, respectively,

$207 Q_{\lambda}=U H$, and $Q_{\phi}=V H$, are fluxes per unit width in x- and y-directions, respectively,

$208 f=2 \Omega \sin \phi=$ the Coriolis parameter,

$209 \Omega=$ the angular speed of the earth,

$210 \mathrm{P}_{\mathrm{s}}=$ the atmospheric pressure at free surface,

$211 \mathrm{~g}=$ acceleration due to gravity,

$212 \eta=$ the Newtonian equilibrium tidal potential,

$213 \alpha=$ the effective earth elasticity factor, 
$\rho_{0}=$ the reference density of water,

$215 \tau_{s, \text { winds }}, \tau_{s, \text { waves }}=$ the applied free surface stress due to winds and waves, respectively,

$216 \tau_{b}=$ bottom stress ,

$217 M_{\lambda}, M_{\phi}$ are lateral stress gradients,

$218 D_{\lambda}, D_{\phi}$ are momentum dispersion terms

$219 \tau_{0}$ is a numerical parameter that optimizes the phase propagation properties (Kolar et al. 1994;

220 Atkinson et al. 2004)

221 ADCIRC utilizes the mass conservation in the depth-integrated form of Generalized Wave-

222 Continuity Equation (GWCE) and the momentum conservation subjected to incompressibility.

223 Additionally, equations of motion in the ADCIRC model are formulated based on the

224 traditional hydrostatic pressure, Boussinesq approximations. The GWCE formulation

225 developed by Lynch \& Gray (1979) eliminate the spurious node-node oscillations associated

226 with a primitive Galerkin finite element formulation of the vertically-integrated continuity

227 equation. The model utilizes FEM for spatial discretisation and FDM for temporal

228 discretisation. ADCIRC uses a linear Lagrange interpolation to solve for the water levels $(\zeta)$

229 and velocities $(U$ and $V$ ) at every node point of the unstructured triangular mesh. The GWCE

230 can an use explicit or implicit time stepping scheme. The momentum equation uses a consistent

231 or lumped mass matrix. The 2DDI form uses the explicit time stepping scheme and in order to

232 avoid the instability in the computation a suitable time step was selected to satisfy the Courant-

233 Friedrichs-Lewy (CFL) (Courant et al. 1928) stability criteria.

\section{$234 \quad 3.2 .2 \quad S W A N$}

235 SWAN is a third generation wave model that simulates the nearshore waves (Booij et al. 1999)

236 that represents the wave field as phase averaged spectrum. The wave action density, $237 N(t, \lambda, \phi, \sigma, \theta)$ is allowed to evolve in time $(\mathrm{t})$, geographic space $(\lambda, \phi)$ and spectral space 238 (relative frequencies $\sigma$ and directions $\theta$ ). The governing action balance equation is

$$
\frac{\partial N}{\partial t}+\frac{\partial}{\partial \lambda}\left[\left(c_{\lambda}+U\right) N\right]+\cos ^{-1} \phi \frac{\partial}{\partial \phi}\left[\left(c_{\phi}+V\right) N \cos \phi\right]+\frac{\partial}{\partial \theta}\left[c_{\theta} N\right]
$$




$$
+\frac{\partial}{\partial \sigma}\left[c_{\sigma} N\right]=\frac{S_{t o t}}{\sigma}
$$

239 where, $c_{\lambda}, c_{\phi}$ are the group velocities; $\mathrm{U}, \mathrm{V}$ are the ambient current; $c_{\theta}, c_{\sigma}$ are the propagation

240 velocities in $\theta$ - and $\sigma$-spaces; $S_{\text {tot }}$ is wave growth by wind action lost due to white capping, 241 surf breaking and bottom friction and action exchanged between spectral components due to 242 nonlinear effects in deep and shallow water.

243 The radiation stress gradients are computed by

$$
\begin{gathered}
\tau_{s x, \text { waves }}=-\frac{\partial S_{x x}}{\partial x}-\frac{\partial S_{x y}}{\partial y} \\
\tau_{s y, \text { waves }}=-\frac{\partial S_{x y}}{\partial x}-\frac{\partial S_{y y}}{\partial y}
\end{gathered}
$$

244 where, $S_{x x}, S_{x y}$, and $S_{y y}$ are the wave radiation stresses (Longuet-Higgins and Stewart 1964; 245 Battjes 1972) and are given as:

$$
\begin{aligned}
& S_{x x}=\rho_{0} g \iint\left(\left(n \cos ^{2} \theta+n-\frac{1}{2}\right) \sigma N\right) d \sigma d \theta \\
& S_{x y}=\rho_{0} g \iint(n \sin \theta \cos \theta \sigma N) d \sigma d \theta \\
& S_{y y}=\rho_{0} g \iint\left(\left(n \sin ^{2} \theta+n-\frac{1}{2}\right) \sigma N\right) d \sigma d \theta
\end{aligned}
$$

246 where, $\mathrm{n}$ is the ratio of group velocity to phase velocity.

247 Zijlema (2010) introduced a numerical procedure to compute the wind-wave spectra using 248 SWAN on unstructured-grid. A vertex based, fully implicit, finite difference method accommodated the unstructured meshes with high variability associated with bathymetry in the nearshore region and irregular shoreline. A point to point multi-directional Gauss-Seidel iteration method requiring a number of sweeps through the grid was adopted for the numerical solution method. The implicit time scheme permitted stability in the computation even in case of local refinement in the area of interest.

\subsubsection{Coupled ADCIRC+SWAN}

255 A coupled wave and circulation model can define shelf, nearshore and inland hydrodynamics better during a cyclone event. The wave effects are incorporated in the circulation model by 
parallelly coupling the third generation wave model, SWAN with ADCIRC(Dietrich et al. 2012). The unstructured-mesh SWAN spectral wave model and the ADCIRC shallow-water circulation model have been integrated into a tightly-coupled ADCIRC + SWAN model.

260 The tight coupling of the unstructured SWAN model and ADCIRC allows physical interaction between the wave-circulation to be resolved correctly in both models. ADCIRC passes wind velocities, water levels, and currents through local memory to SWAN, which is utilized for its computation. SWAN computes wave radiation stresses and their gradients and passes radiation stress gradients as a forcing function to ADCIRC at the end of each its time steps. ADCIRC time step is relatively small in order to satisfy the Courant number criteria of its explicit features as well as to limit the propagation speed of wetting front during a time step. Whereas, SWAN is unconditionally stable and allows large time steps. Thus, the coupling interval is the same as the SWAN time step. The models are run sequentially to ensure that either ADCIRC or SWAN runs alternatively passing information to each other (Dietrich et al. 2011, 2012).

270

At the beginning of the coupling interval ADCIRC can access the radiation stress gradient computed by SWAN at times corresponding to the beginning and end of the previous interval. At the end of the coupling time interval, ADCIRC passes the wind velocities, water levels, currents and roughness lengths to SWAN. SWAN recalculates the water depth and related wave process (wave propagation, depth-induced breaking, etc.) at the coupling time. SWAN is run for the same time step to bring the same moment in time as ADCIRC. The radiation stresses are computed at each mesh node and are interpolated into the space of continuous, piecewise linear functions and differentiated to obtain the radiation stress gradient that is constant on each element. The area-weighted average of the radiation stress gradient on the element is projected onto the mesh nodes. The radiation stress gradients used by ADCIRC are always extrapolated forward in time, while the wind speed, water levels and currents used by SWAN are always averaged over each of its time step (Dietrich et al. 2011).

ADCIRC and SWAN are run in parallel mode for the present study. ADCIRC and SWAN have a one-to-one correspondence between geographic locations of the mesh vertices as they use the same local sub-mesh. Information such as water level, currents, wind velocities and radiation stress gradients are passed directly through the local cache or memory, without any need for interpolation. 


\subsection{Generating the Wind field and Pressure Field}

288 Holland et al. (2010) proposed a revision to the parametric Holland (1980) model to represent 289 the surface wind profile more accurately. The earlier model utilized the central and 290 environmental surface pressure, maximum winds and radius of maximum wind, while the 291 revised model is capable of incorporating the wind observations at some radius within the 292 hurricane circulation. The revised model is considerably less sensitive to data errors. The 293 surface pressure $\mathrm{P}_{\mathrm{s}}$ is given by

$$
P_{s}=P_{c S}+\left(P_{n s}-P_{c S}\right) e^{-\left(\frac{R_{m}}{r}\right)^{b}}
$$

294 where, $\mathrm{P}_{\mathrm{s}}$ is surface pressure at radius $\mathrm{r}, \mathrm{P}_{\mathrm{cs}}$ is central pressure, $\mathrm{P}_{\mathrm{ns}}$ is the external pressure to 295 the centre of the cyclone, $R_{m}$ is the radius of maximum winds. $b$ is the scaling parameter that 296 defines the proportion of pressure gradient near the maximum wind, e is the exponential 297 function.

$$
V_{s}=V_{m s}\left\{\left(\frac{r_{v_{m s}}}{r}\right)^{b_{s}} e^{\left[1-\left(\frac{r_{v_{m s}}}{r}\right)^{b_{s}}\right]}\right\}^{x}
$$

298 where, $V_{s}=$ surface wind (wind at any level), $\mathrm{V}_{\mathrm{ms}}=$ maximum surface wind, $\mathrm{rVms}$ is the radius 299 of maximum wind, $b_{s}=b_{s}{ }^{\mathrm{x}}$, where, $g_{s}$ is the reduction factor for gradient to surface winds, $e$ is 300 the base of natural logarithm. Based on the central pressure value, bs is obtained as follows;

$$
\begin{aligned}
& b_{s}=-4.4 \times 10^{-5} \Delta P_{s}^{2}+0.01 \Delta P_{s}+0.03 \frac{\partial P_{c s}}{\partial t}-0.014 \phi+0.15 V_{t}^{x}+1.0 \\
& x=0.5\left(1-\frac{\Delta P_{s}}{215}\right) \\
& V_{m s}=\left(\frac{100 b_{s}}{\rho_{m s} e} \Delta P_{s}\right)^{0.5}
\end{aligned}
$$

301 where, $\Delta P_{s}$ is in $\mathrm{hPa}, \partial P_{c s} / \partial t$ intensity change in $\mathrm{hPa} / \mathrm{h}, \varphi$ is the absolute value of latitude in 302 degree, $V_{t}$ is the cyclone translate speed in $\mathrm{m} / \mathrm{s}$.

303 The surface air density can be derived as

$$
\begin{aligned}
& \rho_{s}=\frac{100 P_{s}}{R T_{v S}}, \\
& T_{v S}=\left(T_{s}+273.15\right)\left(1+0.61 q_{s}\right)
\end{aligned}
$$




$$
\begin{aligned}
& q_{S}=R H_{S}\left(\frac{3.802}{100 P_{S}}\right) e^{\frac{17.67 T_{S}}{243.5+T_{S}}} \\
& T_{S}=S S T-1
\end{aligned}
$$

304 where, $\mathrm{R}=286.9 \mathrm{~J} \mathrm{~kg}^{-1} \mathrm{~K}^{-1}$ is the gas constant for dry air, $\mathrm{T}_{\mathrm{vs}}=$ the virtual surface temperature 305 (in K), $\mathrm{q}_{\mathrm{s}}$ is the surface moisture (in $\mathrm{g} \mathrm{kg}^{-1}$ ), $\mathrm{T}_{\mathrm{s}}=$ surface temperature, SST is the sea surface 306 temperature (both in ${ }^{\circ} \mathrm{C}$ ), $\mathrm{RH}_{\mathrm{s}}=$ surface relative humidity.

307 The radius of maximum wind is computed using Willoughby \& Rahn (2004) equation given 308 by

$$
R_{m}=46.4 e^{\left(-0.0515 V_{m}+0.0169 \phi\right)}
$$

309 The storm parameters (track positions, maximum sustained wind speeds and estimated 310 pressures) obtained from the JTWC best track for cyclones Hudhud, Helen and Laila to 311 compute their respective wind and pressure fields from this modified Holland Model (MHM).

312 The radius of the maximum winds are computed using the Willoughby \& Rahn (2004) 313 equation. For the numerical experiments the radius of maximum winds varies based on the 314 wind speed and is as shown in Figure 6. Further, for the numerical experiments, adopting the 315 track positions of Laila Cyclone maximum sustained wind speeds and the minimum central 316 pressures are varied at selected time instances as shown in Figure 7. These wind and pressure 317 information are interpolated in space onto the ADCIRC grid and in time to match the wind and 318 pressure information with the model time step. The wind drag coefficients are adopted from 319 Garratt(1977) for all the simulations.

\section{$320 \quad 3.4 \quad$ Model Set up and Initialization}

321 The numerical simulations are carried out using standalone model ADCIRC and coupled model ADCIRC+SWAN on the domain consisting of the BoB basin of NIO. The model domain is discretised into highly flexible unstructured mesh as shown Figure 8. The model domain consists of 85,371 triangular elements and 459,419 nodes, with a resolution of $100 \mathrm{~m}$ along the east coast of India. However, the coastal belt of this region is low lying with gentle slopes and is categorized as highly vulnerable to storm surge (Kallepalli et al. 2017). Figure 9(a) shows BoB model domain with interpolated bathymetry from GEBCO. Figure 9(b) shows the enlarged view of the K-G basin. Before conducting the numerical experiment, the model is validated with the water levels obtained at Visakhapatnam and Krishnapatnam during Helen 
330 (2013), which made landfall as a SCS as well as the water levels obtained at Visakhapatnam

331 during Hudhud (2014) that made landfall as an ESCS. In Figure 9, in addition to the 332 bathymetry, the cyclone tracks of Laila, Helen and Hudhud are also incorporated. The landfall 333 locations as well as the tide gauge stations are shown in the enlarged view of the study area 334 (Figure 9(b)).

335 Boundary conditions used in the present simulations include mainland boundary and islands 336 with no normal flow condition and free tangential slip and open ocean boundary with specified 337 tidal constituents for harmonic forcing. The meteorological forces comprising the wind and 338 pressure field during cyclone events of Hudhud, Helen and Laila are computed from the MHM.

339 In addition to the boundary conditions, an elemental wetting-drying scheme with minimum 340 water depth $0.05 \mathrm{~m}$ and a minimum velocity of $0.05 \mathrm{~m} / \mathrm{s}$ is adopted. A constant bottom friction 341 coefficient of 0.0028 that uses the quadratic friction formulation is used for bottom friction 342 parameterisation. The time step of 6 s satisfied the Courant number criteria.

343 The model is initially run for 60 days in cold start with tidal forcing and potential constituents 344 obtained from Le Provost database allowing 20 days for the model to spin up. The numerical 345 simulation is forced with all 13 forcing and potential tidal constituents $\left(2 \mathrm{~N}_{2}, \mathrm{~K}_{1}, \mathrm{~K}_{2}, \mathrm{~L}_{2}, \mathrm{M}_{2}\right.$, $\left.346 \mathrm{MU}_{2}, \mathrm{~N}_{2}, \mathrm{NU}_{2}, \mathrm{O}_{1}, \mathrm{P}_{1}, \mathrm{Q}_{1}, \mathrm{~S}_{2}, \mathrm{~T}_{2}\right)$ at the open ocean boundary. The simulation is initialised 347 with tidal potential forcing. Further, simulations are carried out hot starting the computational 348 domain with meteorological forcing for another 5 days (life of Laila Cyclone).

\section{Results and Discussion}

350 The simulations carried out using the ADCIRC model considers the effect of atmospheric 351 forcing of a cyclone along with tide are referred to as storm tide (ST) conditions. Similarly, 352 simulations carried out using ADCIRC+SWAN model consider the effect of wave setup along 353 with the storm tide and are referred to as storm-tide-wave (STW) conditions in the following 354 sections.

\subsection{Validation of water level}

356 The water levels simulated during Helen cyclone is compared with the tide gauge observations at Visakhapatnam and Krishnapatnam obtained from INCOIS and is shown in Figure 10. It is seen the numerical model slightly under predicts the amplitude of the water levels but the phase is in good agreement with each other. The observed water levels are recorded by the tide gauge 
station located inside the Visakhapatnam port, whereas, the numerical model point lies in the open coast without considering the port enclosure. Also, the numerical model used GEBCO bathymetry only. The results might further improve by considering more refined bathymetry information from hydrographic charts for the K-G basin region. Further, the water levels simulated during an ESCS Hudhud Cyclone are compared with the tide gauge observations at Visakhapatnam, where the cyclone made its landfall and are shown in Figure 11. The model could capture the amplitude as well as phase of the total water level using the coupled ADCIRC+SWAN model with a CC value of 0.98 and RMSE of $0.02 \mathrm{~m}$.

\subsection{Maximum Wind Speed and Minimum Pressure}

In the present study, to investigate the impact of intensification on the coastal storm surge, cyclones are intensified gradually by increasing the maximum sustained wind speed by 2.57 $\mathrm{m} / \mathrm{s}$ (5 knots), $5.14 \mathrm{~m} / \mathrm{s}$ (10 knots) and $7.71 \mathrm{~m} / \mathrm{s}$ (15 knots) as well as rapidly by $15.4 \mathrm{~m} / \mathrm{s} \mathrm{(30}$ knots) and $30.86 \mathrm{~m} / \mathrm{s}$ (60 knots) for 10 hypothetical different durations. The maximum sustained wind speed and pressure variation during the life of the cyclone are presented in Figure 7, which are used for generating the wind fields in the numerical simulations. With respect to the change in the wind speed there will be change in the radius of maximum winds as well. The radius of maximum winds corresponding to the maximum sustained wind speed is shown in Figure 6. When the cyclones are intensified, changes occur in wind speed, pressure as well as in the radius of maximum wind of the cyclone. The spatial distribution of the maximum wind speed during Laila Cyclone and for increased intensities of test scenario A (where the cyclone intensity was increased 24 hours prior to landfall and 6 hours after landfall as shown in Figure 5) is shown in Figure 12. Since the highest maximum sustained wind speeds are increased by 5, 10, 15, 30 and 60 knots, they are designated as A5, A10, A15, A30 and A60, respectively. Similarly, the spatial distributions of minimum pressure experienced during Laila Cyclone and for increased intensities of test scenario A are shown in Figure 13.

From Figure 12, we can see that with an increase in wind speed by $2.57 \mathrm{~m} / \mathrm{s}$ ( 5 knots), the highest wind speed of A5 (Figure 12(b)) increases by $0.5 \mathrm{~m} / \mathrm{s}$ of Laila Cyclone (Figure 12(a)). The increased wind speed between $24-32 \mathrm{~m} / \mathrm{s}$, closer to the landfall, belongs to SCS. While with an increase of 5.14(10), 7.71(15) $\mathrm{m} / \mathrm{s}(\mathrm{knots})$, as seen in Figure 12(c) and (d), the maximum wind speed near the landfall changed to VSCS category. Similarly, an increase in the wind speed by 15.4 (30) and 30.86(60) m/s(knots), seen in Figure 12(e) and (f), resulted in ESCS and $\operatorname{SuCS}(62.4 \mathrm{~m} / \mathrm{s})$. 
Spatial plots of maximum wind speed with $30.86 \mathrm{~m} / \mathrm{s}$ (60 knots) increase for different test scenarios $(A-J)$ representing varying durations are shown in Figure 14(a-j). Similarly, the corresponding minimum pressures are shown in Figure 15(a-j). The highest wind speed for Cyclone Laila is $34 \mathrm{~m} / \mathrm{s}$ whereas the lowest pressure value is $9.94 \mathrm{~m}$ of water. The highest maximum wind speeds and the lowest central pressures for all the test scenarios considered for the study are provided in

Table 3.

400

From

401

402 Table 3, it could be seen that the highest maximum wind speed and lowest minimum pressure

403 values are same for A, B, C, D, E scenarios because the highest intensification of Laila Cyclone 404 occurred 24 hours prior to landfall that is captured by all these scenarios. For other scenarios, 405 the highest maximum wind speed and lowest minimum pressure values vary depending on the 406 specific time instance considered. Sensitivity of the duration and intensity on the maximum 407 water levels and significant wave heights are investigated using the wind and pressure fields 408 of different scenarios.

\subsection{Maximum Water Elevation (MWE)}

410 The MWE refers to the peak values of water levels obtained throughout the computational 411 domain for the total period of simulation considered for the study. The MWEs are computed 412 for ST conditions using ADCIRC model, where cyclonic surge is simulated along with tide. 413 Similarly, MWEs are also computed for STW conditions using ADCIRC+SWAN model to 414 consider the effect of wave setup along with storm tide.

415 The peak MWE of ST and STW are computed for all the test scenarios and are shown in Figure 416 16. The peak MWEs of STW increase up to $39 \%$ of peak MWEs of ST for varying cyclone 417 intensity and duration of intensification considered here. The peak MWEs are recorded at 418 different locations for different scenarios and selected locations of peak MWEs are shown in 419 Figure 17 along with the bathymetric depth. The farthest peak MWE is observed north of 420 Machilipatnam ( $90 \mathrm{~km}$ from landfall). As seen in Figure 5, the intensifications are considered 421 over a duration (A-E) and at specific time instances (F-J). The scenarios B-F, C-G, D-H and 422 E-I are paired together as their intensification ends at the same time. The comparison of the 423 peak MWEs among these paired scenarios is done to understand the impact of duration of 424 intensification. The MWE obtained for Laila Cyclone (highest maximum sustained wind 
intensity of $34 \mathrm{~m} / \mathrm{s}$ occurred 30 hours prior to the landfall) is also plotted along with the scenarios to compare and understand the effect of intensification and duration.

From Figure 16 it could be concluded that the duration of intensification is trivial. The peak MWE of STW in the K-G basin with $30.86 \mathrm{~m} / \mathrm{s}$ (60 knots) increase in intensity shows $10.8 \%$, $17.8 \%, 1.4 \%$ and $14.7 \%$ higher MWEs for B, C, D and E scenarios compared to F, G, H and I scenarios, respectively. In order to understand the impact of the intensification, percentage increase in the peak water levels of STW with respect to that of Laila is estimated and is provided in Table 4. As explained earlier, an increase in wind speed by $2.57,5.14$, and $7.71 \mathrm{~m} / \mathrm{s}$ results in gradual intensification and an increase in wind speed by $15.4,30.86 \mathrm{~m} / \mathrm{s}$ results in rapid intensification (>15 m/s change within 24 hours) of the cyclone. The scenario A where the intensification continued even after landfall shows substantial increase in the MWEs with increasing intensities. Similarly, scenarios B, C, F, and G show significant increase in MWEs for increasing intensities. However, scenarios D and H show considerable increase for rapid intensification only. Scenarios E and I show an increase in MWEs for an increase of $30.86 \mathrm{~m} / \mathrm{s}$ only below which the effect is negligible.

In the above discussion, it should be noted that the intensification in these scenarios ends at different positions of cyclones where the water depths are also varying. As we observe, the scenarios B, C, F, and $\mathrm{G}$ intensification continued over the shallow continental shelf region, where the bathymetry is less than 200m (seen in Figure 9(b)). Whereas, the scenarios D and H intensifications happened up to the continental slope $(500-2000 \mathrm{~m})$ and scenarios $\mathrm{E}$ and I intensifications were limited to deeper water regions beyond the continental slope $(\sim 3000 \mathrm{~m})$. Now referring to

Table 4, it can be concluded that intensification over shallow continental shelf regions has significant effect on the MWEs. Similarly, intensification in deeper water regions beyond continental slope has minimal effect on MWEs for gradual intensification but considerable effect for rapid intensification. The scenario $J$ where the intensification takes place in deep water (> $3000 \mathrm{~m}$ ) 24 hours prior to landfall shows insignificant effect on the MWEs along the coast. Overall, we could conclude that an intensification on shallower regions results in higher MWEs along the coast for both gradual and rapid intensification. On the contrary, a rapid intensification in deep water regions can affect the MWEs along the coast but not a gradual intensification.

Although the analysis of peak MWEs has been discussed, it is prudent to investigate the spatial variation of MWEs along the coast. The spatial contours of MWEs for the extreme case with $30.86 \mathrm{~m} / \mathrm{s}$ (60 knots) intensification are presented in Figure 18 along with the base case of Laila Cyclone. The scenarios $\mathrm{B}$ and $\mathrm{F}$ with the same intensity have different duration of 
461

462

463

464

465

466

467

468

469

470

471

472

473

474

475

476

477

478

479

480

481

482

483

484

485

486

487

488

489

490

intensification. For scenario B, where the intensification happens over duration, the extent of MWEs along the coast is larger compared to that of scenario $F$ with specific time intensification. This difference in the extent of influence is mainly due to the locations of intensification. As in scenario B the intensification happened even farther away from the coast, the generated surge could reach a wider stretch of the coast. While in scenario $F$, the effect of intensification is restricted to a smaller stretch of the coast. Similarly, the location of intensification also influences the location of MWE along the coast. The spatial MWEs for scenario J60 and Laila are similar without much variation as seen in Figure 18(j) and (k), respectively. Therefore, the intensification before 24 hours of landfall does not affect the overall surge characteristics along the coast.

It was also observed that the locations of peak MWEs for ST and STW cases do not occur at the same locations for all scenarios (as seen in Figure 18). The MWEs of ST are subtracted from STW simulation to obtain the contribution of wave setup and are shown in Figure 19. Figure 19(a) shows the peak MWEs due to storm tide and wave setup contribution at locations where the peaks were recorded during STW simulations. Similarly, Figure 19(b) shows the values from coupled STW simulations but at locations where the peaks were recorded during ST simulations. This helps to understand the wave setup contribution and its effect at various locations along the coast. Figure 19(a) shows locations where the storm tide component is zero signifying that these locations were not inundated when only storm tide simulations were carried out. However, Figure 19(b) shows less wave setup contribution and more storm tide contribution at locations where peak MWEs were observed during ST simulations. Hence, coupled STW modelling is necessary to accurately assess the vulnerability of coastal regions due to cyclones.

The results for scenario A60 show a substantial increase in the ST and STW values. The tidal range at this location is $0.4-0.6 \mathrm{~m}$, which means the surge and wave setup contribution is highest. To understand the local process and STW amplification, the wind field around the region and maximum water elevations are shown in Figure 20. It can be seen that this location has a coastal profile with high curvature and can trap the flow without much escape of flux. This could lead to piling of water resulting in very high MWE, emphasizing the importance of coastal geometry on the resultant flooding and inundation. 
492 The depth averaged velocities $\left(\mathrm{V}_{\text {avg }}\right)$ are obtained from the coupled model, and the $\mathrm{V}_{\text {avg_max }}$

493 refers to the highest $V_{\text {avg }}$ in the computational domain during the considered simulation period.

494 The peak $\mathrm{V}_{\text {avg_max }}$ for Laila cyclone is $5.4 \mathrm{~m} / \mathrm{s}$, while for different test scenarios the peak

$495 V_{\text {avg_max }}$ is given in Table 5. On the first hand observation, it can be seen that the peak $V_{\text {avg_max }}$

496 has increased for all scenarios with rapid intensification. However, the same is not seen in case

497 of gradual intensification and with 2.54 (5) and 5.14 (10) $\mathrm{m} / \mathrm{s}$ (knots) increase, most scenarios

498 show reduced peak $\mathrm{V}_{\text {avg_max. }}$ In case of $7.71 \mathrm{~m} / \mathrm{s}$ (15 knots) increase, scenarios A, B, C, D, H,

499 and I show increased peak $V_{\text {avg_max. }}$ A closer look suggests that an increase in average velocity

500 magnitude is observed where the gradual intensification takes place over the continental slope region (where bathymetric gradient is very high). For gradually intensifying cyclones, a variation in the peak $\mathrm{V}_{\text {avg_max }}$ up to $11 \%$ is observed compared to Laila. In order to understand the spatial variation of average velocities, the $V_{\text {avg_max }}$ with the extreme case $(30.86 \mathrm{~m} / \mathrm{s}$ intensification) of all scenarios are plotted in Figure 21 along with results of Laila cyclone. A strong velocity field is observed in the shelf region for scenarios A, B, C, and G, whereas, the magnitude reduces for the scenarios D, E, F, H, I, and J. It is important to note that scenario G shows similar current magnitudes as of the scenarios A, B, and C, those intensify over duration.

508 This clearly states that the intensification along the continental slope results in higher currents along the cyclone path in the shelf region.

510 Although, the increase in current magnitude is less for many scenarios shown in Figure 21(a-

$511 \mathrm{j}$ ), it is higher compared to the current magnitudes generated due to Laila cyclone (Figure

$51221(\mathrm{k}))$. It can be concluded that a rapid intensification of cyclones in deep and shallow water

513 can result in increased current magnitudes in the shelf region.

514 It is also important to identify the locations of peak $\mathrm{V}_{\text {avg_max }}$ in addition to the increased 515 magnitude. The locations and bathymetry of the peak $\mathrm{V}_{\text {avg_max }}$ for all the scenarios are shown 516 in Figure 22. It can be seen that for all simulations, the peak $\mathrm{V}_{\text {avg_max }}$ are recorded along the coast, 517 which could affect the coastal dynamics and processes during the event. Unlike the peak 518 MWEs that were influenced up to a distance of $\sim 90 \mathrm{~km}$ from the landfall point, the effect on 519 peak $\mathrm{V}_{\text {avg_max }}$ is wider extending up to $\sim 400 \mathrm{~km}$, mostly on the right side of the landfall point 520 (seen in Figure 22). Overall, a rapid intensification of cyclones increases the current magnitudes 521 in the shelf region as well as along the coast. Intensification over the continental slope region 522 significantly increases the currents along the coast. Thus, it is necessary to consider such 
523 intensifying cyclones while assessing the cyclone impact on coastal processes and sediment 524 transport during such extreme events.

\section{5. Conclusions}

526 The present study shows the sensitivity of coastal water levels with respect to increased cyclonic intensity with different intensification periods. The studies conclude that duration of intensification is trivial for gradually intensifying cyclones. The duration of intensification contributes to about 10-18\% change in the water levels when rapidly intensified over the continental shelf region. Intensification on shallower regions results in higher MWEs along the coast for both gradual and rapid intensification. On the contrary, in deep water region, only rapid intensification can affect the peak MWEs and the effect of gradual intensification in deep water is insignificant on peak MWEs. A rapid intensification before 24 hours to the landfall does not affect the overall surge characteristics along the coast. Coupled storm-tide-wave (STW) simulations result up to $39 \%$ increase in peak MWEs compared to storm tide (ST) simulations. Therefore, a coupled storm surge-tide-wave (STW) modelling should be carried out to obtain accurate MWEs and its location for identifying vulnerable coastal regions due to cyclones. Coastal geometry plays an important role in localized amplification of surge characteristics.

540 A gradually intensifying cyclone over the continental slope region, resulted in a variation in the peak $\mathrm{V}_{\text {avg_max }}$ is up to $11 \%$. While a rapidly intensifying cyclone in deep and shallow water regions can increase the current magnitudes in the shelf region as well as along the coast. The

543 effect on peak $V_{\text {avg_max }}$ can extend up to $400 \mathrm{~km}$ mostly on the right side of the landfall point.

544 Thus, it is necessary to consider such intensifying cyclones while assessing the cyclone impact on coastal processes and sediment transport under extreme events.

\section{Acknowledgement}

547 The first author would like to thank the financial support from the Industrial Research \& 548 Consultancy Centre (07IR001) and Department of Civil Engineering (DF/1111020) at Indian 549 Institute of Technology (IIT) Bombay for carrying out this work. All the simulations were 550 carried out at the High Performance computing facility at IIT Bombay, hence we also 551 acknowledge the SpaceTime-2 supercomputing facility at IIT Bombay for the computing time.

552 We wish to thank the Earth System Science Organization (ESSO)-Indian National Centre for 
553 Ocean Information Services (INCOIS), India for providing the observed tide gauge data free 554 of cost.

555

556

557

558

559

560

561

562

563

564

565

566

567

568

569

570

571

572

573

574

575

576

577

578

579

580

\section{References}

Albert J, Bhaskaran PK (2020) Evaluation of track length, residence time and translational speed for tropical cyclones in the North Indian ocean. ISH J Hydraul Eng 00:1-8. https://doi.org/10.1080/09715010.2020.1825124

API (2003) Recommended Practice for Planning, Designing and Constructing Fixed Offshore Platforms - Working Stress Design

Atkinson JH, Westerink JJ, Luettich RA (2004) Two-dimensional dispersion analyses of finite element approximations to the shallow water equations. Int $\mathbf{J}$ Numer Methods Fluids 45:715-749. https://doi.org/10.1002/fld.701

Balaguru K, Foltz GR, Leung LR (2018) Increasing Magnitude of Hurricane Rapid Intensification in the Central and Eastern Tropical Atlantic. Geophys Res Lett 45:42384247. https://doi.org/10.1029/2018GL077597

Balaguru K, Taraphdar S, Leung LR, Foltz GR (2014) Increase in the intensity of postmonsoon Bay of Bengal tropical cyclones. Geophys Res Lett 41:3594-3601. https://doi.org/10.1002/2014GL060197

Battjes JA (1972) Radiation stresses in short-crested waves. J Mar Res 30:1-56.

Bhatia KT, Vecchi GA, Knutson TR, et al (2019) Recent increases in tropical cyclone intensification rates. Nat Commun 10:1-9. https://doi.org/10.1038/s41467-019-08471-z

Booij N, Ris RC, Holthuijsen LH (1999) A third-generation wave model for coastal regions 1. Model description and validation. J Geophys Res Ocean 104:7649-7666. https://doi.org/10.1029/98JC02622

Courant R, Friedrichs KO, Lewy H (1928) Uber die partiellen differenzangleichungen der mathematisches. Math Ann 100:32-74

Cyclone eAtlas-IMD (2020) Tracks of Cyclones and Depressions over North Indian Ocean (from 1891 onwards). Chennai

Cyriac R, Dietrich JC, Fleming JG, et al (2018) Variability in Coastal Flooding predictions due 
to forecast errors during Hurricane Arthur. Coast Eng 137:59-78.

DGH (2015) Krishna Godavari - Basin NDR - National Data Repository India. https://www.ndrdgh.gov.in/NDR/?page_id=647

585

Dietrich JC, Tanaka S, Westerink JJ, et al (2012) Performance of the unstructured-mesh, SWAN+ ADCIRC model in computing hurricane waves and surge. J Sci Comput 52:468497. https://doi.org/10.1007/s10915-011-9555-6

Dietrich JC, Zijlema M, Westerink JJ, et al (2011) Modeling hurricane waves and storm surge using integrally-coupled, scalable computations. Coast Eng 58:45-65. https://doi.org/10.1016/j.coastaleng.2010.08.001

Dvorak VF (1975) Tropical Cyclone Intensity Analysis and Forecasting from Satellite Imagery. Mon Weather Rev 103:420-430

Elsner JB, Kossin JP, Jagger TH (2008) The increasing intensity of the strongest tropical cyclones. Nature 455:92-5. https://doi.org/10.1038/nature07234

Garratt JR (1977) Review of Drag Coefficients over Oceans and Continents. Mon Weather Rev 105:915-929. https://doi.org/10.1175/1520-0493(1977)105

Holland GJ (1980) An Analytic Model of the Wind and Pressure Profiles in Hurricanes. Mon Weather Rev 108:1212-1218

Holland GJ, Belanger JI, Fritz A (2010) A Revised Model for Radial Profiles of Hurricane Winds. Mon Weather Rev 138:4393-4401. https://doi.org/10.1175/2010MWR3317.1

INCOIS (2020) What is the vulnerability of our coastline from the point of view of storm surge potential? In: ESSO- Indian Natl. Cent. Ocean Inf. Serv. (INCOIS), Govt India. https://incois.gov.in/portal/Aboutstormsurge.jsp

Intergovernmental Panel on Climate Change (2019) IPCC Special Report on the Ocean and Cryosphere in a Changing Climate

Irish J, Resio D, Ratcliff J (2008) The influence of storm size on hurricane surge. J Phys Oceanogr 38:2003-2013. https://doi.org/10.1175/2008JPO3727.1

Jain I, Rao AD, Jitendra V, Dube SK (2010) Computation of Expected Total Water Levels 
610 JTWC (2020) North Indian Ocean Best Track Data. In: Jt. Typhoon Warn. Cent. (JTWC), Off. 611 U.S. Navy Website. https://www.metoc.navy.mil/jtwc/jtwc.html?north-indian-ocean

612 Kallepalli A, Kakani NR, James DB, Richardson MA (2017) Digital shoreline analysis system613 based change detection along the highly eroding Krishna - Godavari delta front. J Appl

Keim B, Sathiaraj D, Brown V (2020) SURGEDAT: The World's Storm Surge Data Center. In: South. Clim. Impacts Plan. Progr. http://surge.srcc.lsu.edu/index.html

Knapp KR, Kruk MC (2010) Quantifying interagency differences in tropical cyclone best-track wind speed estimates. Mon Weather Rev 138:1459-1473. https://doi.org/10.1175/2009MWR3123.1

Kolar RL, Gray WG, Westerink JJ, Luettich Jr. RA (1994) Shallow water modeling in spherical 621 coordinates: equation formulation, numerical implementation, and application. J Hydraul Res 32:3-24. https://doi.org/10.1080/00221689409498786

Li A, Guan S, Mo D, et al (2020) Modeling wave effects on storm surge from different typhoon intensities and sizes in the South China Sea. Estuar Coast Shelf Sci 235:106551. https://doi.org/10.1016/j.ecss.2019.106551

Longuet-Higgins MS, Stewart RW (1964) Radiation stresses in water waves; a physical 627 discussion with applications. Deep Res Oceanogr Abstr 11:529-562

Lynch DR, Gray WG (1979) A wave equation model for finite element tidal computations. Comput Fluids 7:207-228. https://doi.org/10.1016/0045-7930(79)90037-9

Mcinnes KL, Walsh KJE, Hubbert GD, Beer T (2003) Impact of sea-level rise and storm surges 631 in a coastal community. Nat Hazards 30:187-207.

633 Mei W, Pasquero C, Primeau F (2012) The effect of translation speed upon the intensity of 634 tropical cyclones over the tropical ocean. Geophys Res Lett 39:7. https://doi.org/10.1029/2011GL050765

636 Poulose J, Rao AD, Dube SK (2020) Mapping of cyclone induced extreme water levels along 
Gujarat and Maharashtra coasts: a climate change perspective. Clim Dyn 55:3565-3581. https://doi.org/10.1007/s00382-020-05463-4

Rao AD, Chittibabu P, Murty TS, et al (2007) Vulnerability from storm surges and cyclone wind fields on the coast of Andhra Pradesh, India. Nat Hazards 41:515-529. https://doi.org/10.1007/s11069-006-9047-4

Rao AD, Murty PLN, Jain I, et al (2013) Simulation of water levels and extent of coastal inundation due to a cyclonic storm along the east coast of India. Nat Hazards 66:14311441. https://doi.org/10.1007/s11069-012-0193-6

Rao KN, Subraelu P, Rao TV, et al (2008) Sea-level rise and coastal vulnerability: an assessment of Andhra Pradesh coast, India through remote sensing and GIS. J Coast Conserv 12:195-207. https://doi.org/10.1007/s11852-009-0042-2

Rego JL, Li C (2009) On the Receding of Storm Surge along Louisiana' s Low-Lying Coast. J Coast Res SI 56: 1045-1049. https://www.jstor.org/stable/25737946

Resio DT, Irish JL, Westerink JJ, Powell NJ (2013) The effect of uncertainty on estimates of hurricane surge hazards. Nat Hazards 66:. https://doi.org/10.1007/s11069-012-0315-1

Resio DT, Westerink JJ (2008) Modeling the physics of storm surges. Phys Today 9:33-38

Sahoo B, Bhaskaran PK (2018) A comprehensive data set for tropical cyclone storm surgeinduced inundation for the east coast of India. Int J Climatol 38:403-419. https://doi.org/10.1002/joc.5184

Sebastian A, Proft J, Dietrich JC, et al (2014) Characterizing hurricane storm surge behavior in Galveston Bay using the SWAN+ADCIRC model. Coast Eng 88:171-181. https://doi.org/10.1016/j.coastaleng.2014.03.002

Sebastian M, Behera MR (2015) Impact of SST on tropical cyclones in North Indian Ocean. In: Procedia Engineering. Elsevier B.V., pp 1072-1077. https://doi.org/10.1016/j.proeng.2015.08.346

Sebastian M, Behera MR (2018) Surge Height and Current Estimation Along K-G Basin. In: Proceedings of the International Conference on Offshore Mechanics and Arctic Engineering - OMAE. American Society of Mechanical Engineers, Madrid, Spain., pp 1- 
667 Sebastian M, Behera MR, Murty PLN (2019) Storm surge hydrodynamics at a concave coast 668 due to varying approach angles of cyclone. Ocean Eng 191:1-16. 669 https://doi.org/10.1016/j.oceaneng.2019.106437

670 Sindhu B, Unnikrishnan AS (2012) Return period estimates of extreme sea level along the east 671 coast of India from numerical simulations. Nat Hazards 61:1007-1028. https://doi.org/10.1007/s11069-011-9948-8

Singh VK, Roxy MK (2020) A review of the ocean-atmosphere interactions during tropical cyclones in the north Indian Ocean. arXiv preprint arXiv:2012.04384

Thomas A, Dietrich JC, Asher TG, et al (2019) Influence of storm timing and forward speed 676 on tides and storm surge during Hurricane Matthew. Ocean Model 137:1-19. https://doi.org/10.1016/j.ocemod.2019.03.004

Willoughby HE, Rahn ME (2004) Parametric Representation of the Primary Hurricane Vortex 679 680 . Part I : Observations and evaluation of the Holland (1980) model. Mon Weather Rev 132:3033-3048. https://doi.org/10.1175/MWR2831.1

681 Wu L, Wen Z, Huang R (2020) Tropical cyclones in a warming climate. Sci China Earth Sci. 682 https://doi.org/10.1007/s11430-019-9574-4

683

Zijlema M (2010) Computation of wind-wave spectra in coastal waters with SWAN on 684 unstructured grids.

Coast

Eng 57:267-277.

685 https://doi.org/10.1016/j.coastaleng.2009.10.011

686

687 


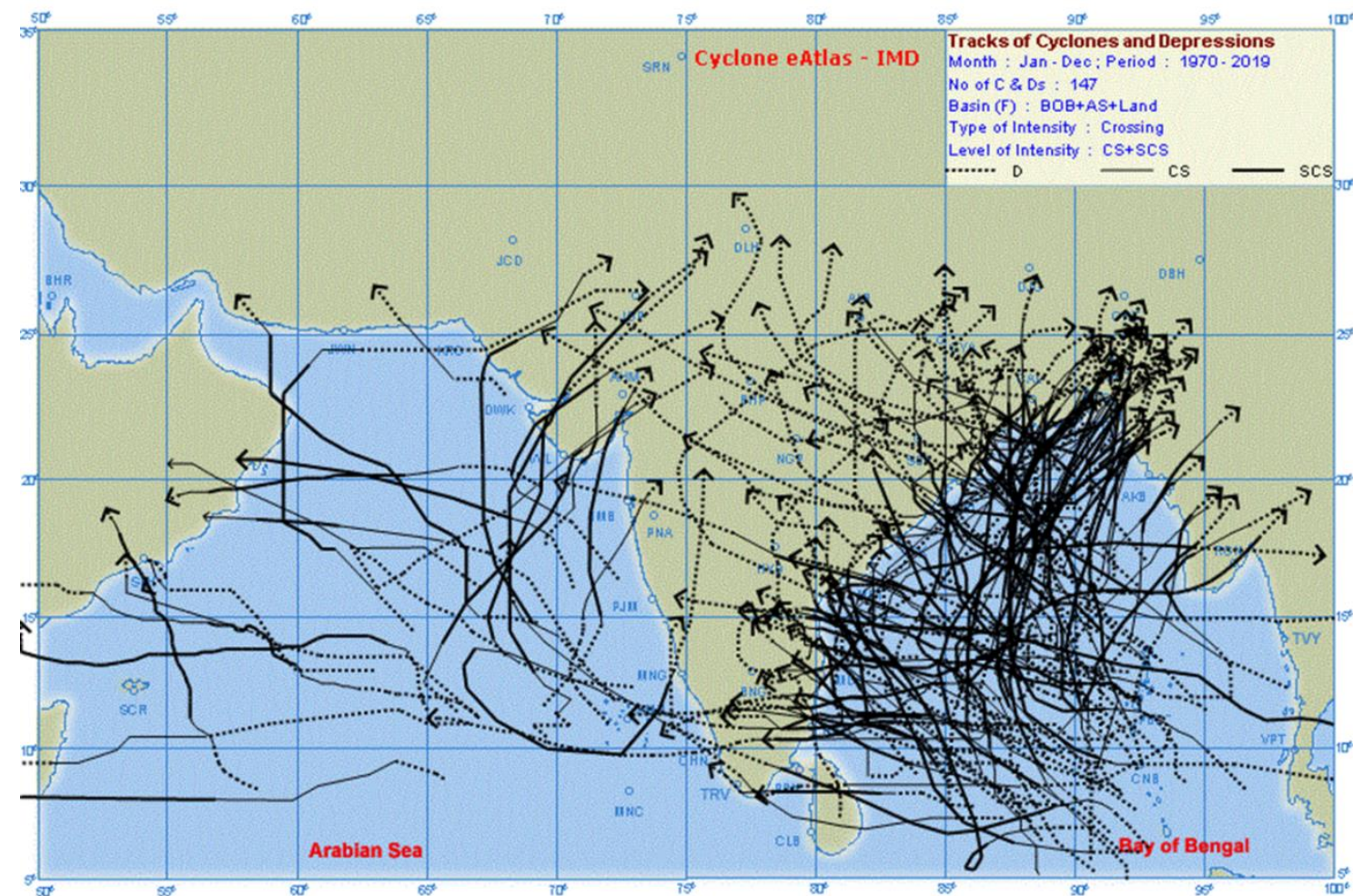

692

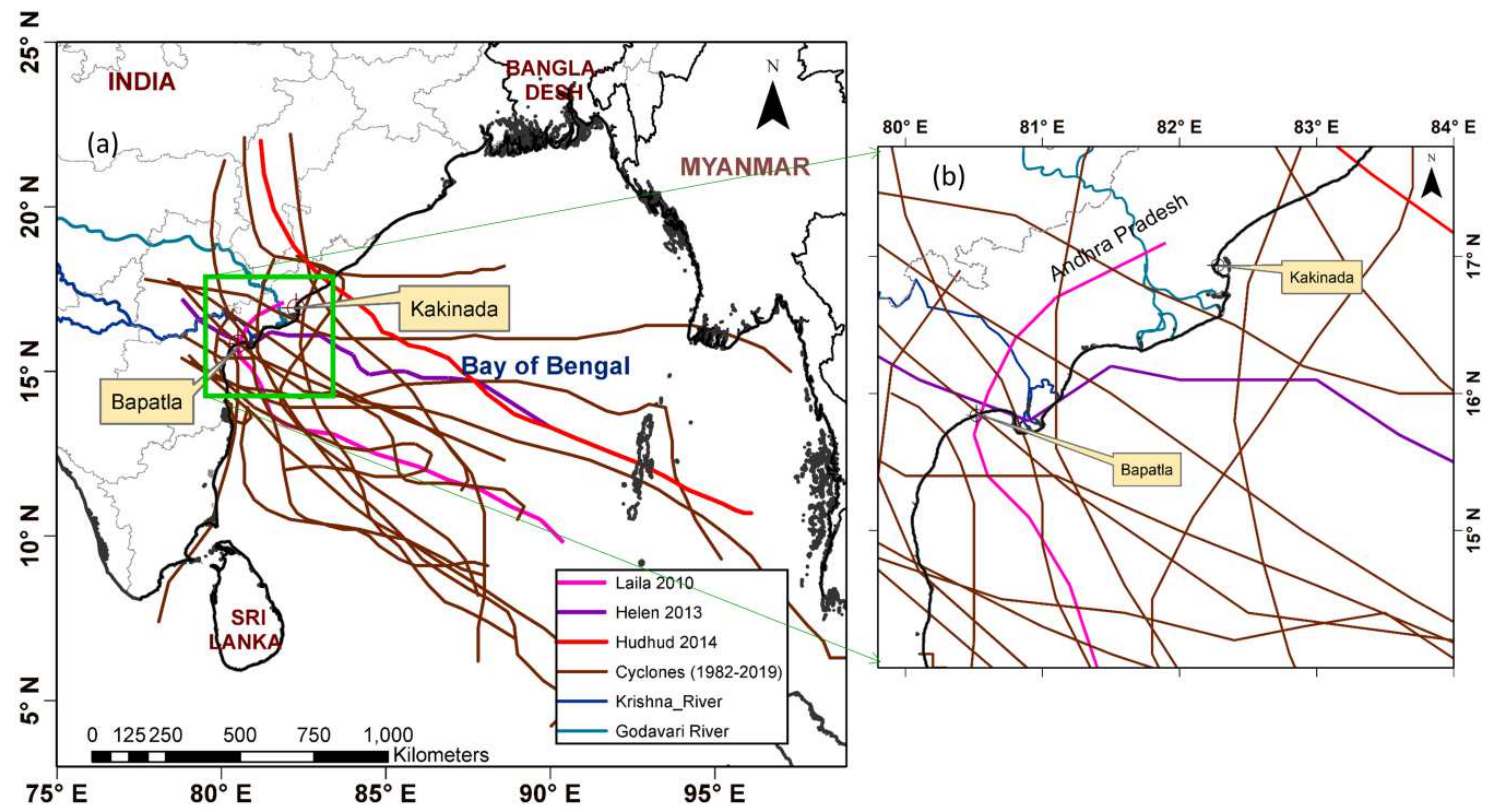

Figure 2(a) Cyclone tracks from year 1982-2019 landfalling in Andhra Pradesh Coast, and(b) Enlarged view along the coast of K-G Basin 


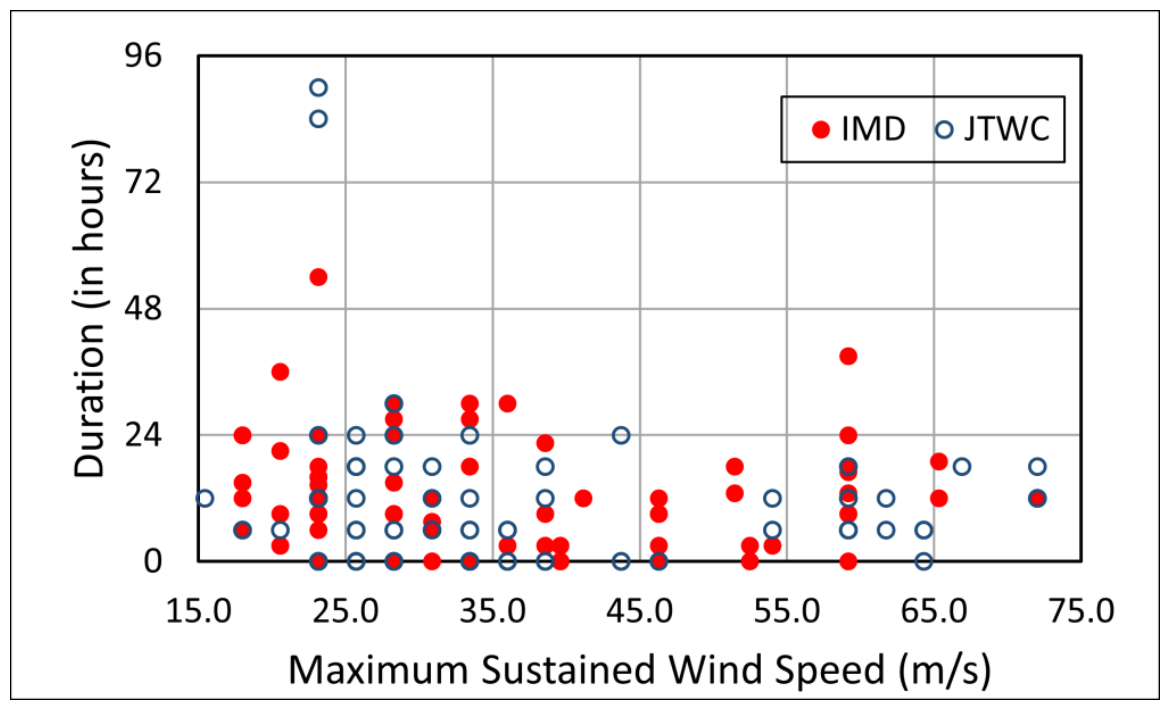

Figure 3 Scatterplot representing the highest associated cyclone intensity and its duration from IMD and JTWC for cyclones landfalling in BoB from 1982-2018
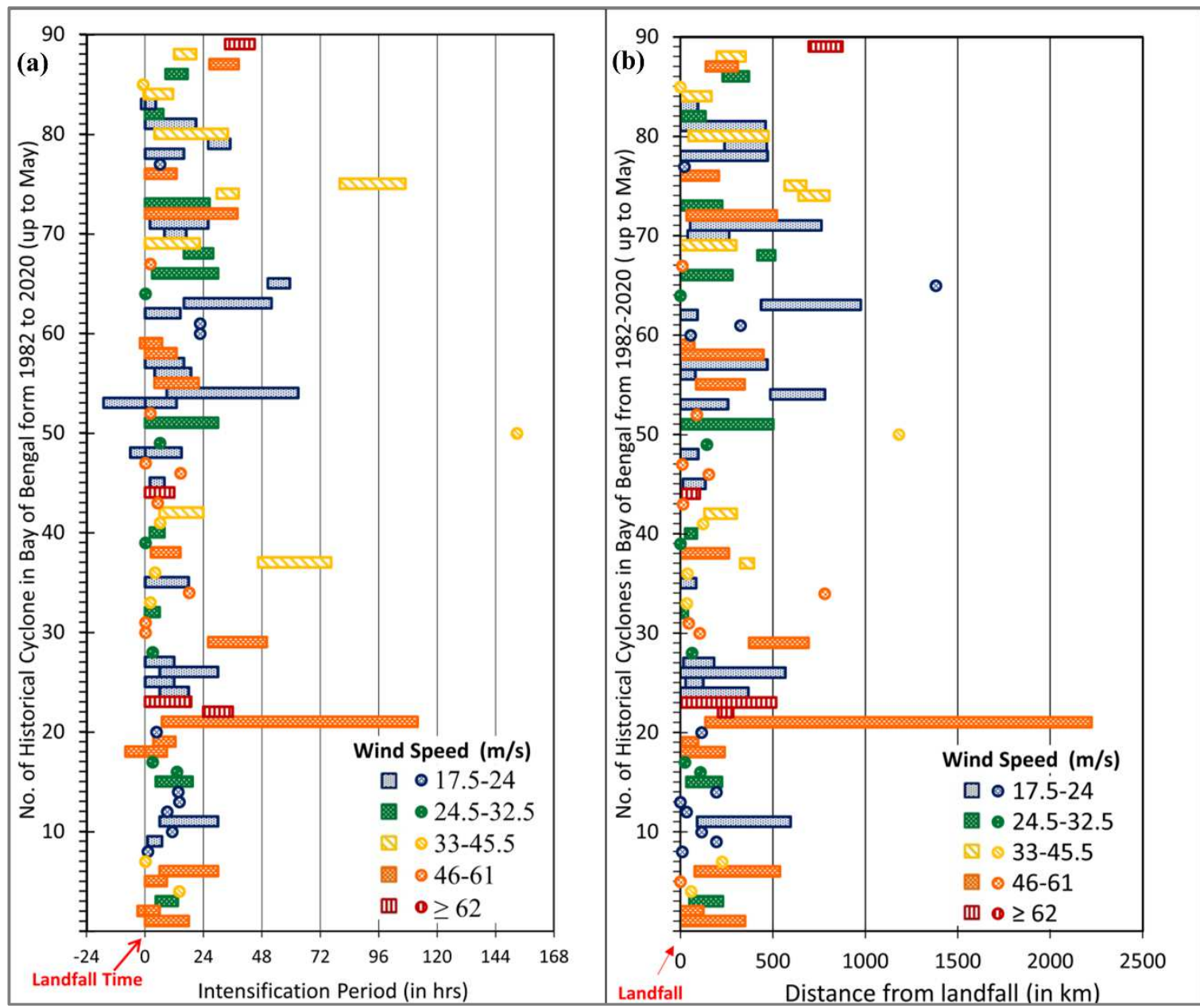

Figure 4 Landfalling TCs in BoB from 1982-2020 (up to May) with their highest maximum sustained wind speed and (a) duration by highest wind speed with respect to landfall time (represented by 0 in the $\mathrm{X}$ axis) (b) distance travelled by highest wind speed estimated from the landfall location (represented by 0 in the $\mathrm{X}$ axis) 


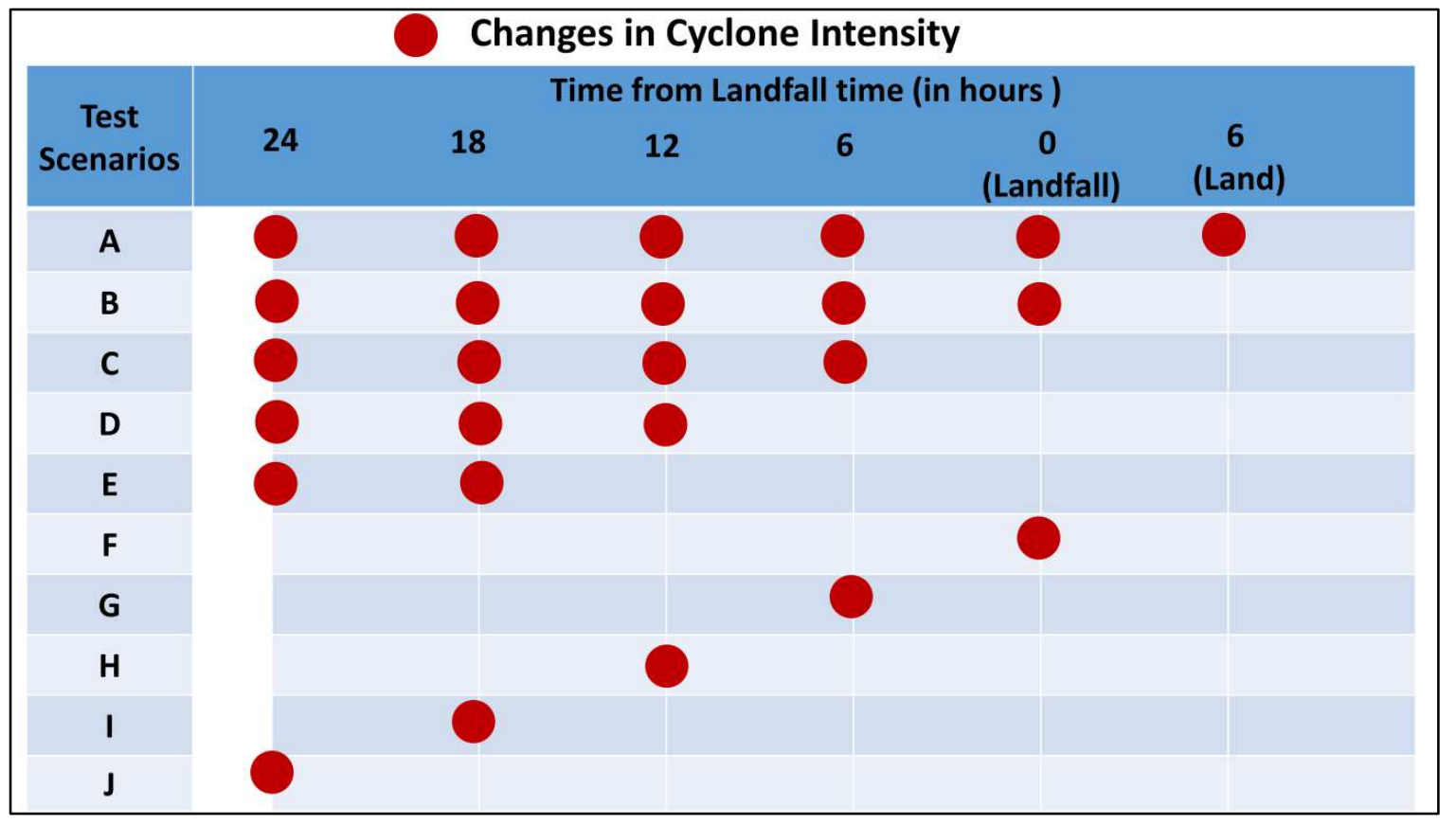

Figure 5 Hypothetical test scenarios showing the cyclone path on temporal scale 24 hours prior to landfall and 6 hours after landfall where the cyclone intensities are altered

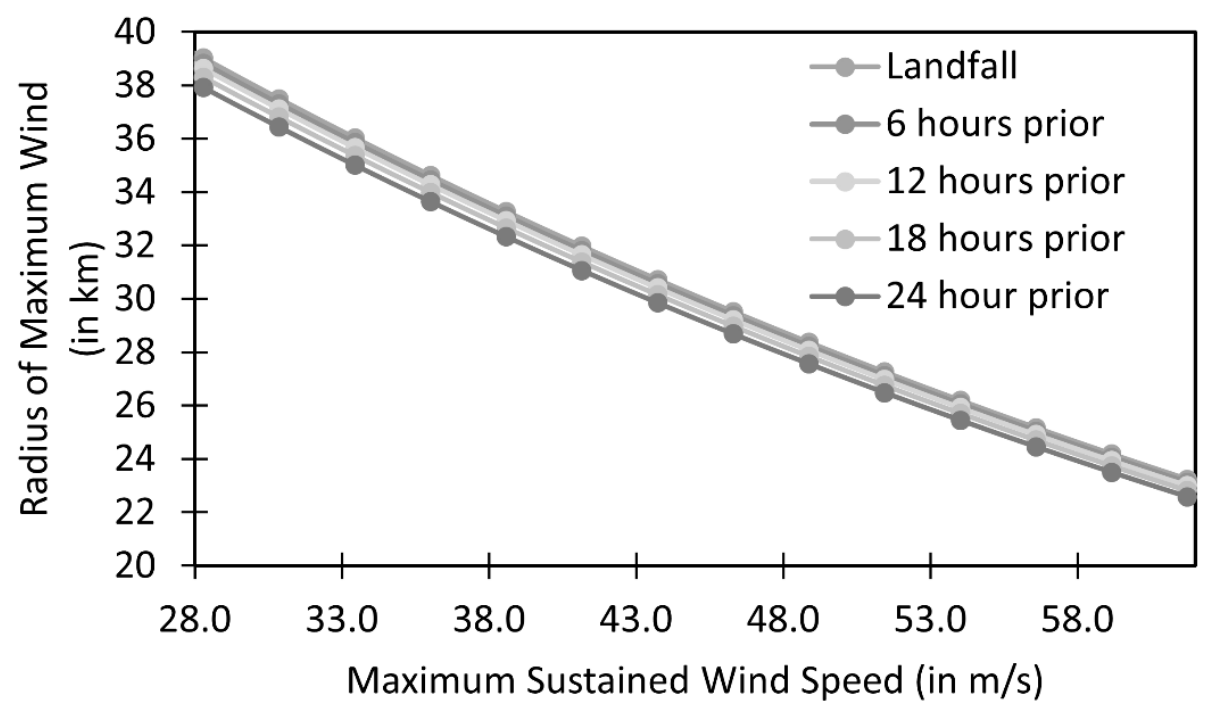

Figure 6 Radius of Maximum Winds corresponding to Maximum Sustained Wind Speed 

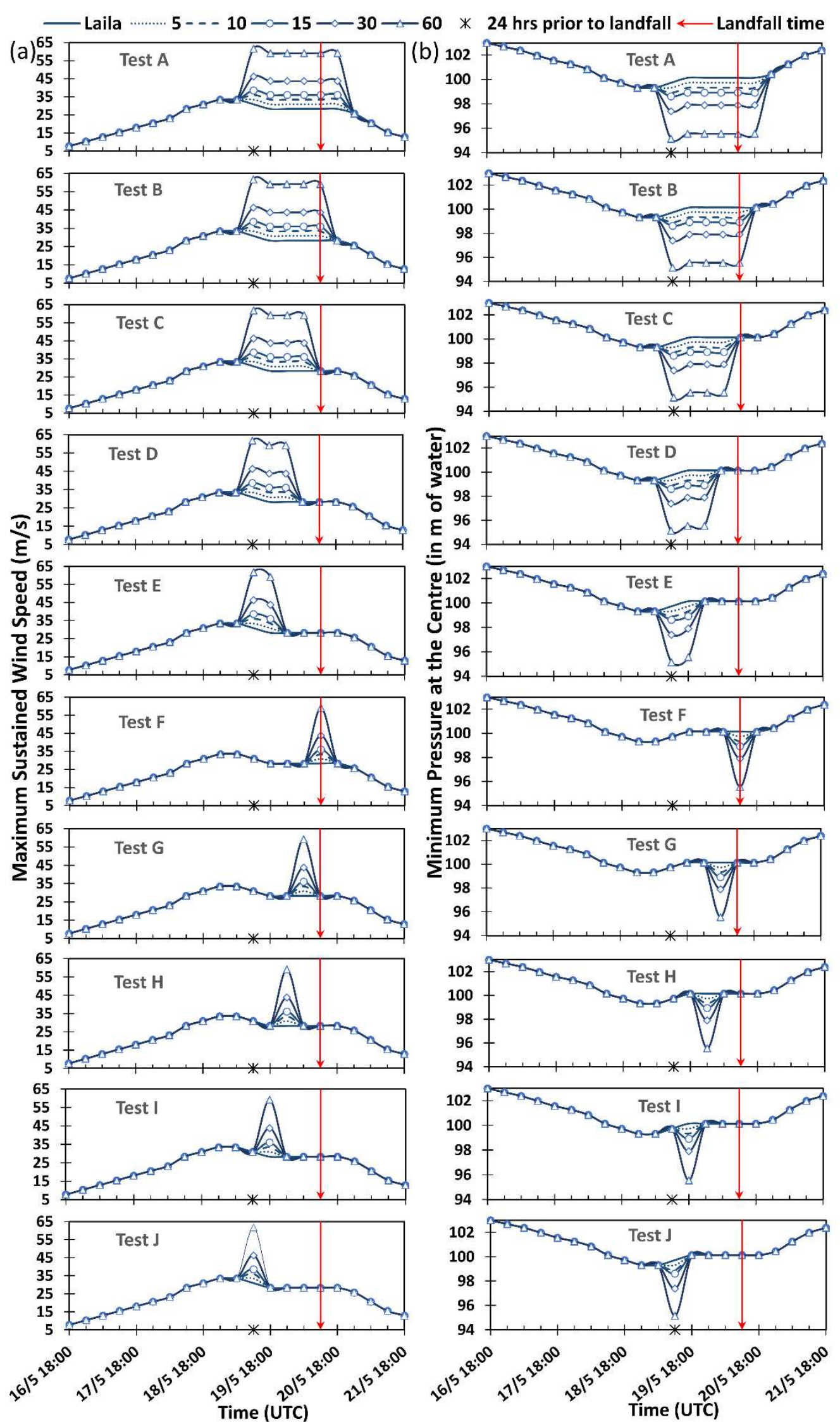

710 Figure 7 Temporal Variation of (a)Maximum sustained wind intensity of Laila and increased by 2.57(5),

$7115.14(10), 7.71(15), 15.4(15)$ and $30.86(60) \mathrm{m} / \mathrm{s}$ (knots) for different durations (A to J), and (b) Central Pressure 712 for Laila and the corresponding changes in the pressure for different durations (A to J) considered for the study 


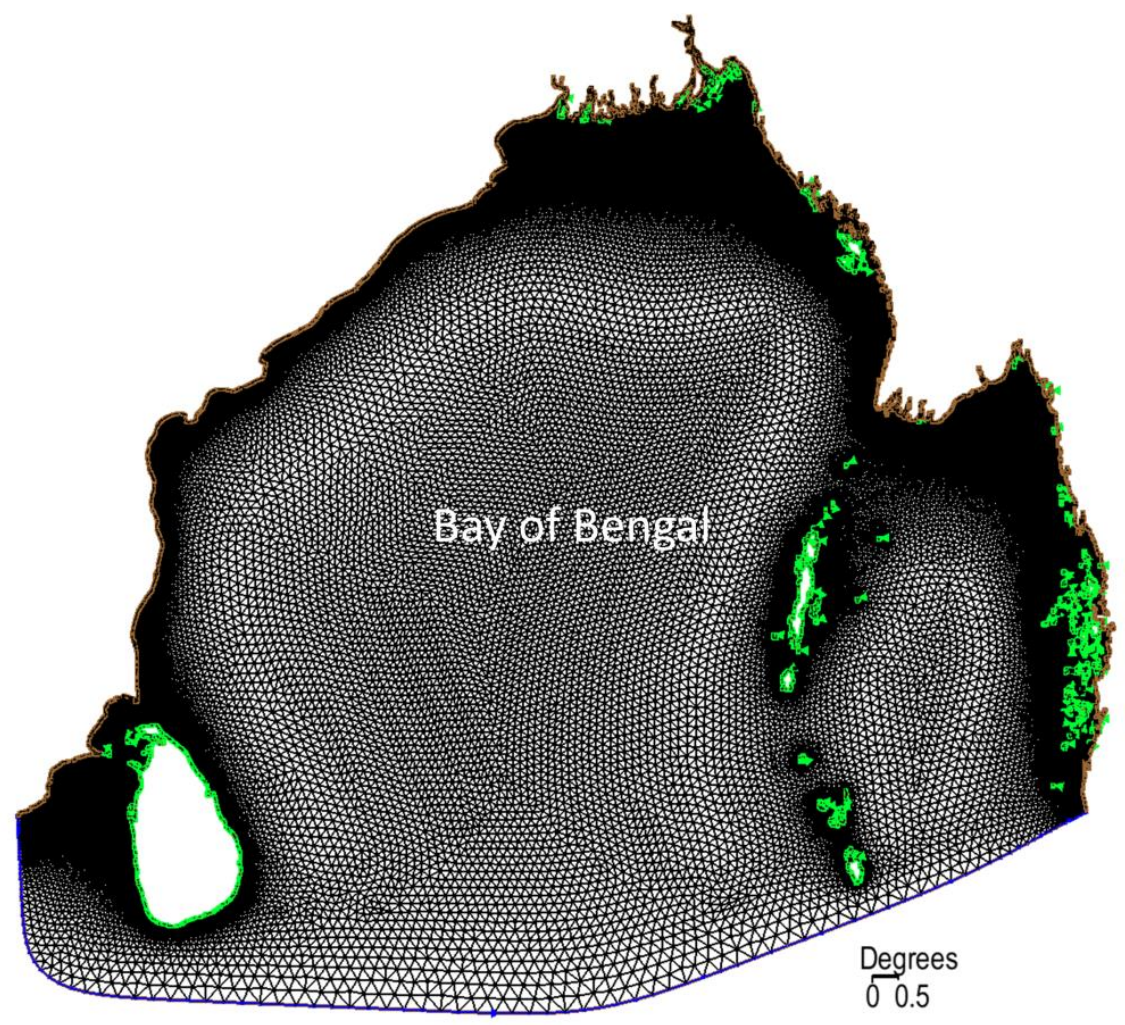

714

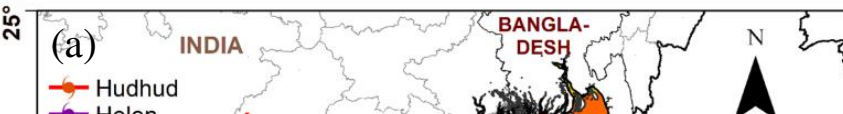

(b)
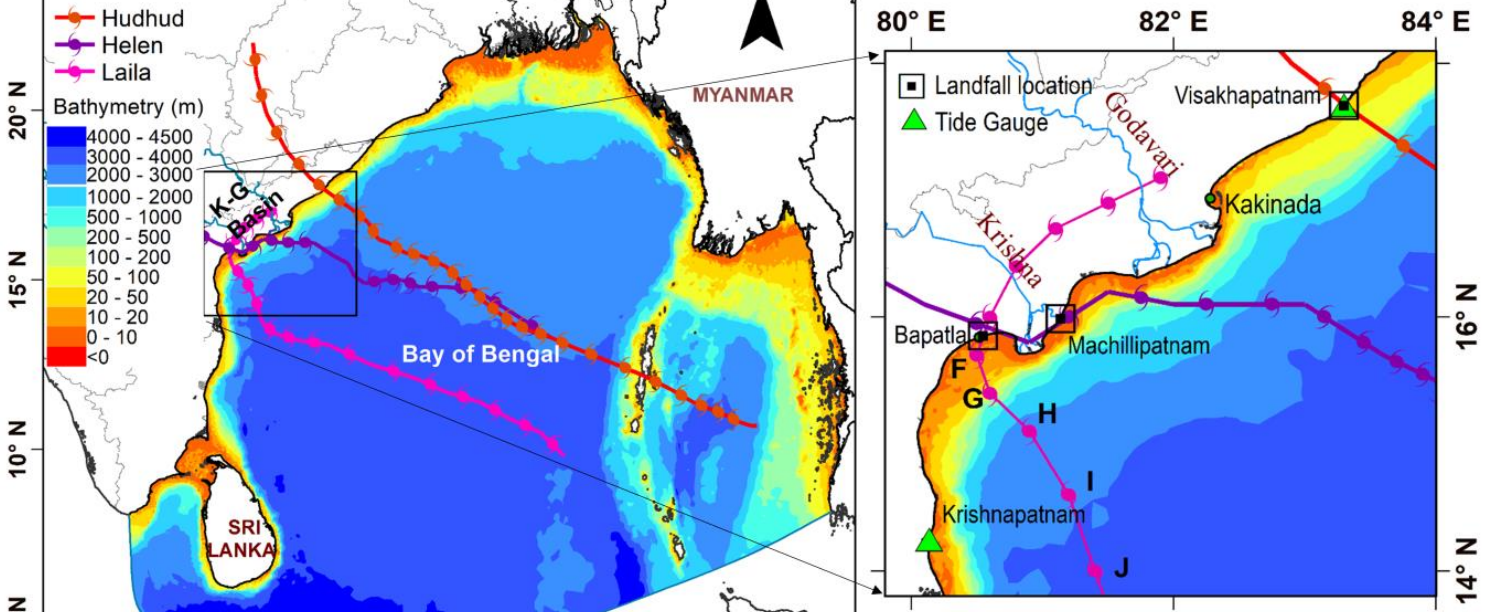

Figure 9(a) Study domain with interpolated bathymetry and the tracks of Laila, Helen, and Hudhud cyclones, and (b) Enlarged View showing the tide gauge stations and location along the Laila track where the intensities are varied for the present study 


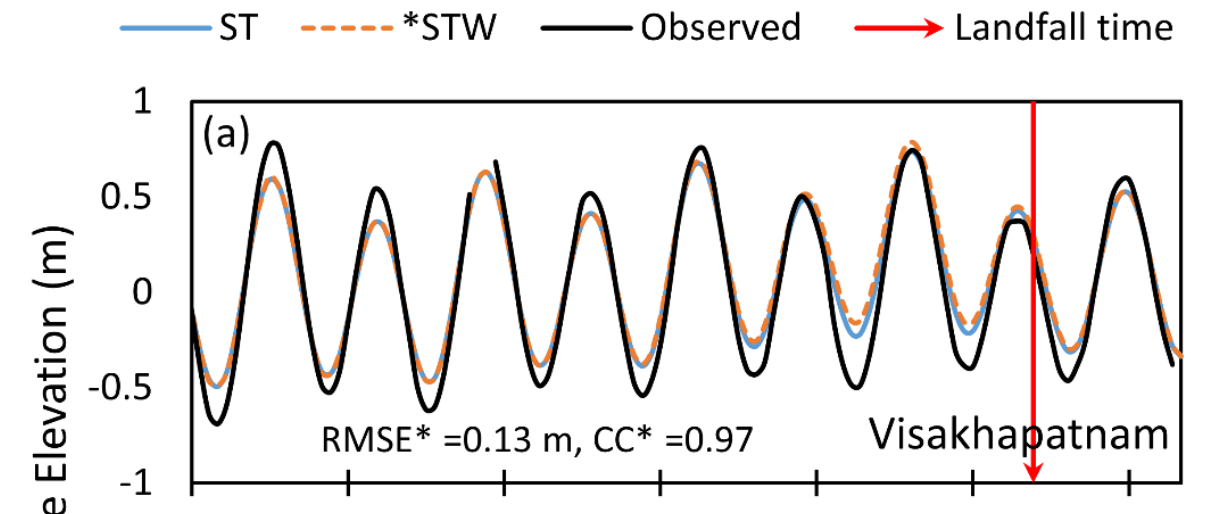

Figure 10 Comparison of observed and computed Water Levels at Visakhapatnam and Krishnapatnam during Time (UTC)

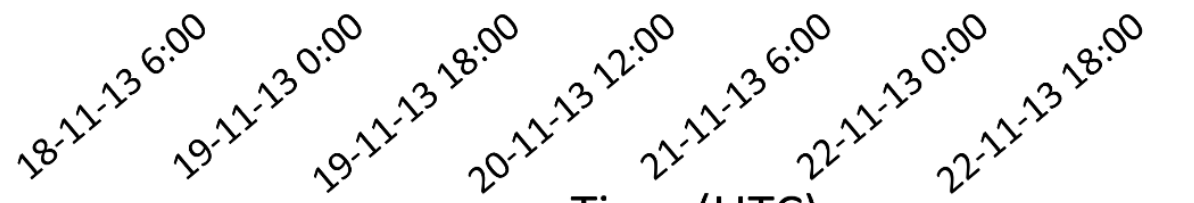
Helen 2013

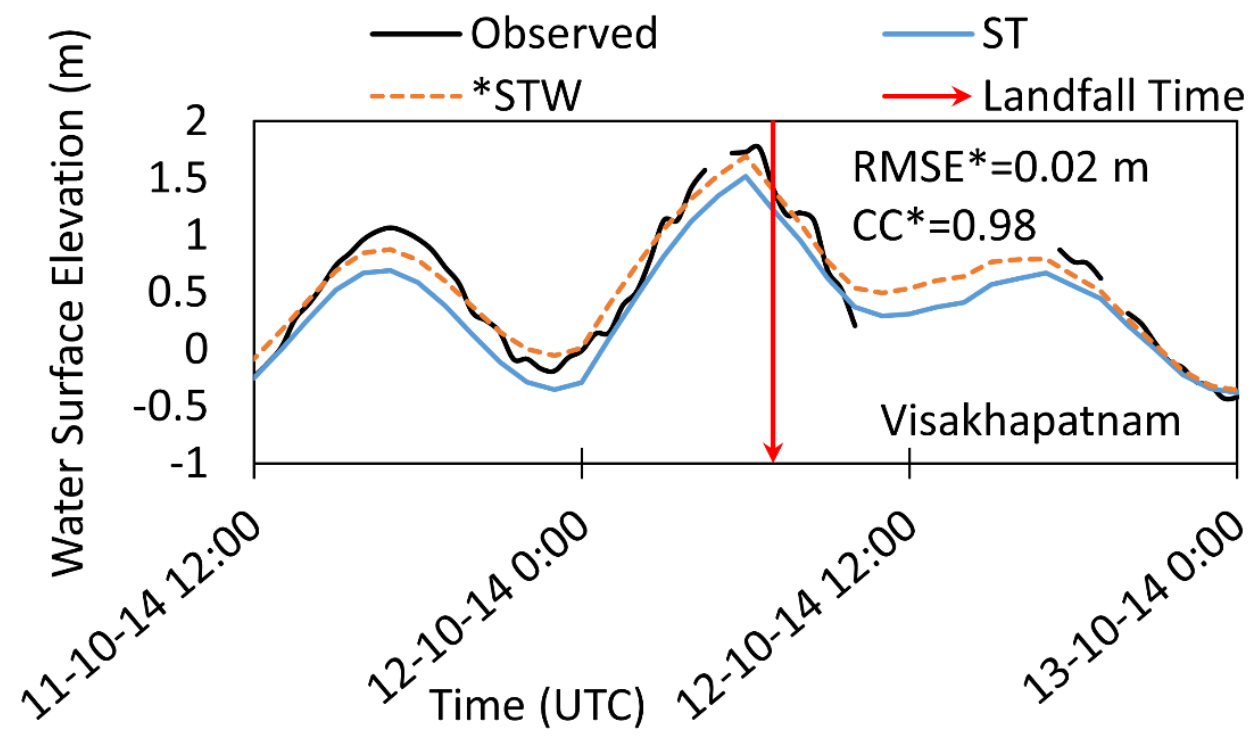




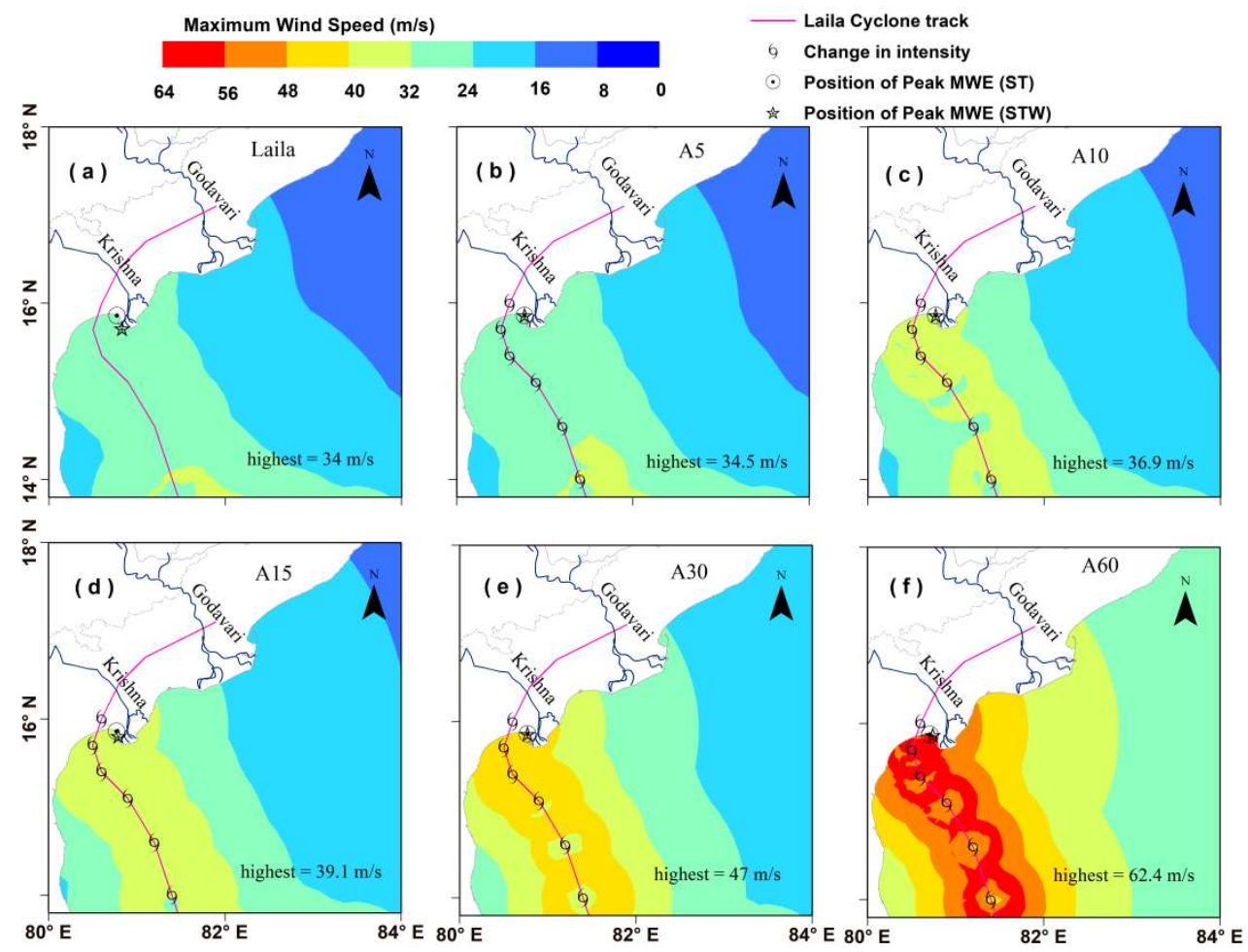

Figure 12 Spatial plot of Maximum Wind Speed during (a) Laila Cyclone and for Test A Scenario where the wind speed increased by (b) $2.57 \mathrm{~m} / \mathrm{s}$ (5 knots), (c) $5.14 \mathrm{~m} / \mathrm{s}$ (10 knots), (d) $7.71 \mathrm{~m} / \mathrm{s}$ (15 knots), (e) $15.4 \mathrm{~m} / \mathrm{s}$ (30 knots), and (f) $30.86 \mathrm{~m} / \mathrm{s}$ (60 knots)
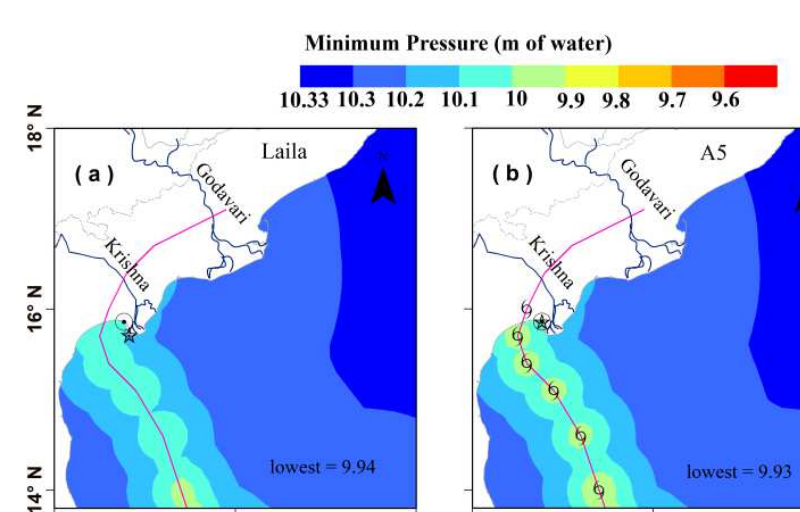

\section{- Laila Cyclone track \\ 9 Change in intensity}

- Position of Peak MWE (ST)

4. Position of Peak MWE (STW)
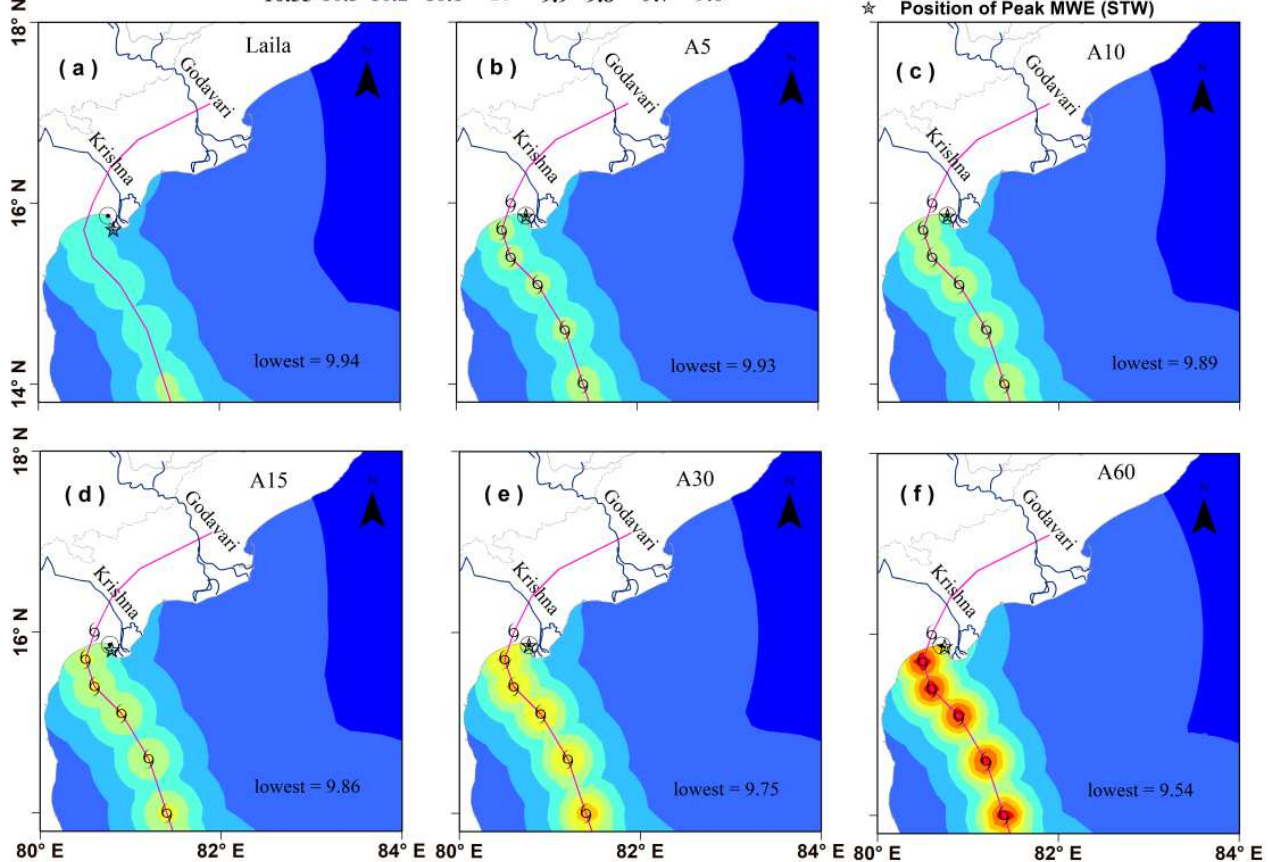

Figure 13 Spatial extent of Minimum Pressure during (a) Laila Cyclone, and for Test Scenario A where the wind speed increased by (b) $2.57 \mathrm{~m} / \mathrm{s}$ (5 knots), (c) $5.14 \mathrm{~m} / \mathrm{s}$ (10 knots), (d) $7.71 \mathrm{~m} / \mathrm{s}$ (15 knots), (e) $15.4 \mathrm{~m} / \mathrm{s}$ (30 knots), and (f) $30.86 \mathrm{~m} / \mathrm{s}$ (60 knots) 

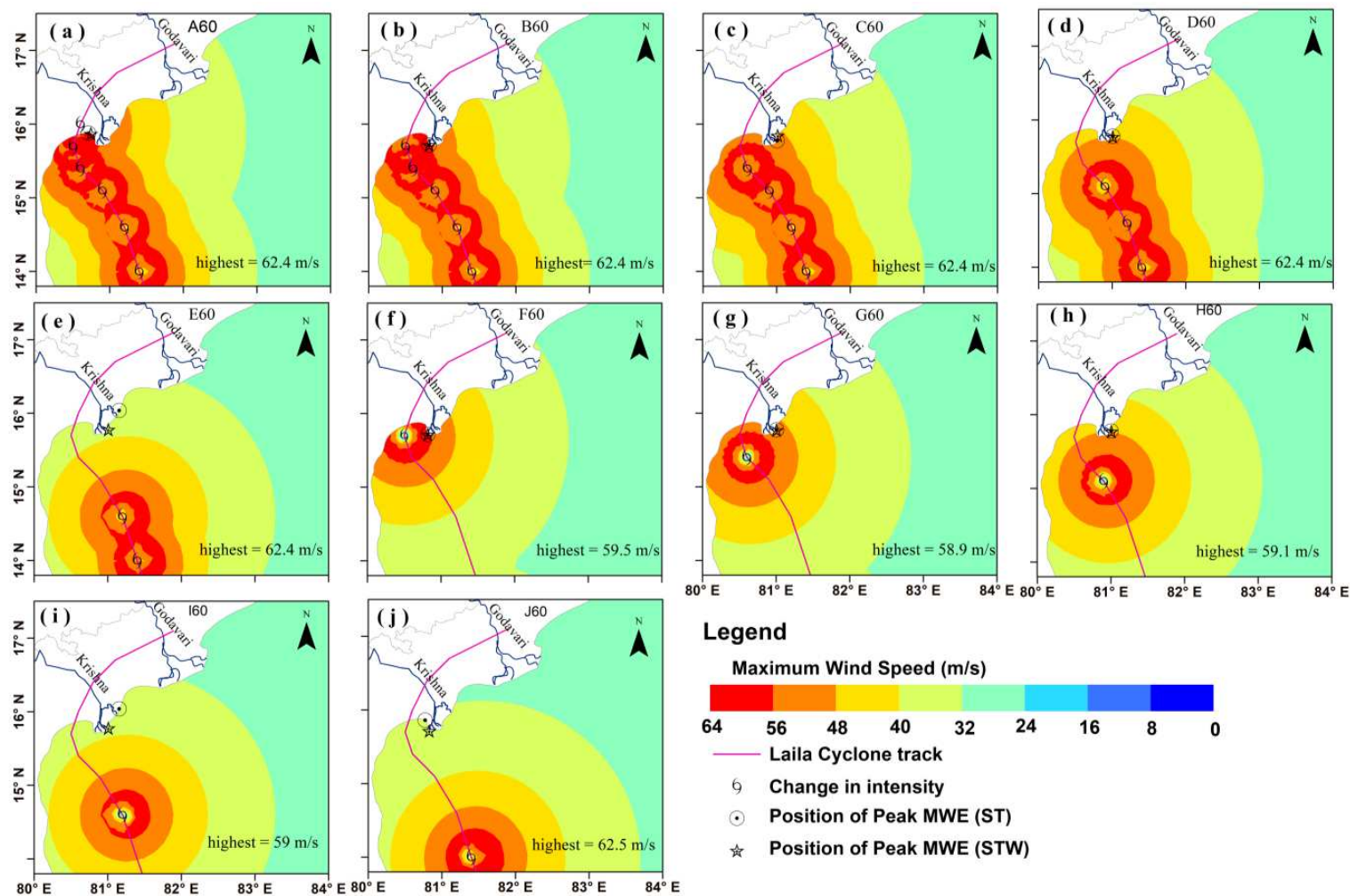

Figure 14 Spatial plot of Maximum Wind Speed with 30 m/s (60 knots) increase for different test scenarios (A -

J)
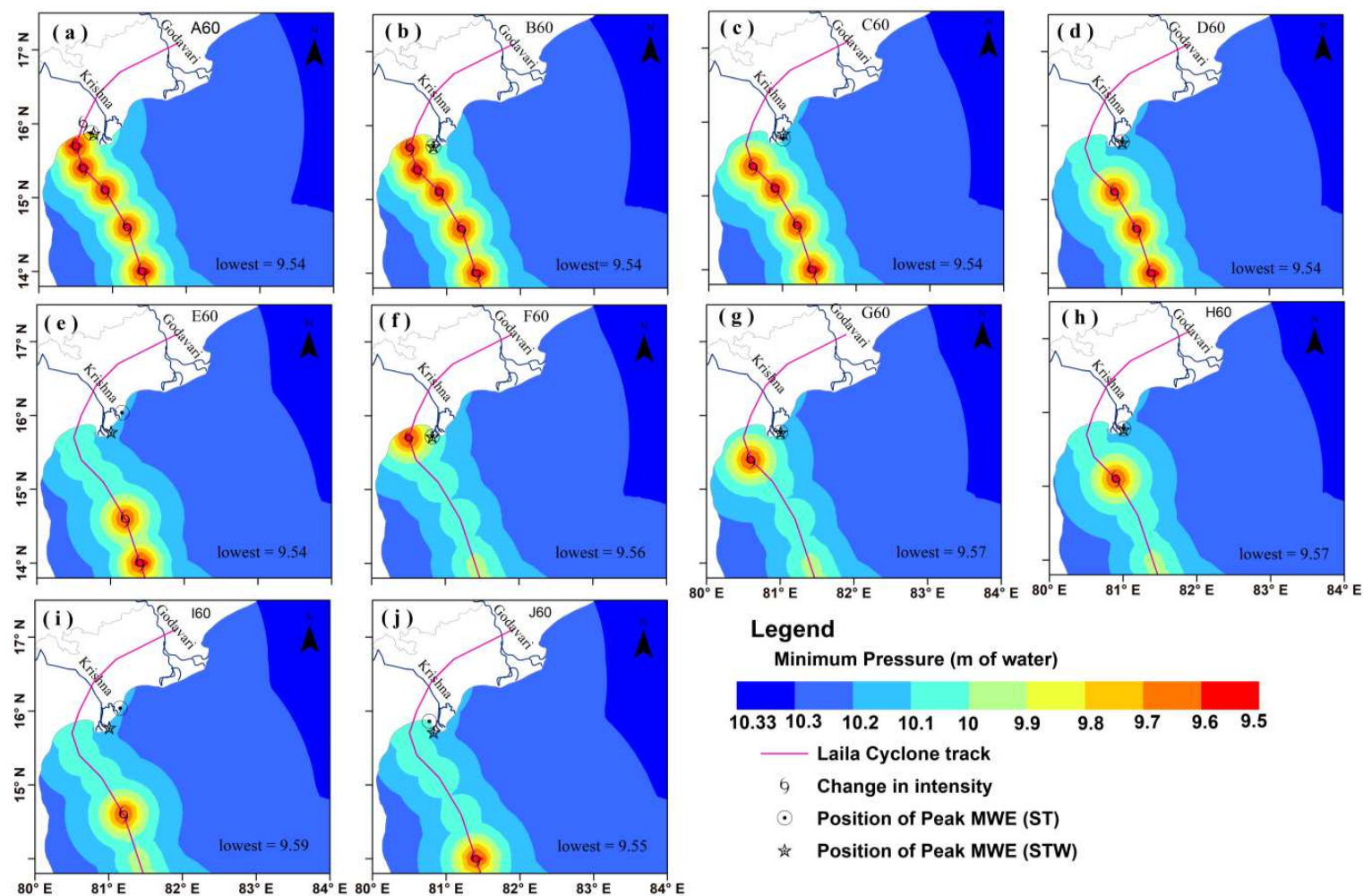

Legend

Minimum Pressure ( $m$ of water)

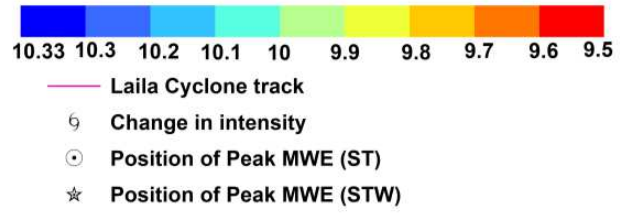

Figure 15 Spatial extent of Minimum Pressure for different Test Scenarios with an increasing wind speed by $30.86 \mathrm{~m} / \mathrm{s}$ (60 knots) considered for the study 

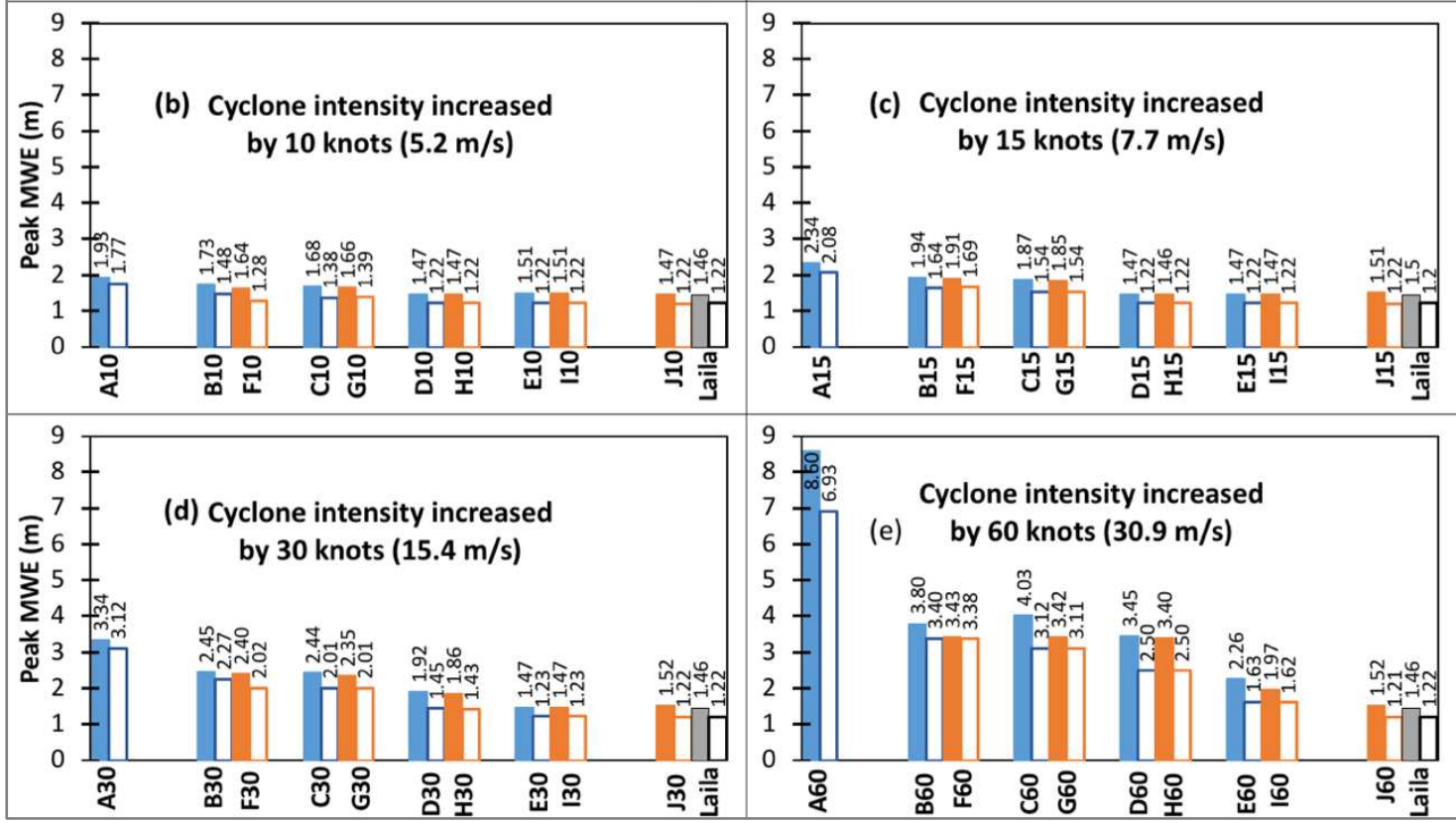

Figure 16 Peak Maximum Water Levels recorded by ST and STW along the K-G basin of Laila along with those of cyclone intensities increase by (a) $(2.57 \mathrm{~m} / \mathrm{s}$ ( 5 knots), (b) $5.14 \mathrm{~m} / \mathrm{s}$ (10 knots), (c) $7.71 \mathrm{~m} / \mathrm{s}$ (15 knots), (d) $15.4 \mathrm{~m} / \mathrm{s}$ (30 knots), and (e) $30.86 \mathrm{~m} / \mathrm{s}$ (60 knots)for 10 test scenarios

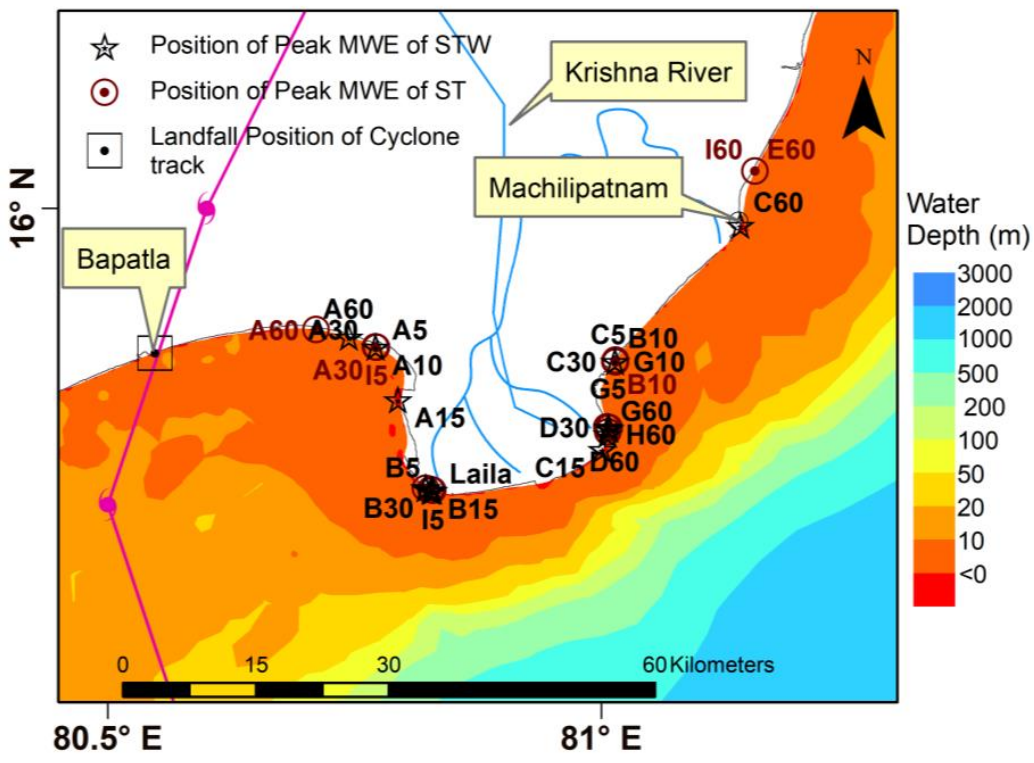

Figure 17 Location showing the Peak MWEs of STW and ST 

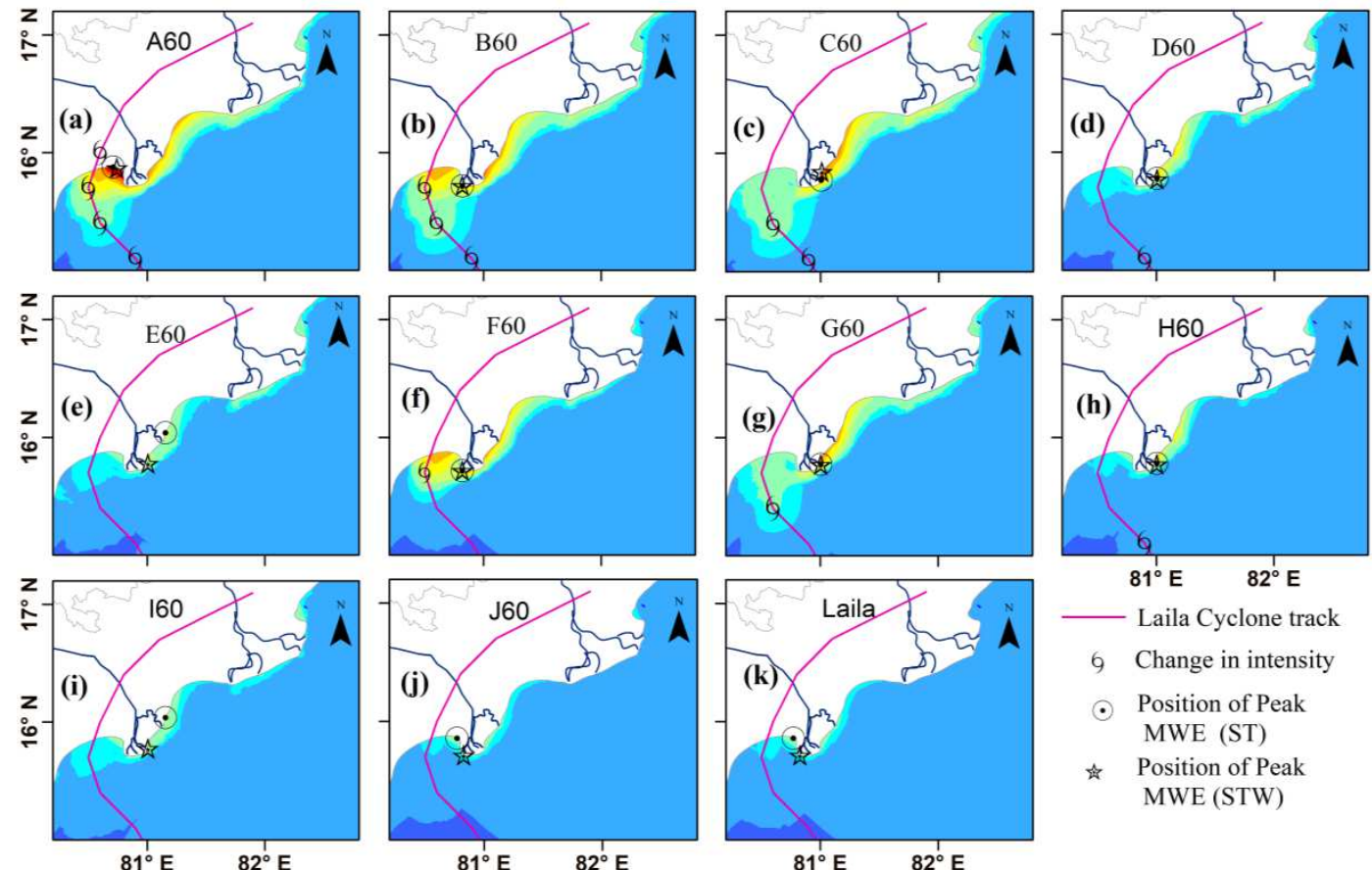

Laila Cyclone track

9 Change in intensity

- Position of Peak MWE (ST)

मे Position of Peak MWE (STW)

Figure 18 Spatial plot showing MWE of STW along the K-G basin for cyclone with increasing wind speed by $30.86 \mathrm{~m} / \mathrm{s}$ (60 knots) for different durations(a-j), and (k) Laila

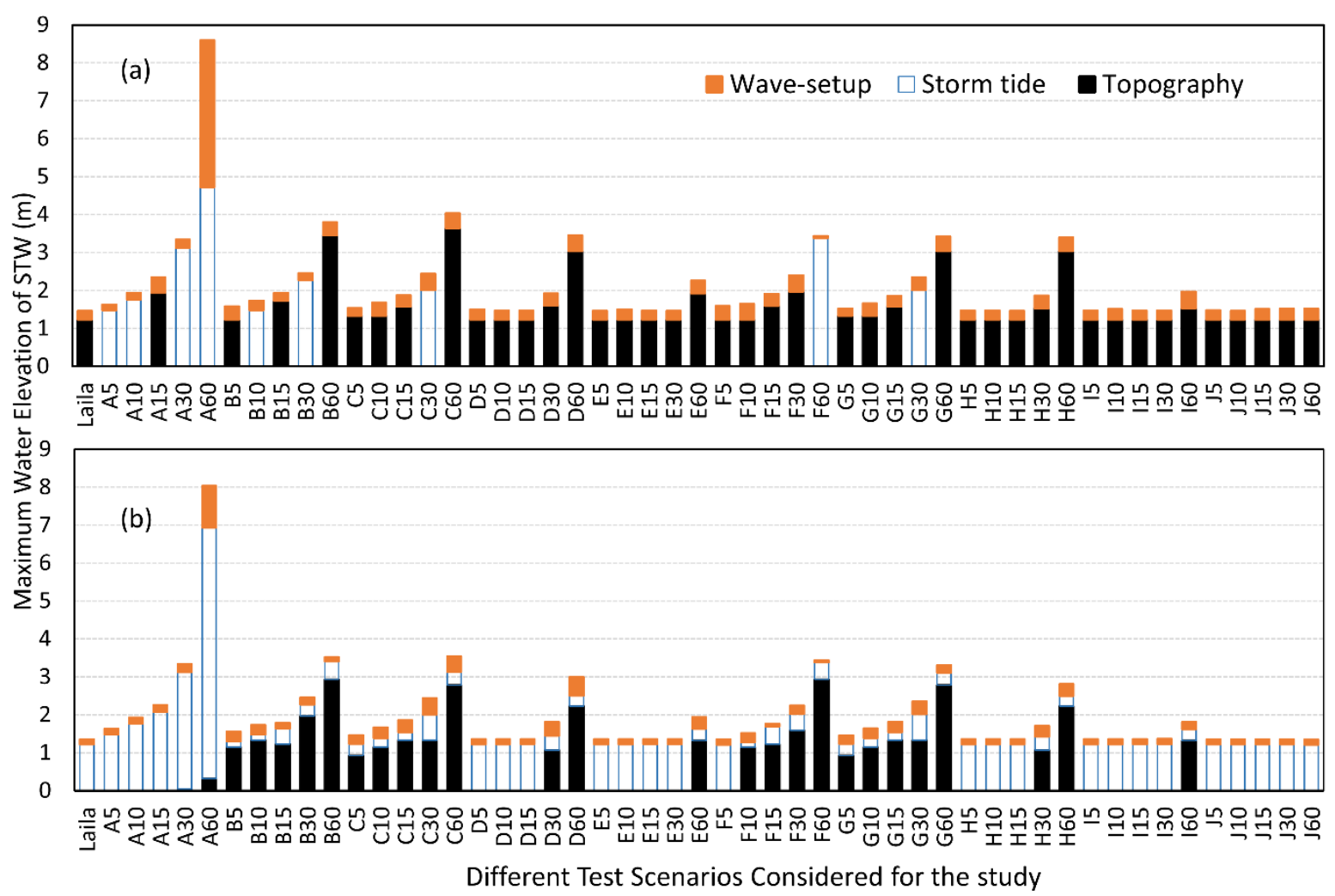

Figure 19 Wave contributions of all the numerical simulations at (a) location of peak MWE of STW (b) location of peak MWE of ST 


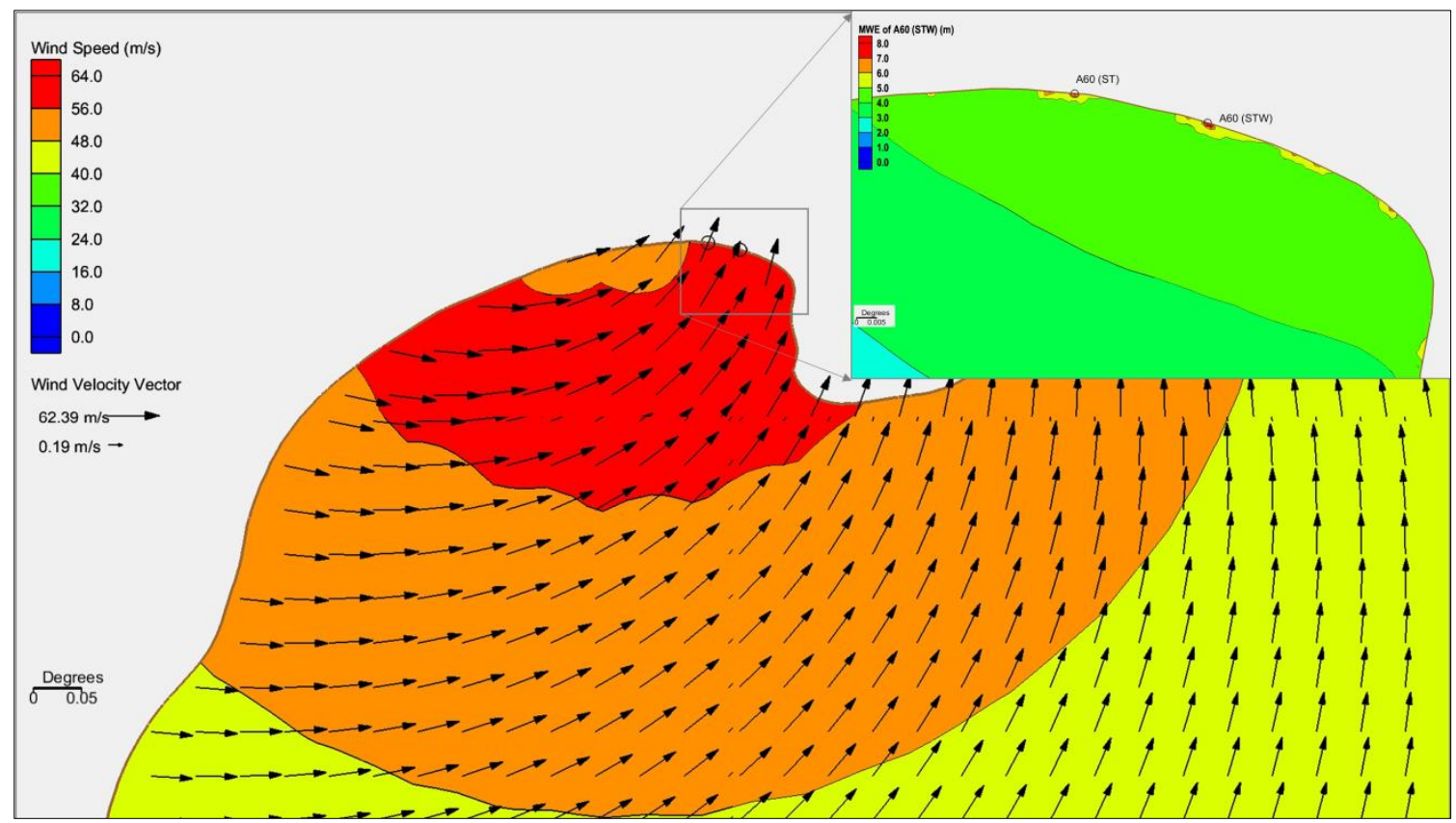

Figure 20 Wind field of Test A60 during the peak MWE for STW and the enlarged MWE showing the peak MWE (top right corner)
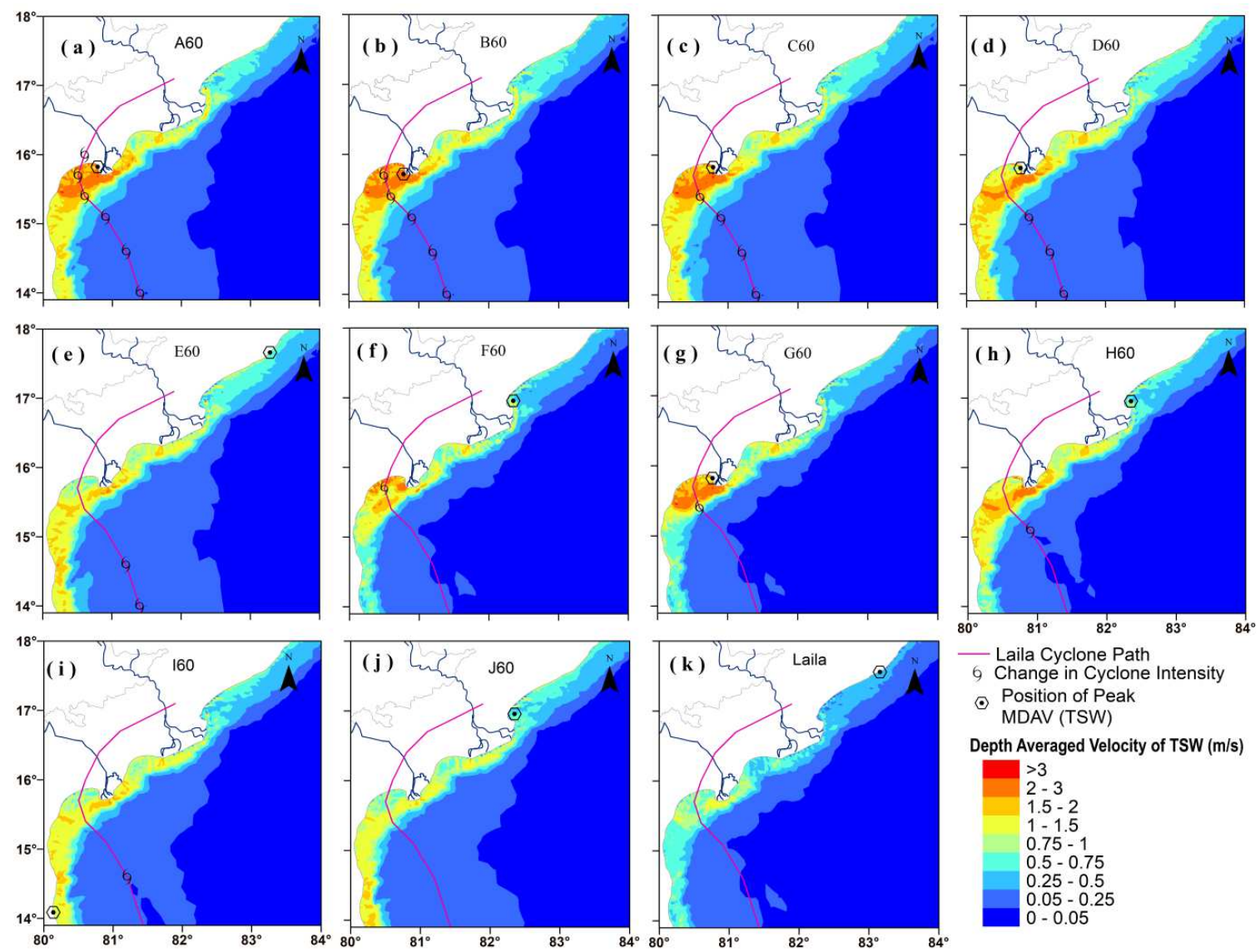

$\odot$ Position of Peak

MDAV (TSW)

Depth Averaged Velocity of TSW $(\mathrm{m} / \mathrm{s})$

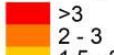

$2-3$
$1.5-2$

$1-1.5$
$0.75-1$

$0.5-0.75$

$0.5-0.75$
$0.25-0.5$

$0.05-0.25$

Figure 21 Spatial extent of $\mathrm{V}_{\text {avg_max }}$ with increasing wind speed by $30.86 \mathrm{~m} / \mathrm{s}$ ( 60 knots) for different durations considered for the study 


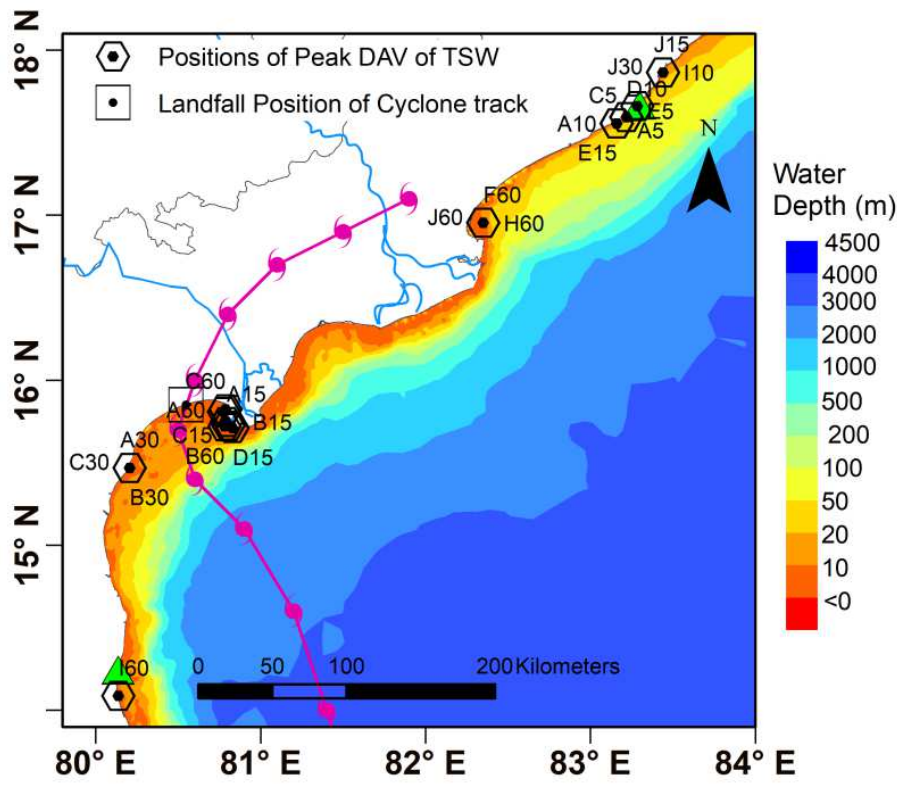

Figure 22 Locations of peak $\mathrm{V}_{\text {avg_max }}$ for all the scenarios

$761 \quad$ Table Captions

762 Table 1 IMD classification of low-pressure system over the Indian Ocean

\begin{tabular}{|c|c|c|c|}
\hline $\begin{array}{l}\text { T- } \\
\text { Number/ } \\
\text { C.I. } \\
\text { Number }\end{array}$ & System & $\begin{array}{l}\text { Maximum } \\
\text { Sustained } \\
\text { Wind Speed } \\
(\mathrm{m} / \mathrm{s})\end{array}$ & $\begin{array}{l}\text { Pressure } \\
\text { Drop (hPa) }\end{array}$ \\
\hline $\mathrm{T} 1.5$ & Depression (D) & $8-14$ & $1.0-3.0$ \\
\hline $\mathrm{T} 2.0$ & Deep Depression (DD) & $14.5-17$ & $3.0-4.5$ \\
\hline $\mathrm{T} 2.5$ & Cyclonic Storm (CS) & $17.5-24$ & $6.1-10$ \\
\hline $\mathrm{T} 3.5$ & Severe Cyclonic Storm (SCS) & $24.5-32.5$ & 15 \\
\hline $\mathrm{T} 4.0$ & Very Severe Cyclonic Storm (VSCS) & $33-45.5$ & 20.9-29.4 \\
\hline T5.0 & Extremely Severe Cyclonic Storm (ESCS) & $46-61$ & $40.2-65.6$ \\
\hline T6.5 & Super Cyclonic Storm (SuCS) & $\geq 62$ & $\geq 80$ \\
\hline
\end{tabular}

763

764 Table 2 Details of the numerical simulations conducted

\begin{tabular}{lllc}
\hline Model & $\begin{array}{l}\text { Increased Maximum } \\
\text { sustained wind speed m/s } \\
\text { (knots) }\end{array}$ & Intensification durations & Experiments \\
\hline ADCIRC & $\begin{array}{l}2.57(5), 5.14(10), 7.71(15), \\
15.4(30) \& 30.86(60)\end{array}$ & A, B, C,D, E,F, G, H, I, J & $5 \times 10=50+$ Laila \\
\hline ADCIRC+SWAN & $\begin{array}{l}2.57(5), 5.14(10), 7.71(15), \\
15.4(30) \& 30.86(60)\end{array}$ & A, B, C,D, E,F, G, H, I, J & $5 \times 10=50+$ Laila \\
\hline & \multicolumn{3}{l}{ Total Experiments } \\
\hline
\end{tabular}


772 Table 3 Highest of the Maximum Wind Speeds ( $\mathrm{m} / \mathrm{s})$ \& Lowest of the Minimum Central Pressures (m of water)

773 for all the considered test cases

\begin{tabular}{|c|c|c|c|c|c|c|c|c|c|c|}
\hline \multirow{2}{*}{$\begin{array}{c}\text { Test } \\
\text { Scenarios }\end{array}$} & \multicolumn{2}{|c|}{$2.57 \mathrm{~m} / \mathrm{s}$ (5 knots) } & \multicolumn{2}{|c|}{$5.14 \mathrm{~m} / \mathrm{s}$ (10 knots) } & \multicolumn{2}{|c|}{$7.71 \mathrm{~m} / \mathrm{s}(15$ knots $)$} & \multicolumn{2}{|c|}{$15.4 \mathrm{~m} / \mathrm{s}$ (30 knots) } & \multicolumn{2}{|c|}{$30.86 \mathrm{~m} / \mathrm{s}$ (60 knots) } \\
\hline & $\begin{array}{l}\text { Wind } \\
\text { Speed }\end{array}$ & $\begin{array}{l}\text { Central } \\
\text { Pressure }\end{array}$ & $\begin{array}{l}\text { Wind } \\
\text { Speed }\end{array}$ & $\begin{array}{l}\text { Central } \\
\text { Pressure }\end{array}$ & $\begin{array}{l}\text { Wind } \\
\text { Speed }\end{array}$ & $\begin{array}{l}\text { Central } \\
\text { Pressure }\end{array}$ & $\begin{array}{l}\text { Wind } \\
\text { Speed }\end{array}$ & $\begin{array}{l}\text { Central } \\
\text { Pressure }\end{array}$ & $\begin{array}{l}\text { Wind } \\
\text { Speed }\end{array}$ & $\begin{array}{l}\text { Central } \\
\text { Pressure }\end{array}$ \\
\hline A & 34.5 & 9.93 & 36.9 & 9.89 & 39.1 & 9.86 & 47 & 9.75 & 62.4 & 9.54 \\
\hline B & 34.5 & 9.93 & 36.9 & 9.89 & 39.1 & 9.86 & 47 & 9.75 & 62.4 & 9.54 \\
\hline $\mathrm{C}$ & 34.5 & 9.93 & 36.9 & 9.89 & 39.1 & 9.86 & 47 & 9.75 & 62.4 & 9.54 \\
\hline $\mathrm{D}$ & 34.5 & 9.93 & 36.9 & 9.89 & 39.1 & 9.86 & 47 & 9.75 & 62.4 & 9.54 \\
\hline $\mathrm{E}$ & 34.5 & 9.93 & 36.9 & 9.89 & 39.1 & 9.86 & 47 & 9.75 & 62.4 & 9.54 \\
\hline $\mathrm{F}$ & 34 & 9.94 & 34.1 & 9.93 & 36.8 & 9.89 & 44.6 & 9.79 & 59.5 & 9.56 \\
\hline G & 34 & 9.94 & 34.1 & 9.93 & 36.7 & 9.89 & 44.2 & 9.79 & 58.9 & 9.57 \\
\hline $\mathrm{H}$ & 34 & 9.94 & 34.3 & 9.93 & 36.7 & 9.89 & 44.1 & 9.79 & 59.1 & 9.57 \\
\hline I & 34 & 9.94 & 34.5 & 9.94 & 37 & 9.90 & 44.4 & 9.80 & 59.0 & 9.59 \\
\hline $\mathrm{J}$ & 34.5 & 9.93 & 36.9 & 9.89 & 39.2 & 9.87 & 47.1 & 9.75 & 62.5 & 9.55 \\
\hline
\end{tabular}

Table 4 Percentage change in the peak MWE(STW) for all the test cases with respect to the peak MWE of Laila (STW)

\begin{tabular}{cccccc}
\hline Test Scenarios & $\begin{array}{c}\mathbf{2 . 5 7} \mathbf{~ m} / \mathbf{s} \\
\mathbf{( 5 ~ k n o t s )}\end{array}$ & $\begin{array}{c}\mathbf{5 . 1 4} \mathbf{~ m} / \mathbf{s} \\
(\mathbf{1 0} \mathbf{k n o t s})\end{array}$ & $\begin{array}{c}\mathbf{7 . 7 1} \mathbf{~ m s} / \\
(\mathbf{1 5} \mathbf{~ k n o t s})\end{array}$ & $\begin{array}{c}\mathbf{1 5 . 4} \mathbf{~ m} / \mathbf{s} \\
\mathbf{( 3 0} \mathbf{~ k n o t s})\end{array}$ & $\begin{array}{c}\mathbf{3 0 . 8 6} \mathbf{~ m} / \mathbf{s} \\
(\mathbf{6 0} \mathbf{~ k n o t s})\end{array}$ \\
\hline $\mathbf{A}$ & 11.5 & 32.0 & 60.1 & 128.3 & 487.4 \\
$\mathbf{B}$ & 8.1 & 18.3 & 32.2 & 67.7 & 159.7 \\
$\mathbf{C}$ & 4.9 & 15.1 & 28.0 & 66.7 & 175.5 \\
$\mathbf{D}$ & 2.8 & 0.6 & 0.6 & 31.2 & 135.5 \\
$\mathbf{E}$ & 0.2 & 2.9 & 0.6 & 0.1 & 54.5 \\
$\mathbf{F}$ & 8.4 & 12.1 & 30.5 & 64.3 & 134.5 \\
$\mathbf{G}$ & 4.4 & 13.4 & 26.7 & 60.6 & 133.5 \\
$\mathbf{H}$ & 0.6 & 0.6 & -0.1 & 27.2 & 132.0 \\
$\mathbf{I}$ & 0.5 & 3.0 & 0.3 & 0.3 & 34.5 \\
$\mathbf{J}$ & 1.1 & 0.2 & 3.4 & 3.6 & 3.6 \\
\hline
\end{tabular}

778

Table 5 Peak $V_{\text {avg_max }}($ in $\mathrm{m} / \mathrm{s}$ ) for different scenarios and intensifications

\begin{tabular}{|c|c|c|c|c|c|}
\hline Test Scenarios & $\begin{array}{l}2.57 \mathrm{~m} / \mathrm{s} \\
\text { (5 knots) }\end{array}$ & $\begin{array}{c}5.14 \mathrm{~m} / \mathrm{s} \\
(10 \mathrm{knots})\end{array}$ & $\begin{array}{c}7.71 \mathrm{~m} / \mathrm{s} \\
(15 \mathrm{knots})\end{array}$ & $\begin{array}{c}15.4 \mathrm{~m} / \mathrm{s} \\
(30 \mathrm{knots})\end{array}$ & $\begin{array}{c}30.86 \mathrm{~m} / \mathrm{s} \\
(60 \mathrm{knots})\end{array}$ \\
\hline $\mathbf{A}$ & 5.2 & 5.1 & 6.3 & 7.9 & 10.3 \\
\hline B & 5.2 & 5.1 & 6.0 & 7.9 & 10.1 \\
\hline C & 5.2 & 5.5 & 6.0 & 8.5 & 12.2 \\
\hline D & 5.2 & 4.9 & 6.0 & 6.4 & 10.6 \\
\hline $\mathbf{E}$ & 5.6 & 5.6 & 5.3 & 5.5 & 6.1 \\
\hline $\mathbf{F}$ & 5.4 & 5.4 & 5.4 & 5.4 & 6.1 \\
\hline $\mathbf{G}$ & 5.0 & 5.0 & 5.0 & 5.6 & 10.4 \\
\hline $\mathbf{H}$ & 5.3 & 5.6 & 5.9 & 6.4 & 7.9 \\
\hline $\mathbf{I}$ & 4.9 & 5.6 & 5.5 & 5.5 & 7.8 \\
\hline $\mathbf{J}$ & 5.3 & 5.2 & 5.3 & 6.0 & 7.9 \\
\hline
\end{tabular}




\section{Figures}

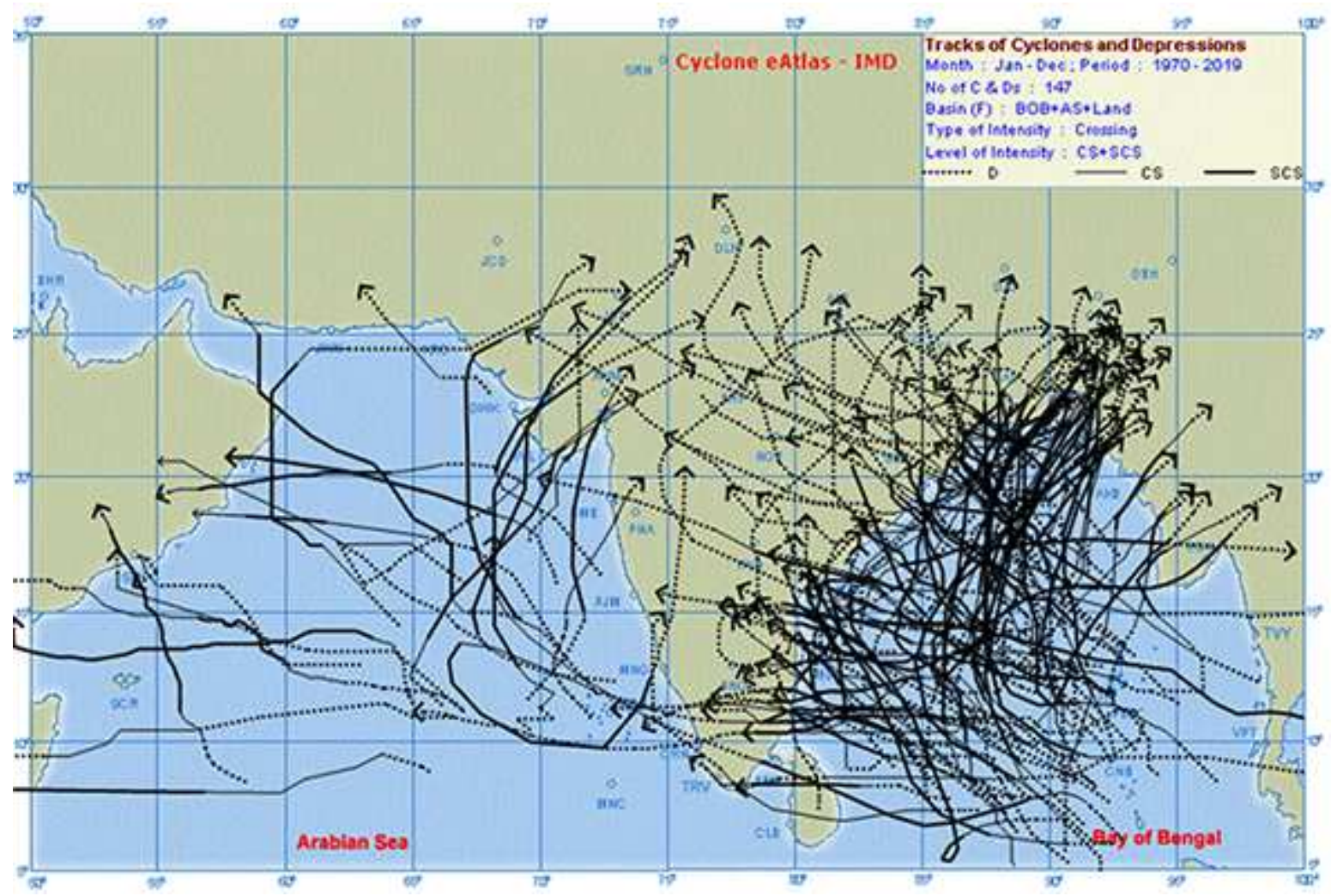

Figure 1

Cumulative tracks of landfalling TCs in NIO region from 1970-2019 (Source : Cyclone eAtlas-IMD 2020) Note: The designations employed and the presentation of the material on this map do not imply the expression of any opinion whatsoever on the part of Research Square concerning the legal status of any country, territory, city or area or of its authorities, or concerning the delimitation of its frontiers or boundaries. This map has been provided by the authors. 


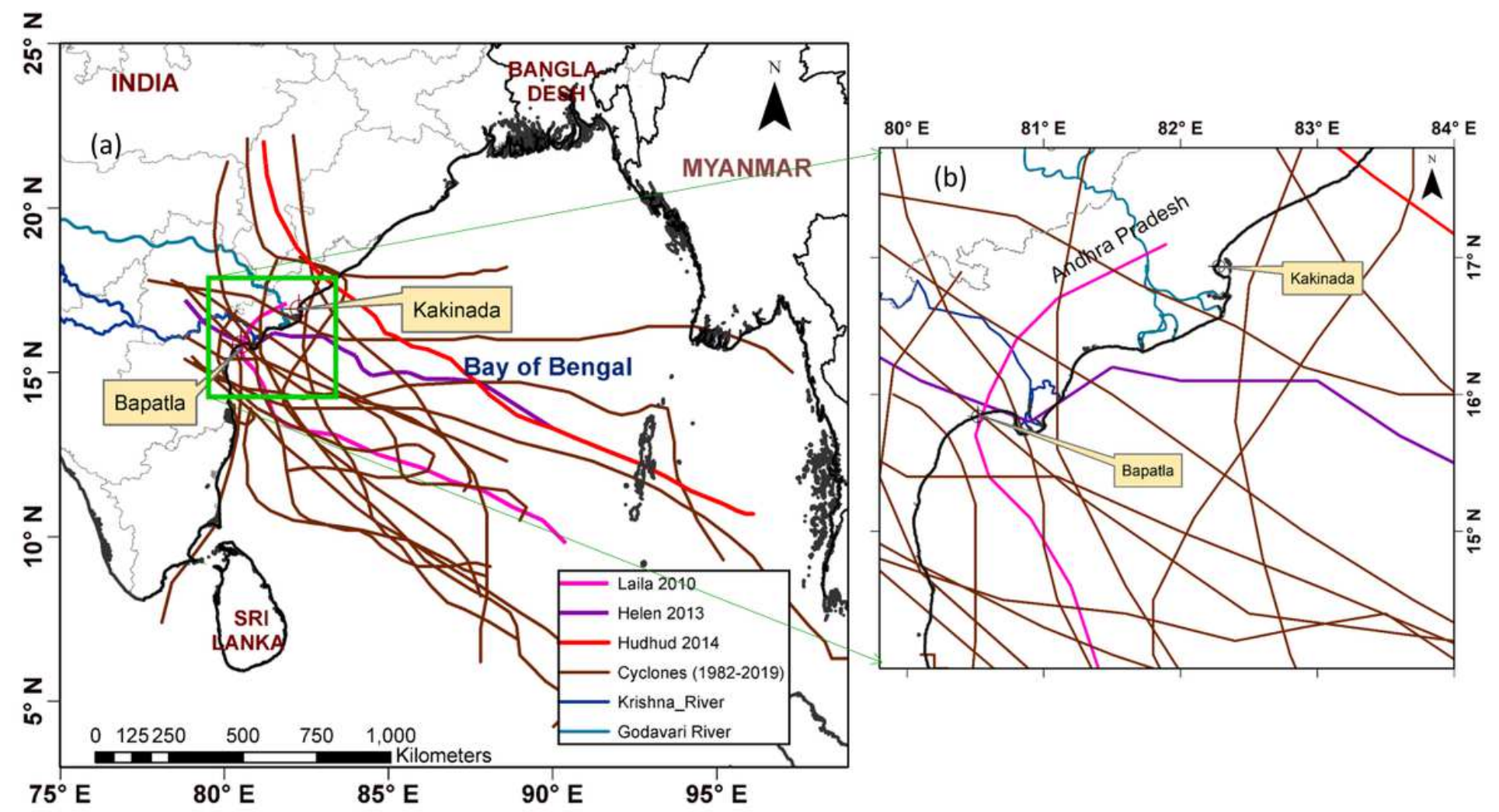

Figure 2

(a) Cyclone tracks from year 1982-2019 landfalling in Andhra Pradesh Coast, and(b) Enlarged view along the coast of K-G Basin Note: The designations employed and the presentation of the material on this map do not imply the expression of any opinion whatsoever on the part of Research Square concerning the legal status of any country, territory, city or area or of its authorities, or concerning the delimitation of its frontiers or boundaries. This map has been provided by the authors. 


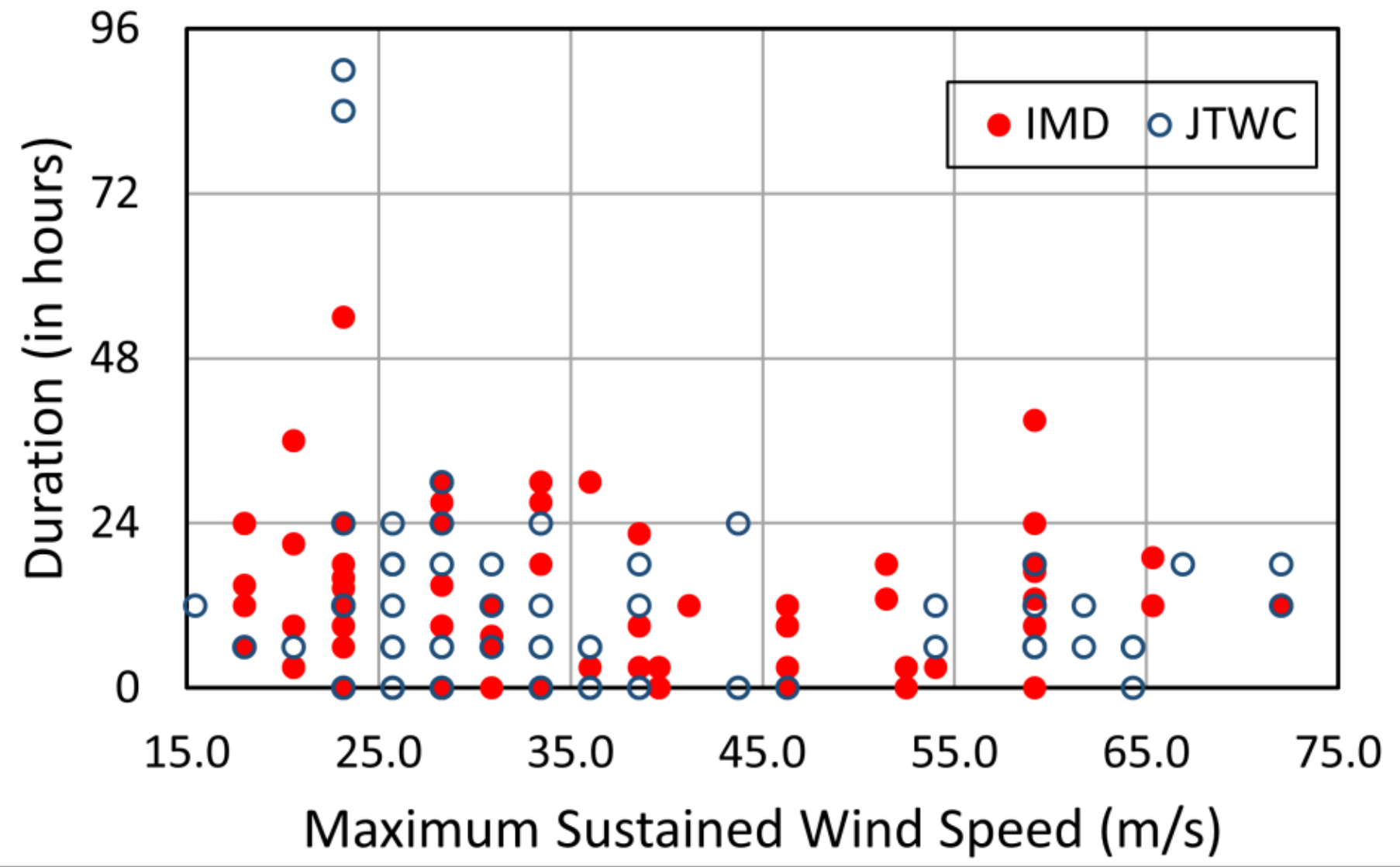

Figure 3

Scatterplot representing the highest associated cyclone intensity and its duration from IMD and JTWC for cyclones landfalling in BoB from 1982-2018 

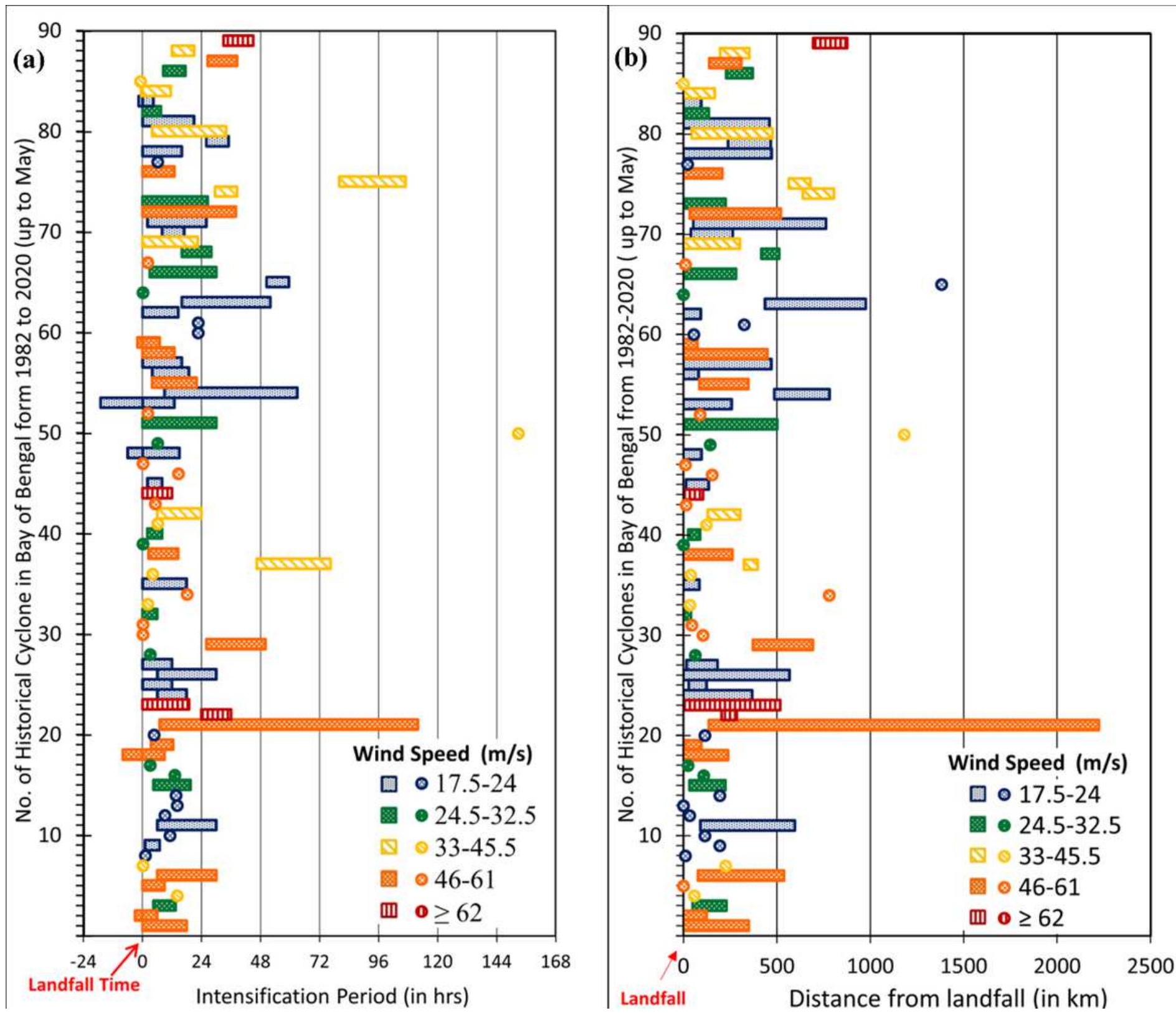

Figure 4

Landfalling TCs in BoB from 1982-2020 (up to May) with their highest maximum sustained wind speed and (a) duration by highest wind speed with respect to landfall time (represented by 0 in the $X$ axis) (b) distance travelled by highest wind speed estimated from the landfall location (represented by 0 in the $X$ axis) 


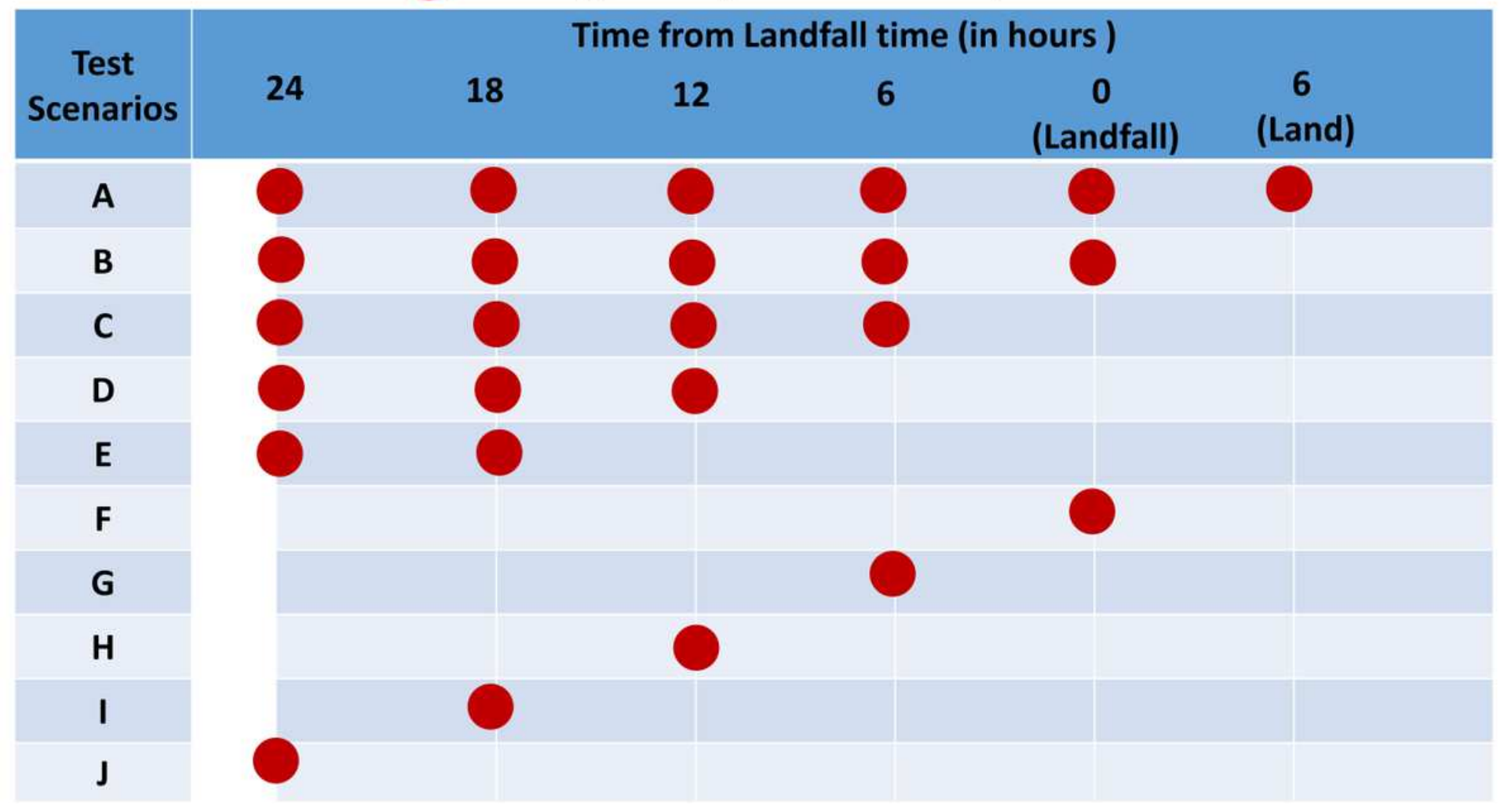

Figure 5

Hypothetical test scenarios showing the cyclone path on temporal scale 24 hours prior to landfall and 6 hours after landfall where the cyclone intensities are altered 


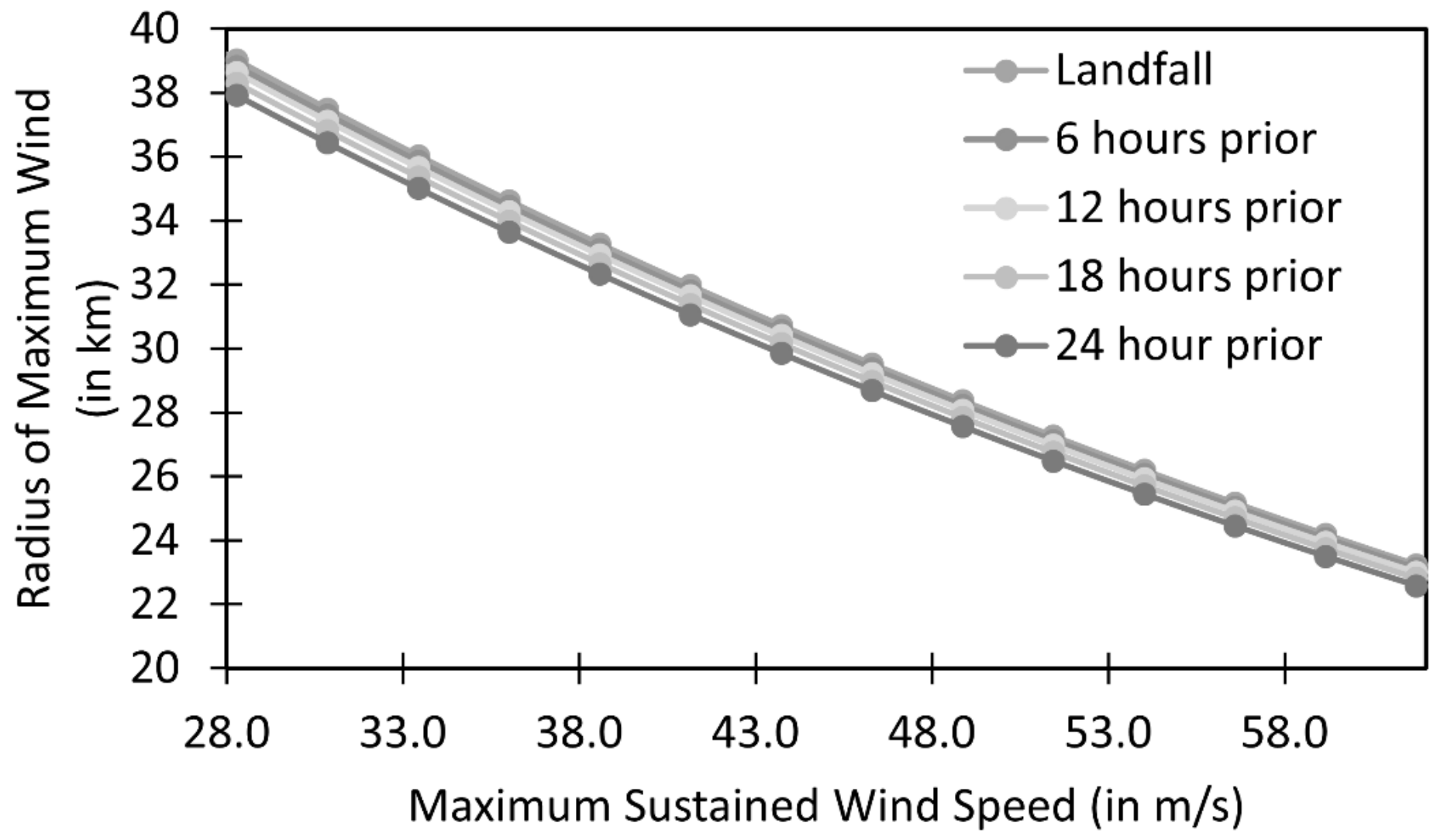

Figure 6

Radius of Maximum Winds corresponding to Maximum Sustained Wind Speed 


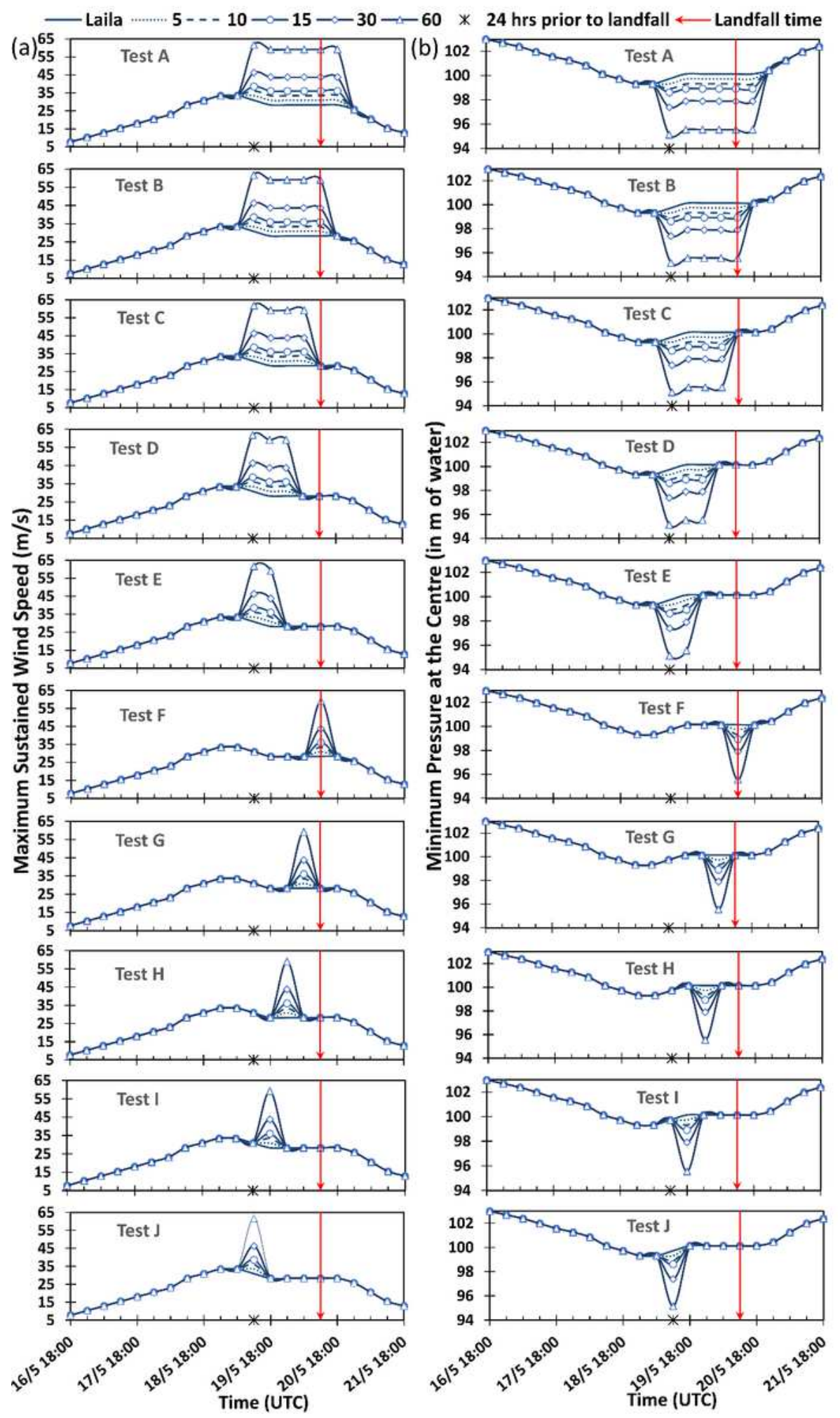

Figure 7

Temporal Variation of (a)Maximum sustained wind intensity of Laila and increased by 2.57(5), 5.14(10), 7.71(15), 15.4 (15) and 30.86 (60) m/s (knots) for different durations (A to J), and (b) Central Pressure for Laila and the corresponding changes in the pressure for different durations ( $A$ to $\mathrm{J}$ ) considered for the study 


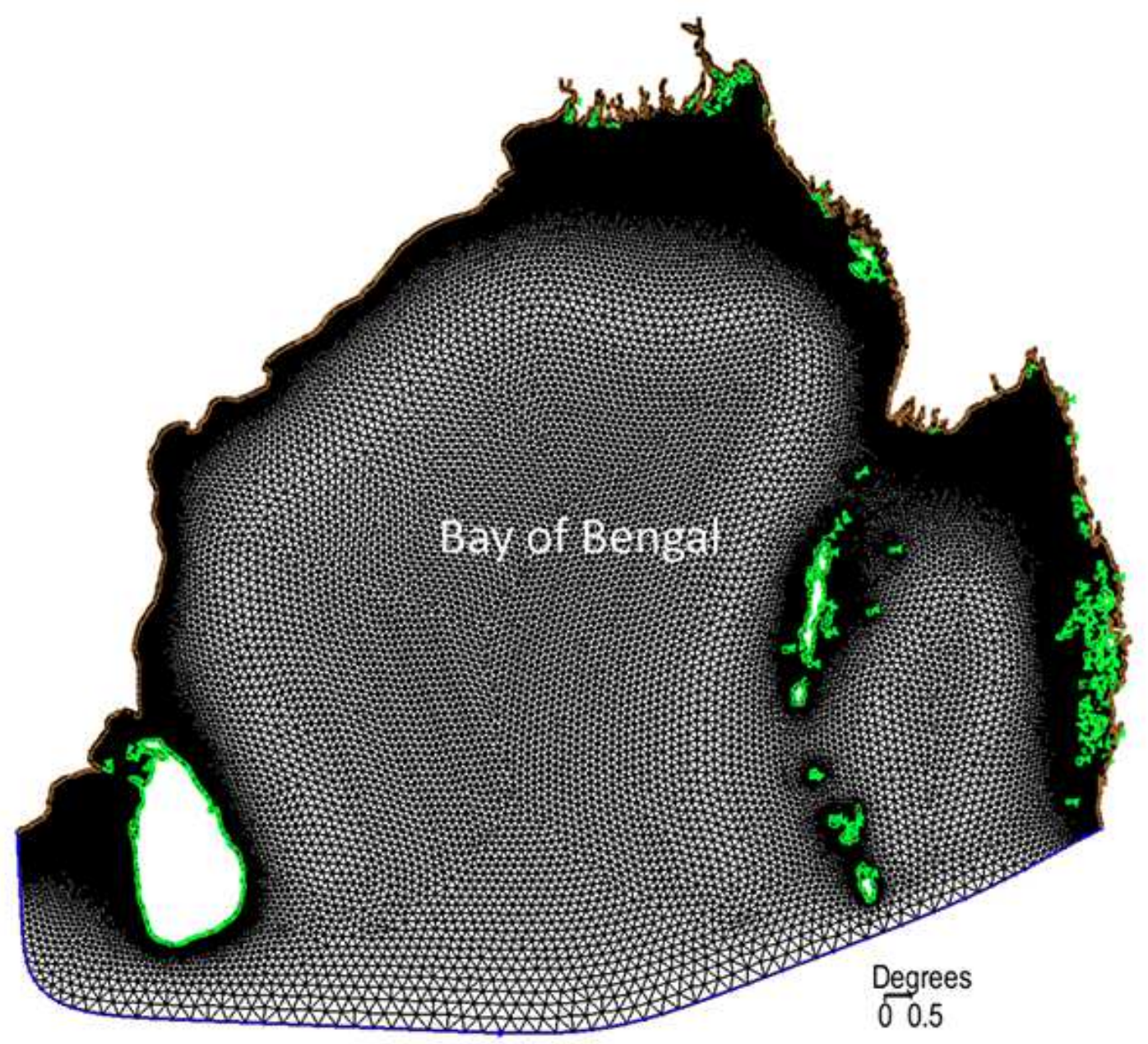

Figure 8

Discretised BoB Domain. Note: The designations employed and the presentation of the material on this map do not imply the expression of any opinion whatsoever on the part of Research Square concerning the legal status of any country, territory, city or area or of its authorities, or concerning the delimitation of its frontiers or boundaries. This map has been provided by the authors. 


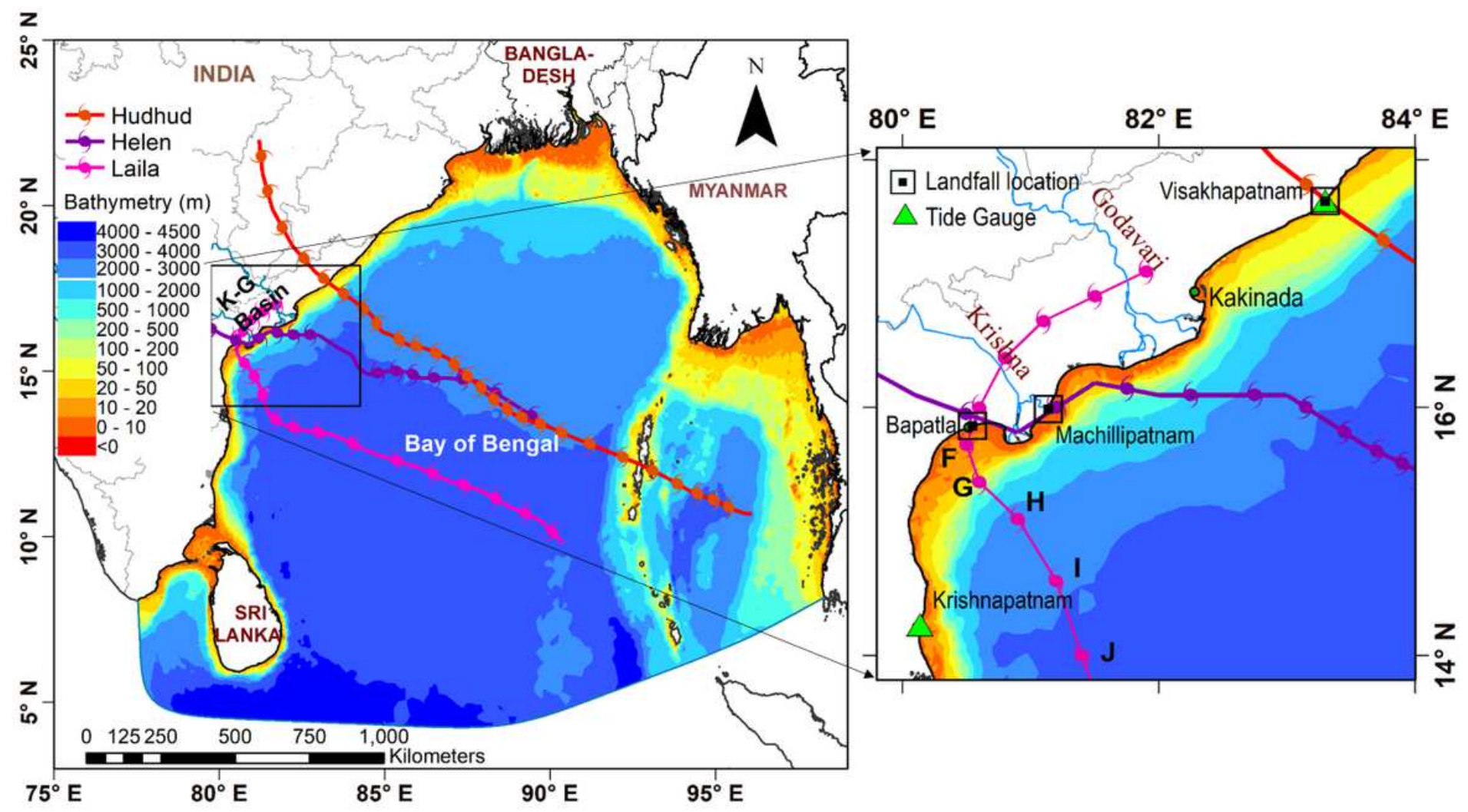

\section{Figure 9}

(a) Study domain with interpolated bathymetry and the tracks of Laila, Helen, and Hudhud cyclones, and (b) Enlarged View showing the tide gauge stations and location along the Laila track where the intensities are varied for the present study Note: The designations employed and the presentation of the material on this map do not imply the expression of any opinion whatsoever on the part of Research Square concerning the legal status of any country, territory, city or area or of its authorities, or concerning the delimitation of its frontiers or boundaries. This map has been provided by the authors. 
$\longrightarrow$ ST ----- *STW — Observed $\longrightarrow$ Landfall time
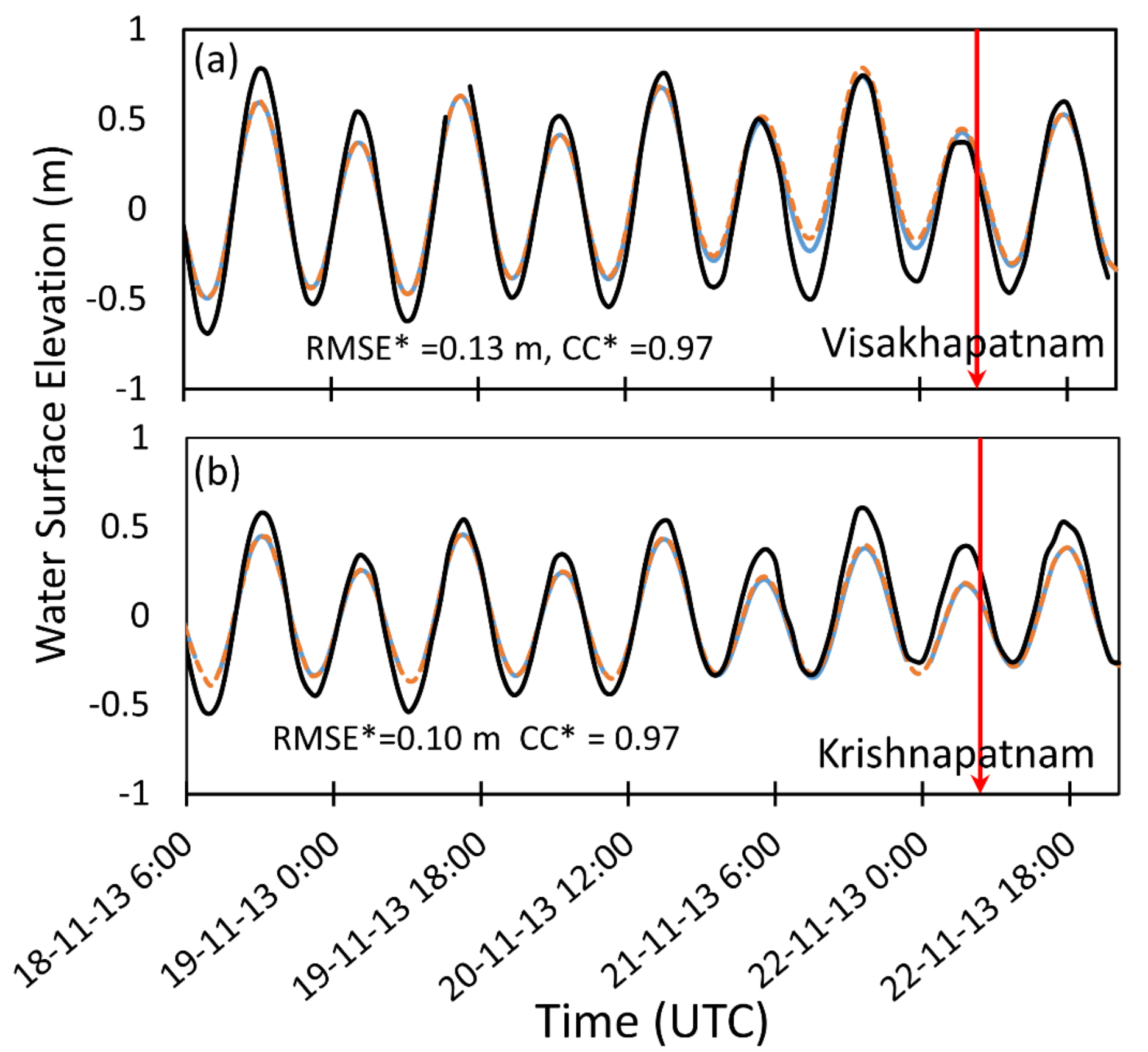

Figure 10

Comparison of observed and computed Water Levels at Visakhapatnam and Krishnapatnam during Helen 2013 


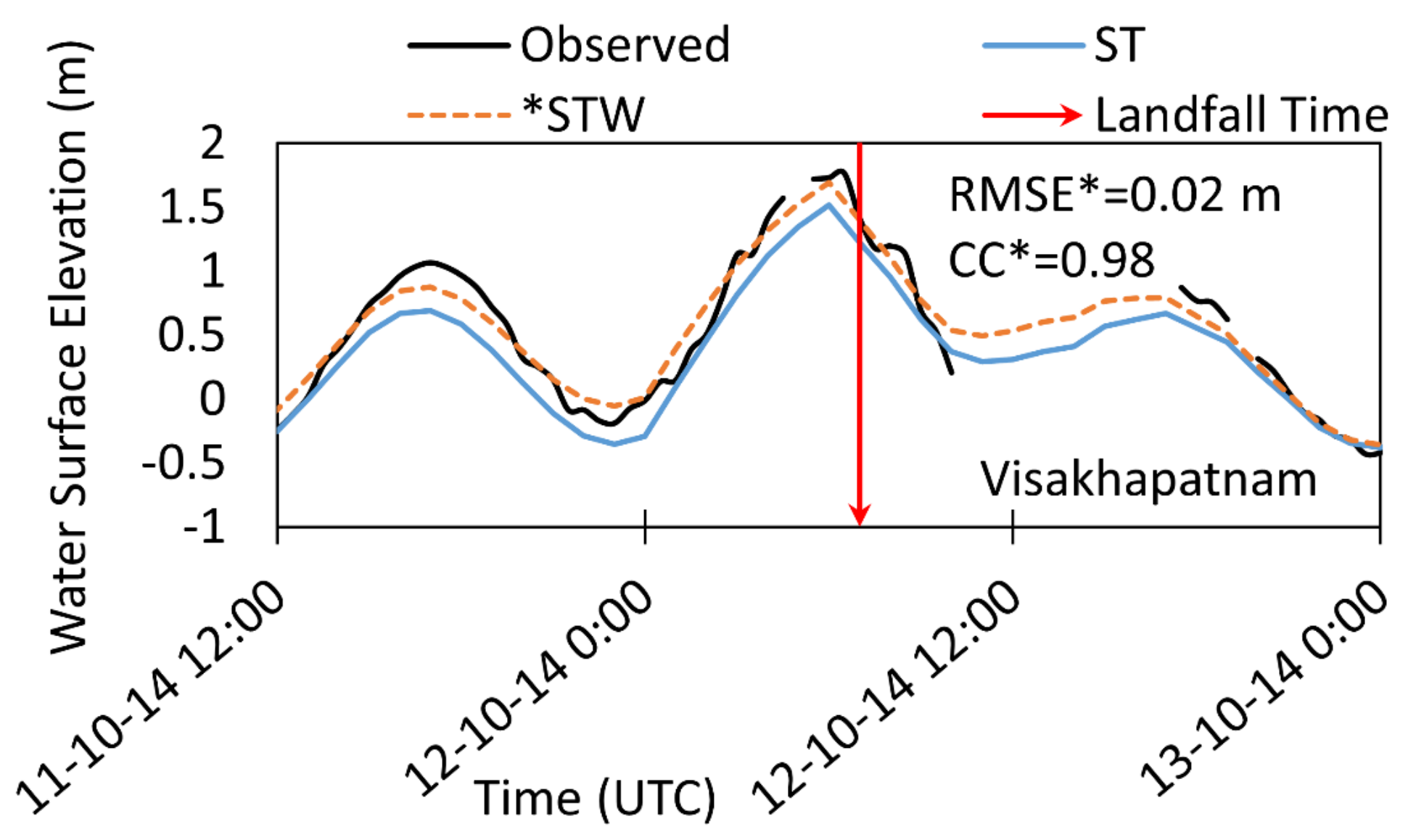

Figure 11

Comparison of observed and computed Water Levels at Visakhapatnam during an ESCS Hudhud 2014 


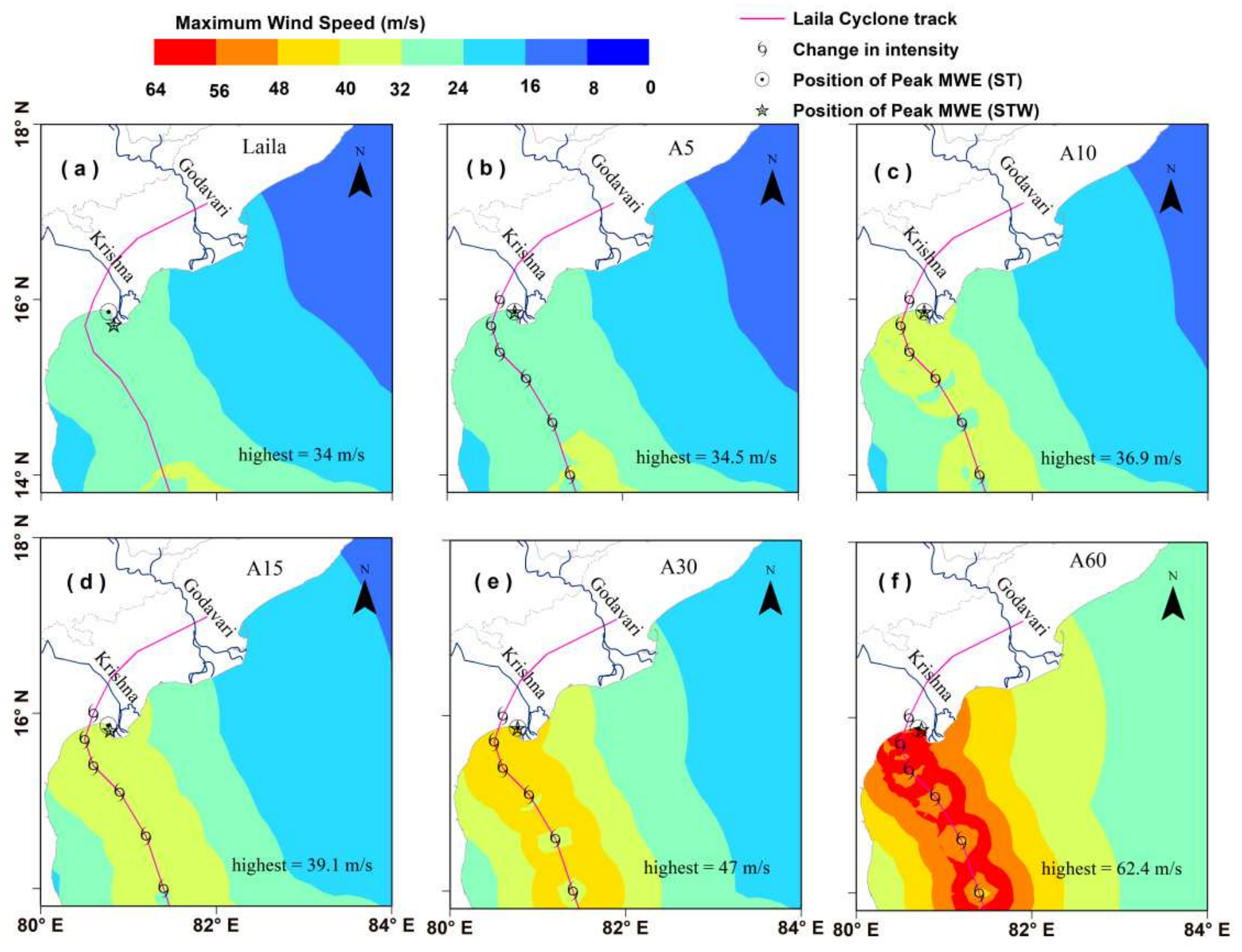

Figure 12

Spatial plot of Maximum Wind Speed during (a) Laila Cyclone and for Test A Scenario where the wind speed increased by (b) $2.57 \mathrm{~m} / \mathrm{s}$ (5 knots), (c) $5.14 \mathrm{~m} / \mathrm{s}$ (10 knots), (d) $7.71 \mathrm{~m} / \mathrm{s}$ (15 knots), (e) $15.4 \mathrm{~m} / \mathrm{s}$ (30 knots), and (f) $30.86 \mathrm{~m} / \mathrm{s}$ (60 knots) Note: The designations employed and the presentation of the material on this map do not imply the expression of any opinion whatsoever on the part of Research Square concerning the legal status of any country, territory, city or area or of its authorities, or concerning the delimitation of its frontiers or boundaries. This map has been provided by the authors. 
Minimum Pressure ( $m$ of water)

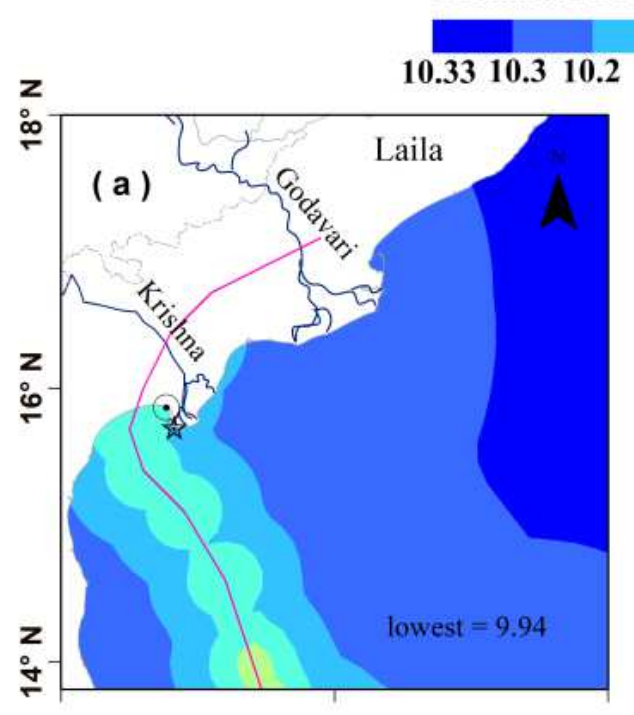

$z$

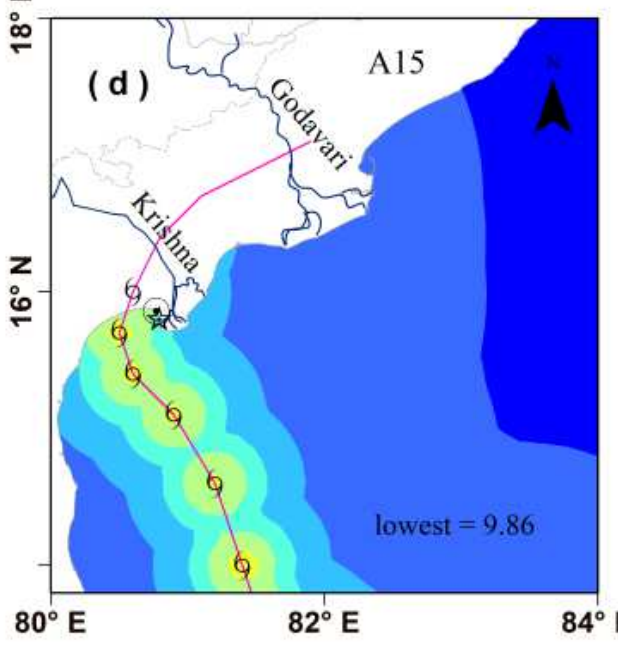

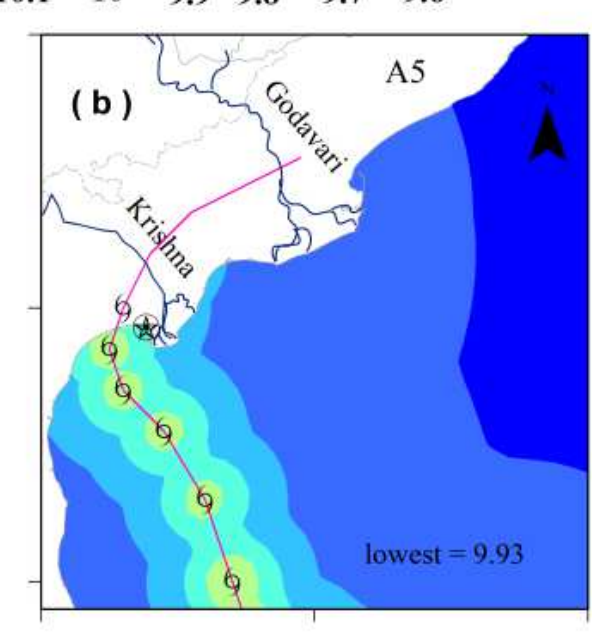

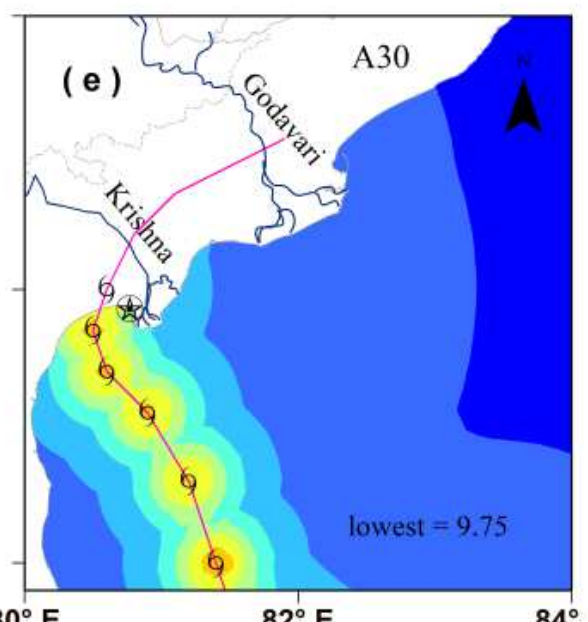

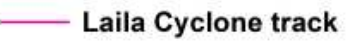

6 Change in intensity

- Position of Peak MWE (ST)

Position of Peak MWE (STW)
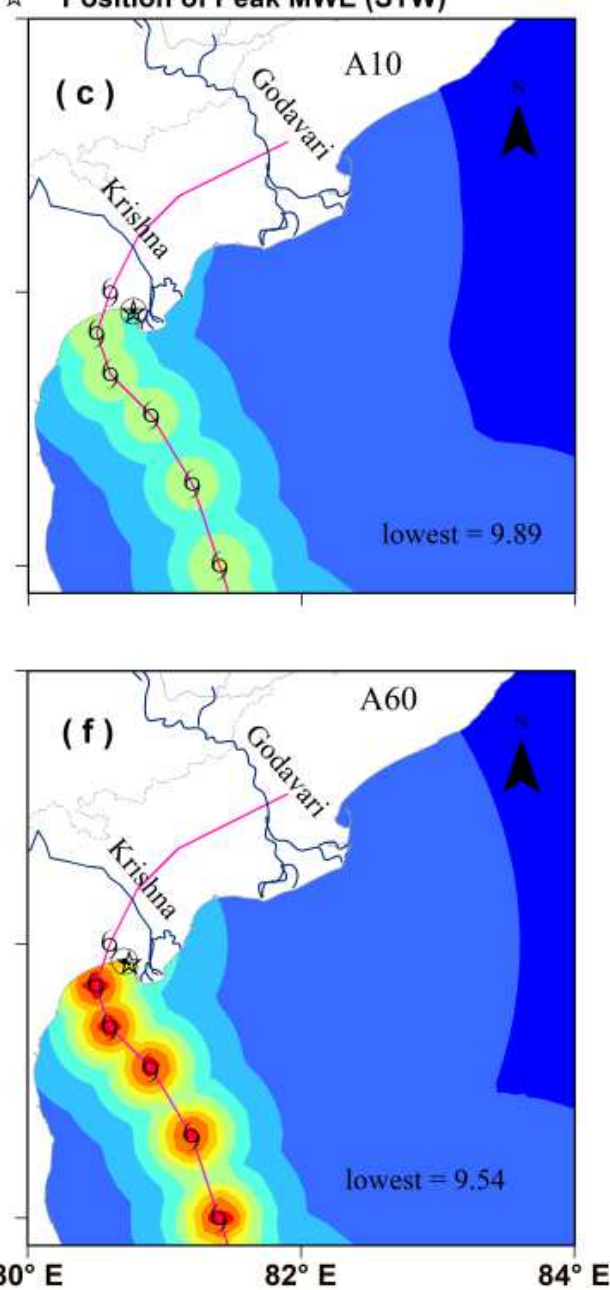

Figure 13

Spatial extent of Minimum Pressure during (a) Laila Cyclone, and for Test Scenario A where the wind speed increased by (b) $2.57 \mathrm{~m} / \mathrm{s}$ (5 knots), (c) $5.14 \mathrm{~m} / \mathrm{s}$ (10 knots), (d) $7.71 \mathrm{~m} / \mathrm{s}$ (15 knots), (e) $15.4 \mathrm{~m} / \mathrm{s}$ (30 knots), and (f) $30.86 \mathrm{~m} / \mathrm{s}$ ( 60 knots) Note: The designations employed and the presentation of the material on this map do not imply the expression of any opinion whatsoever on the part of Research Square concerning the legal status of any country, territory, city or area or of its authorities, or concerning the delimitation of its frontiers or boundaries. This map has been provided by the authors. 

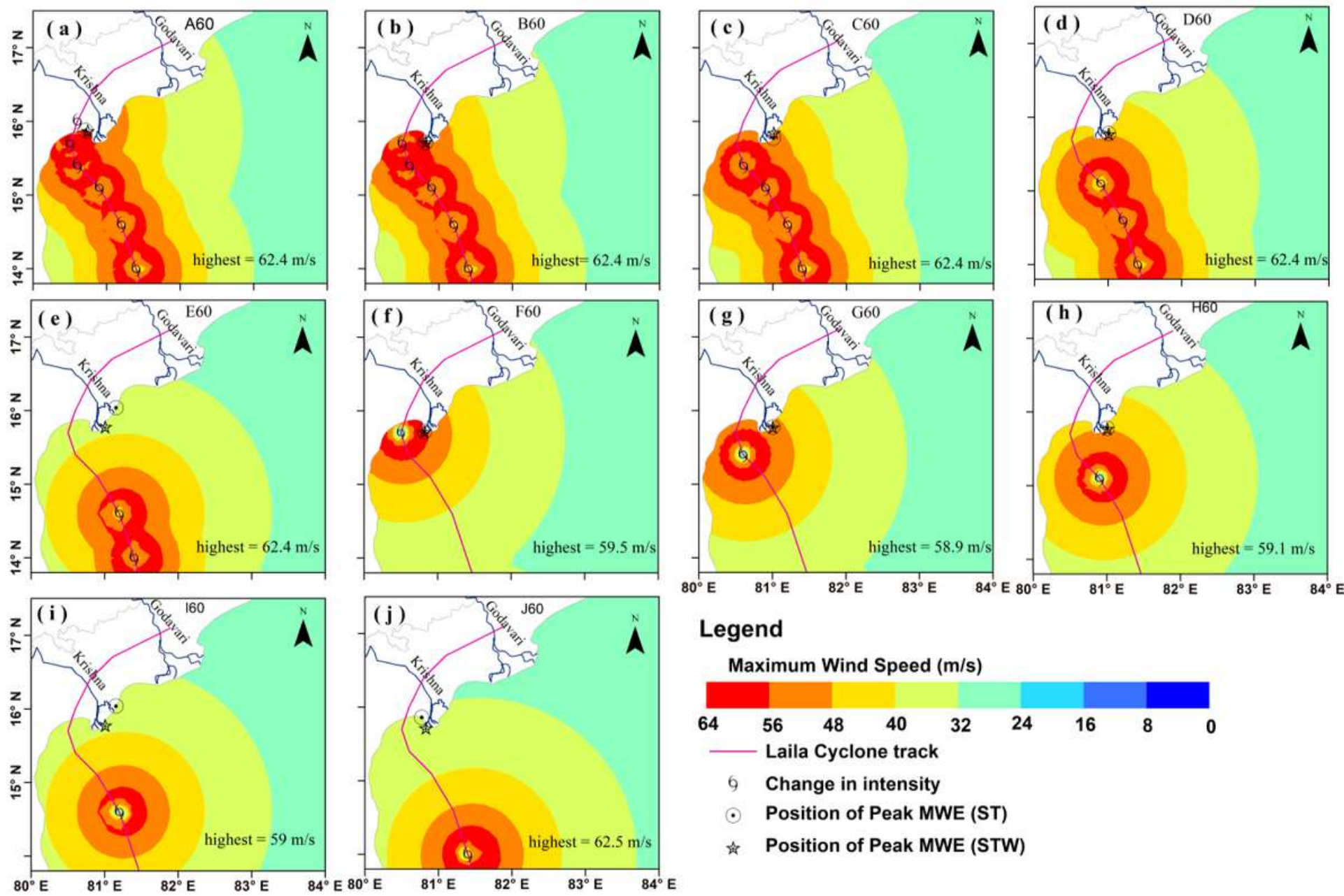

\section{Legend}

Maximum Wind Speed $(\mathrm{m} / \mathrm{s})$

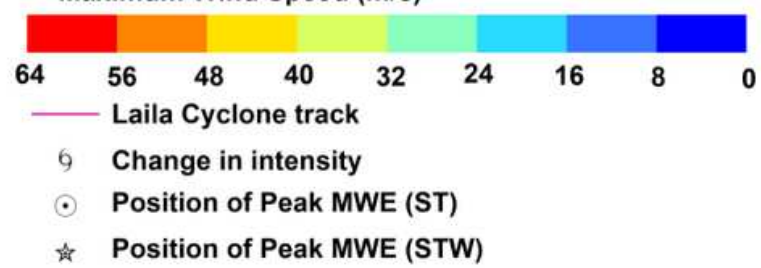

\section{Figure 14}

Spatial plot of Maximum Wind Speed with $30 \mathrm{~m} / \mathrm{s}$ (60 knots) increase for different test scenarios (A - J) Note: The designations employed and the presentation of the material on this map do not imply the expression of any opinion whatsoever on the part of Research Square concerning the legal status of any country, territory, city or area or of its authorities, or concerning the delimitation of its frontiers or boundaries. This map has been provided by the authors. 

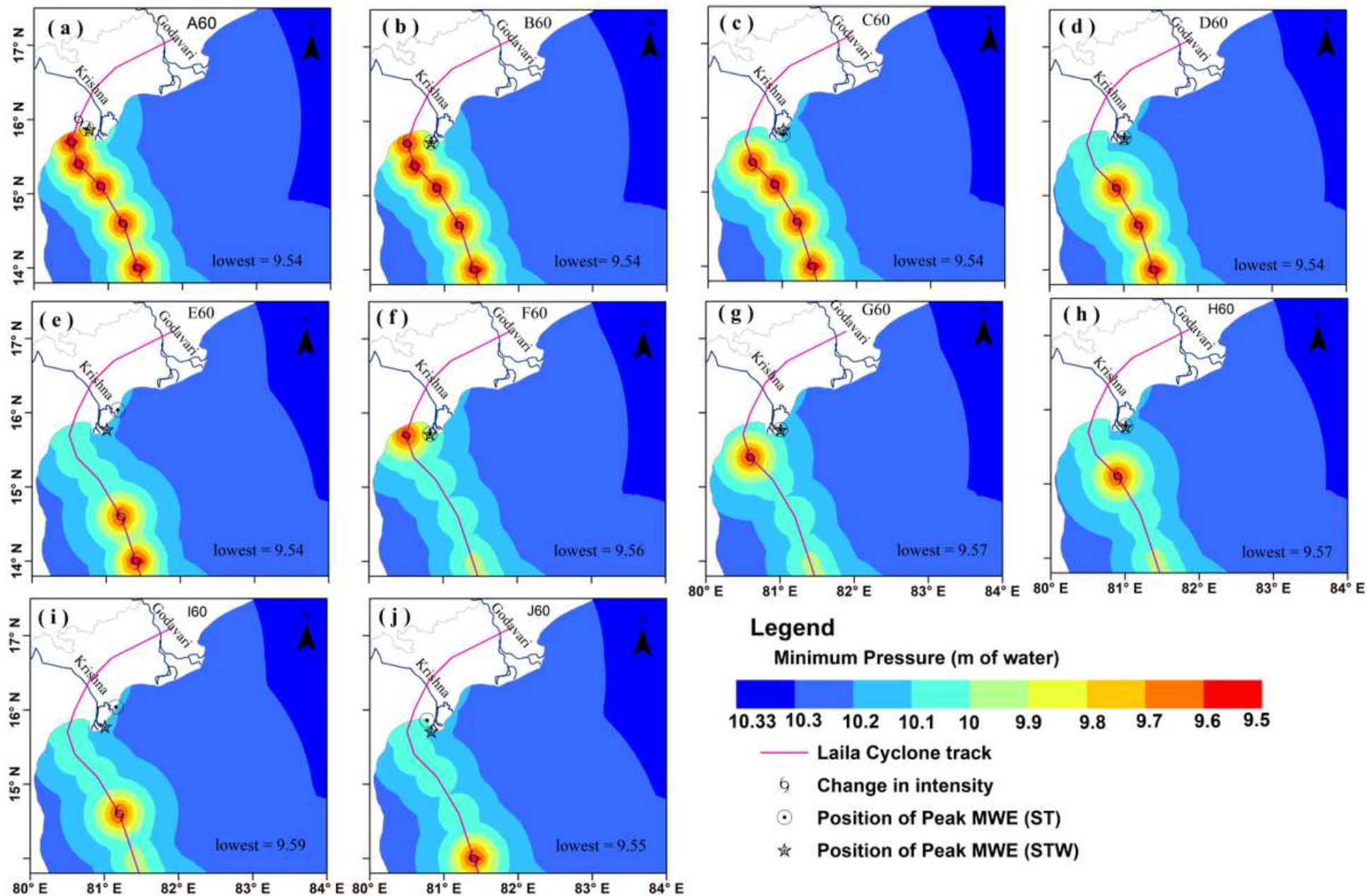

\section{Legend}

Minimum Pressure ( $m$ of water)

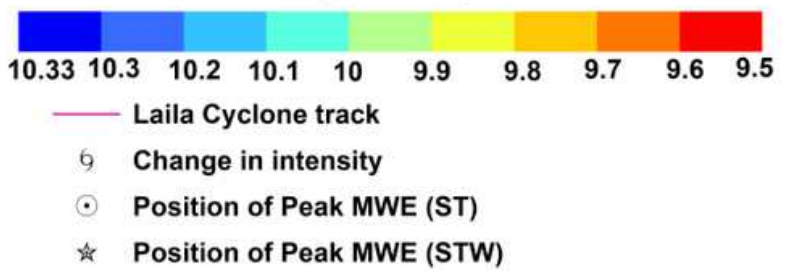

Figure 15

Spatial extent of Minimum Pressure for different Test Scenarios with an increasing wind speed by 30.86 $\mathrm{m} / \mathrm{s}$ (60 knots) considered for the study Note: The designations employed and the presentation of the material on this map do not imply the expression of any opinion whatsoever on the part of Research Square concerning the legal status of any country, territory, city or area or of its authorities, or concerning the delimitation of its frontiers or boundaries. This map has been provided by the authors. 

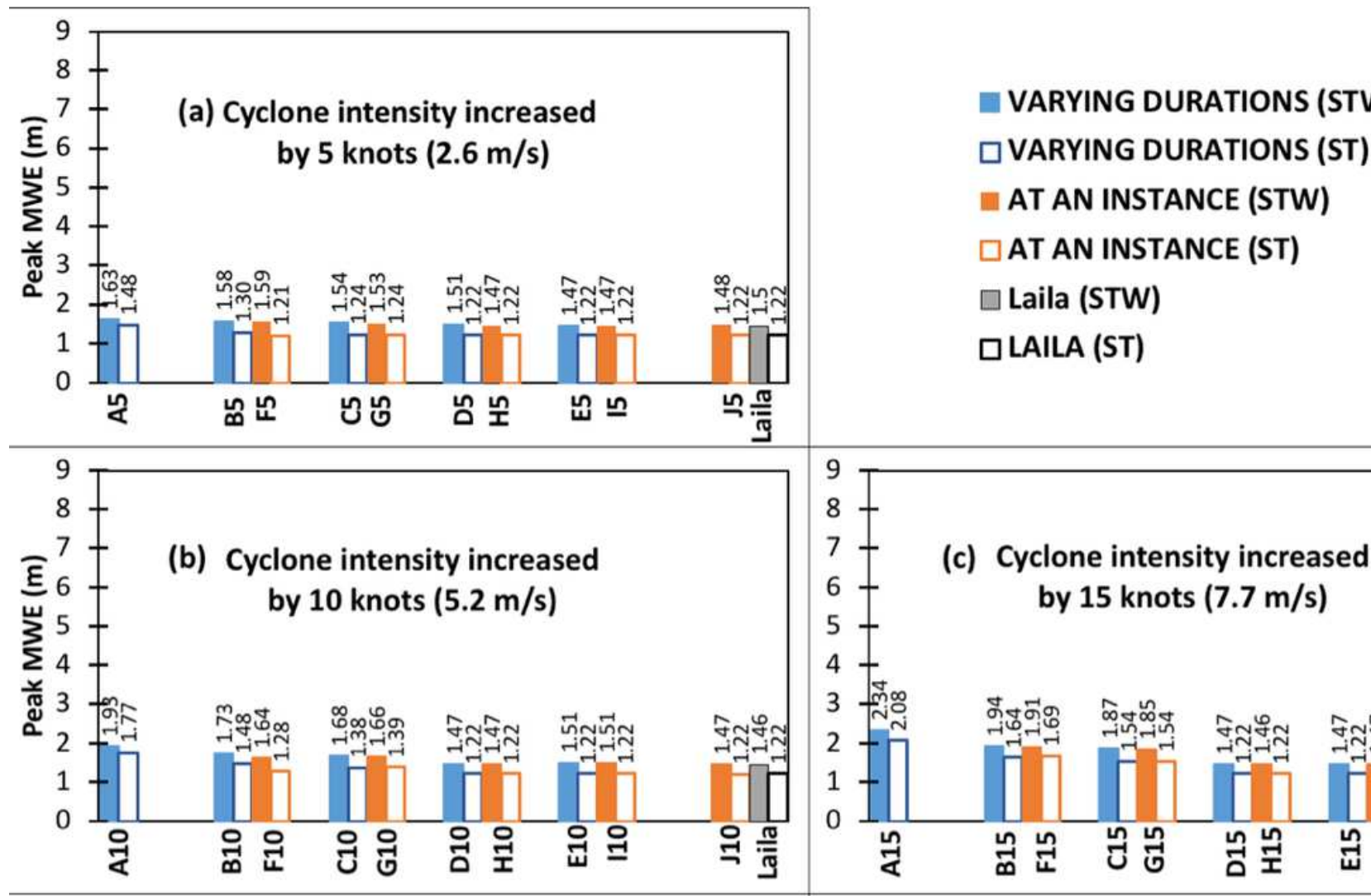

VARYING DURATIONS (STW)

$\square$ VARYING DURATIONS (ST)

AT AN INSTANCE (STW)

$\square$ AT AN INSTANCE (ST)

$\square$ Laila (STW)

口LAILA (ST)
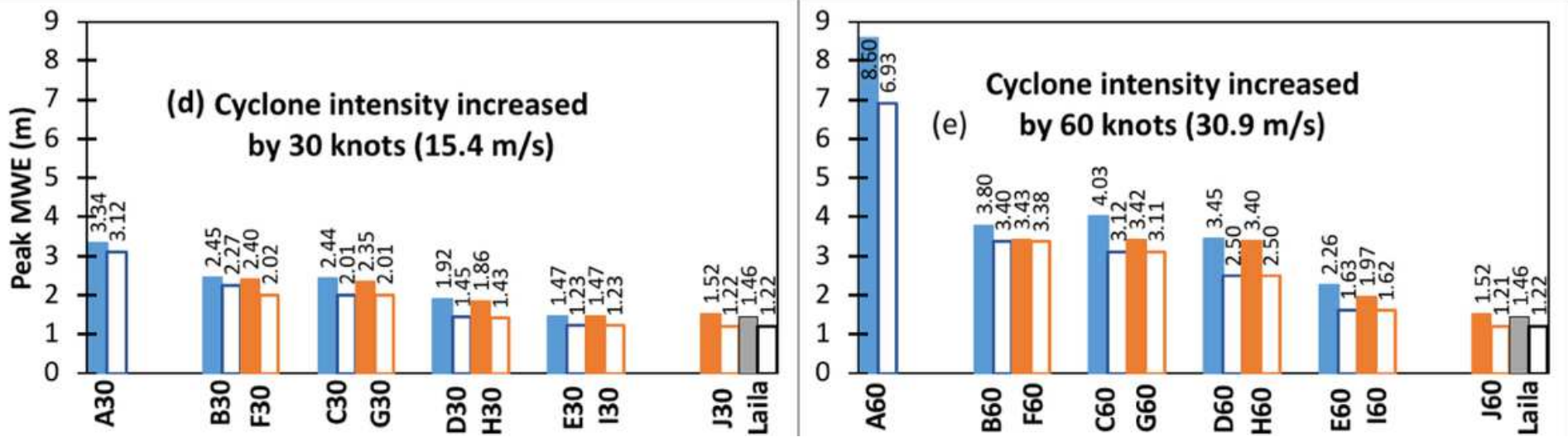

Figure 16

Peak Maximum Water Levels recorded by ST and STW along the K-G basin of Laila along with those of cyclone intensities increase by (a) $(2.57 \mathrm{~m} / \mathrm{s}$ (5 knots), (b) $5.14 \mathrm{~m} / \mathrm{s}$ (10 knots), (c) $7.71 \mathrm{~m} / \mathrm{s}$ (15 knots),

(d) $15.4 \mathrm{~m} / \mathrm{s}$ (30 knots), and (e) $30.86 \mathrm{~m} / \mathrm{s}$ (60 knots)for 10 test scenarios 


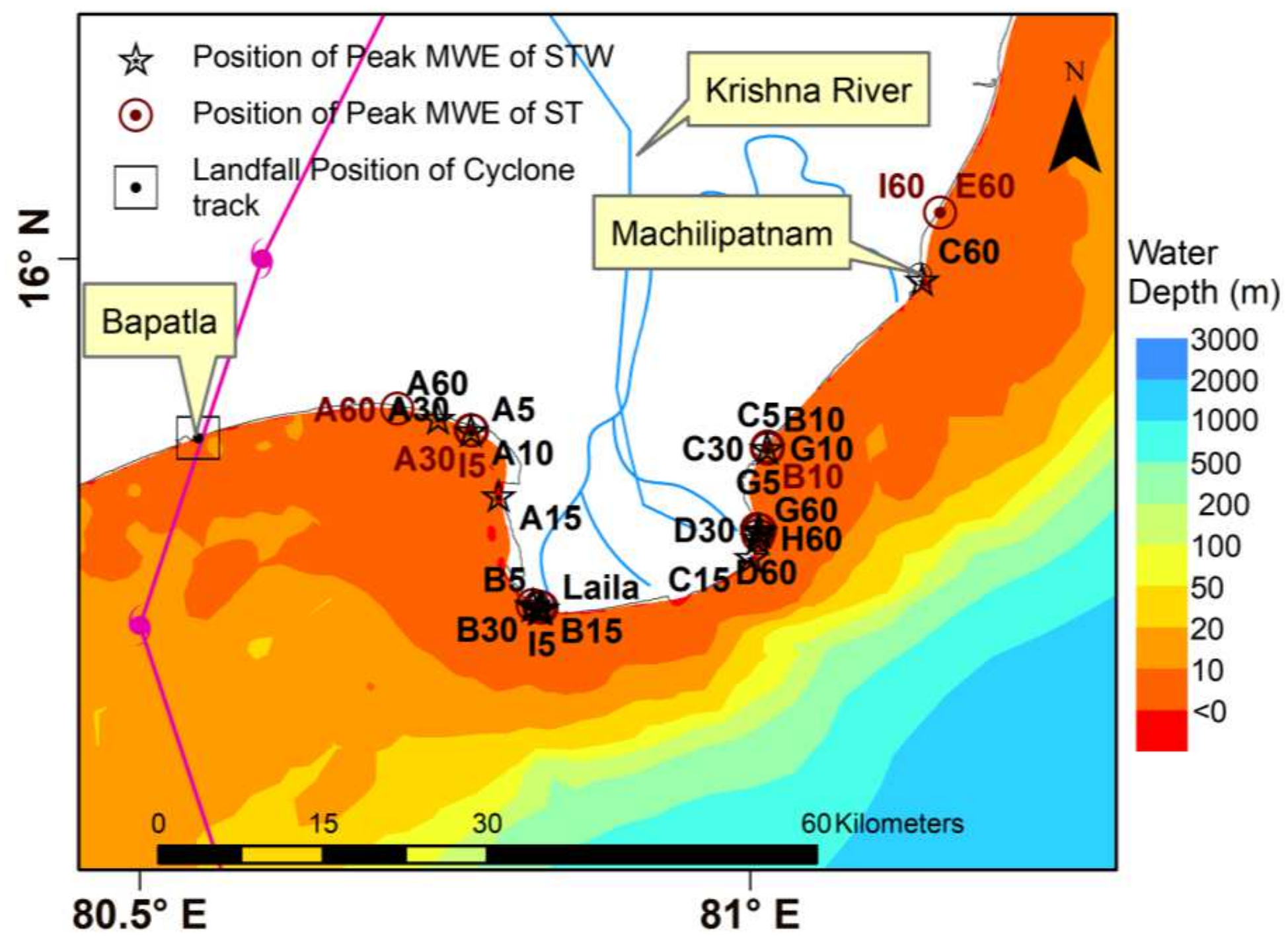

Figure 17

Location showing the Peak MWEs of STW and ST Note: The designations employed and the presentation of the material on this map do not imply the expression of any opinion whatsoever on the part of Research Square concerning the legal status of any country, territory, city or area or of its authorities, or concerning the delimitation of its frontiers or boundaries. This map has been provided by the authors. 

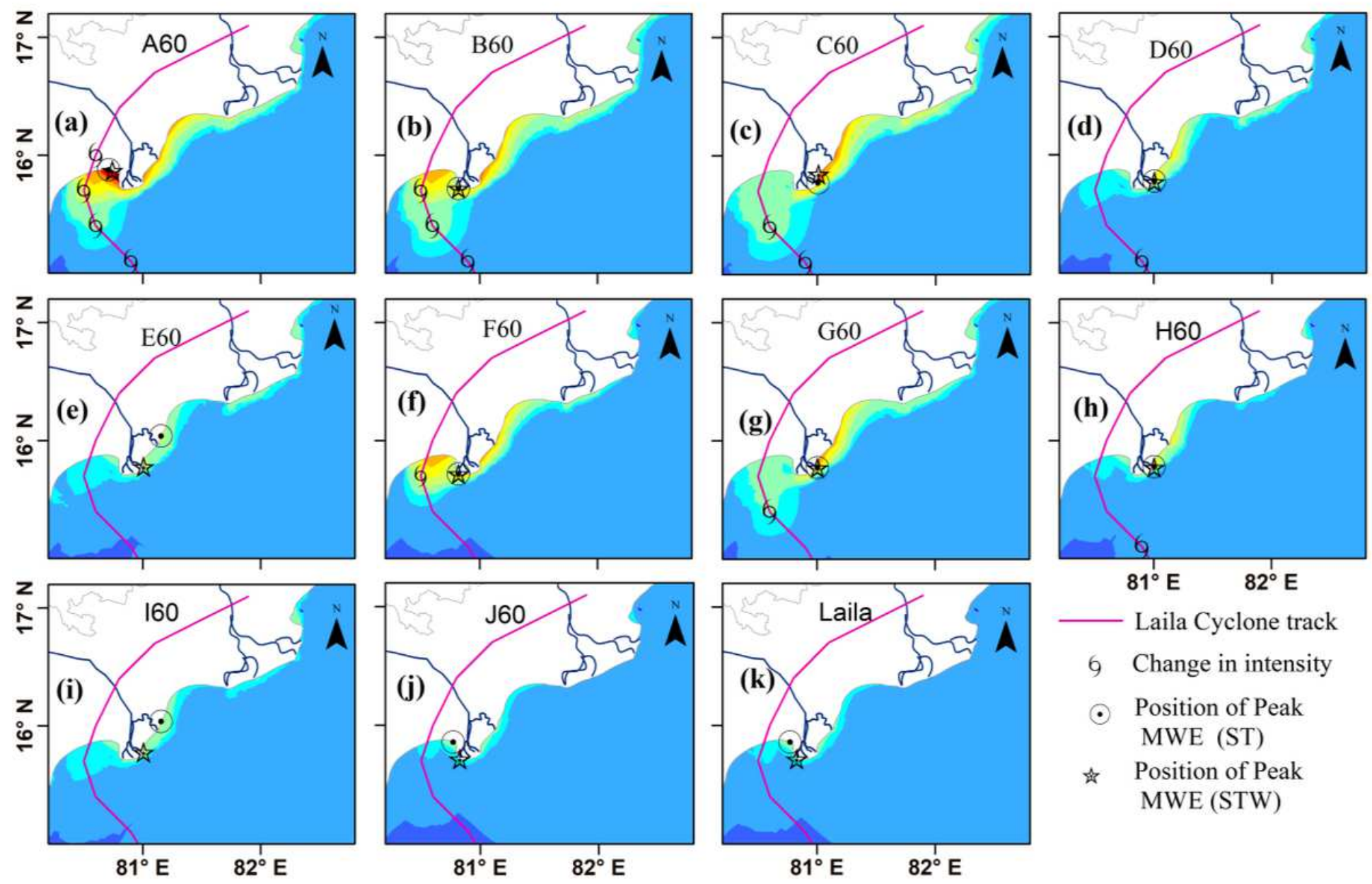

Laila Cyclone track

9 Change in intensity

• Position of Peak MWE (ST)

Position of Peak MWE (STW)

Figure 18

Spatial plot showing MWE of STW along the K-G basin for cyclone with increasing wind speed by 30.86 $\mathrm{m} / \mathrm{s}$ (60 knots) for different durations(a-j), and ( $k$ ) Laila Note: The designations employed and the presentation of the material on this map do not imply the expression of any opinion whatsoever on the part of Research Square concerning the legal status of any country, territory, city or area or of its authorities, or concerning the delimitation of its frontiers or boundaries. This map has been provided by the authors. 


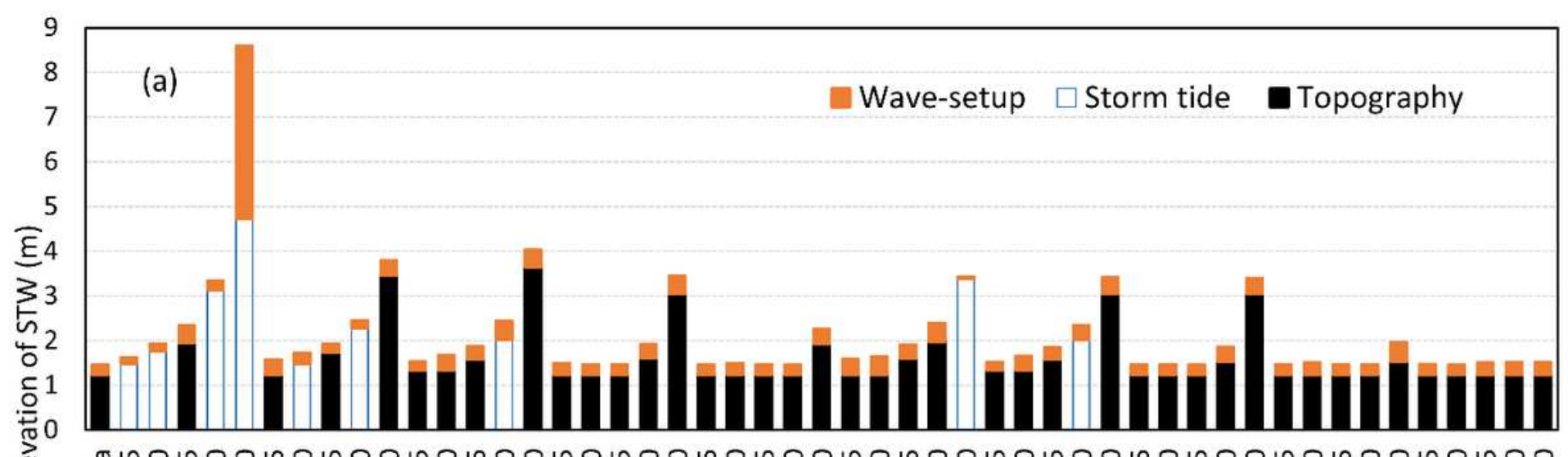

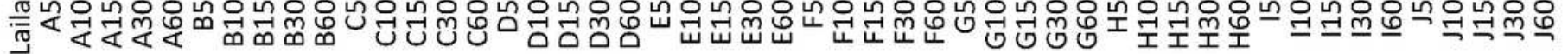
 

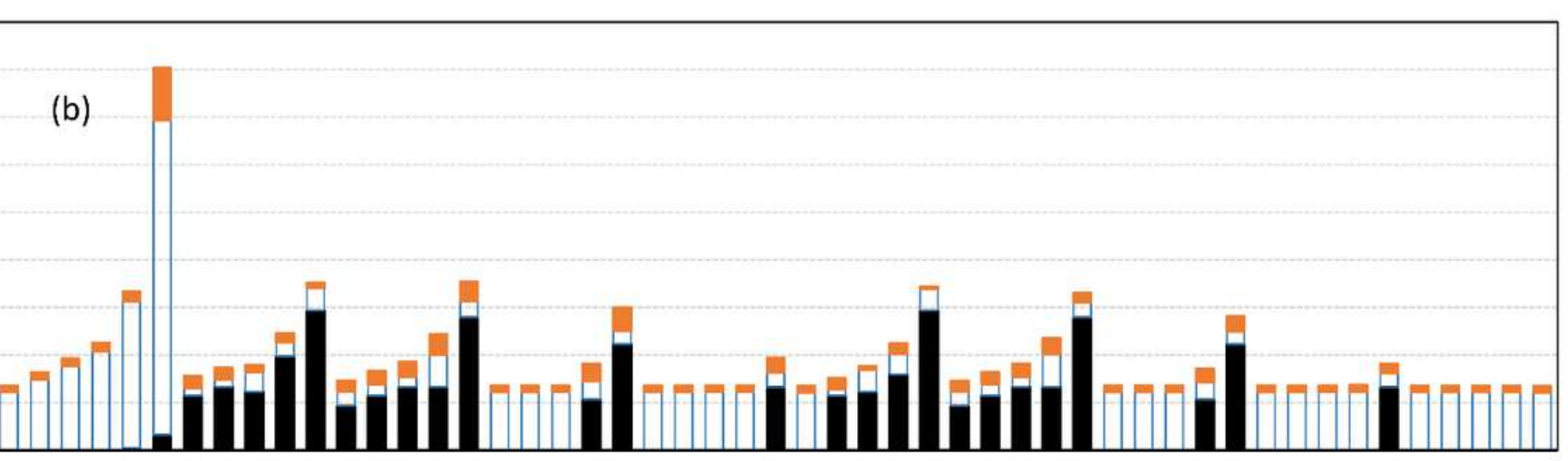

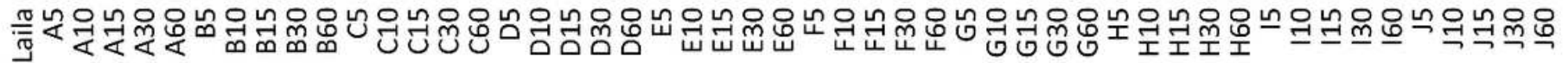
Different Test Scenarios Considered for the study

Figure 19

Wave contributions of all the numerical simulations at (a) location of peak MWE of STW (b) location of peak MWE of ST 


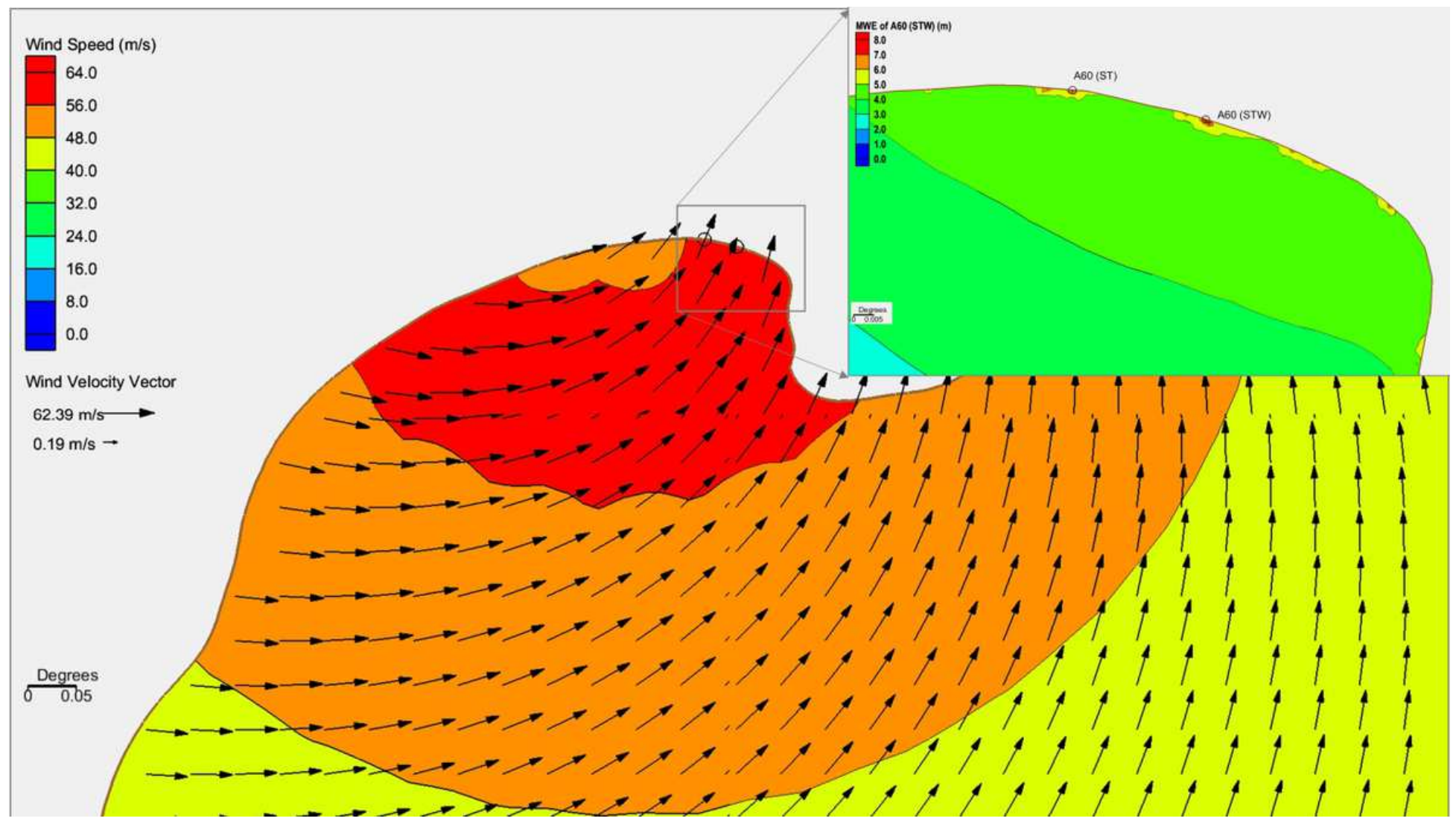

Figure 20

Wind field of Test A60 during the peak MWE for STW and the enlarged MWE showing the peak MWE (top right corner) Note: The designations employed and the presentation of the material on this map do not imply the expression of any opinion whatsoever on the part of Research Square concerning the legal status of any country, territory, city or area or of its authorities, or concerning the delimitation of its frontiers or boundaries. This map has been provided by the authors. 

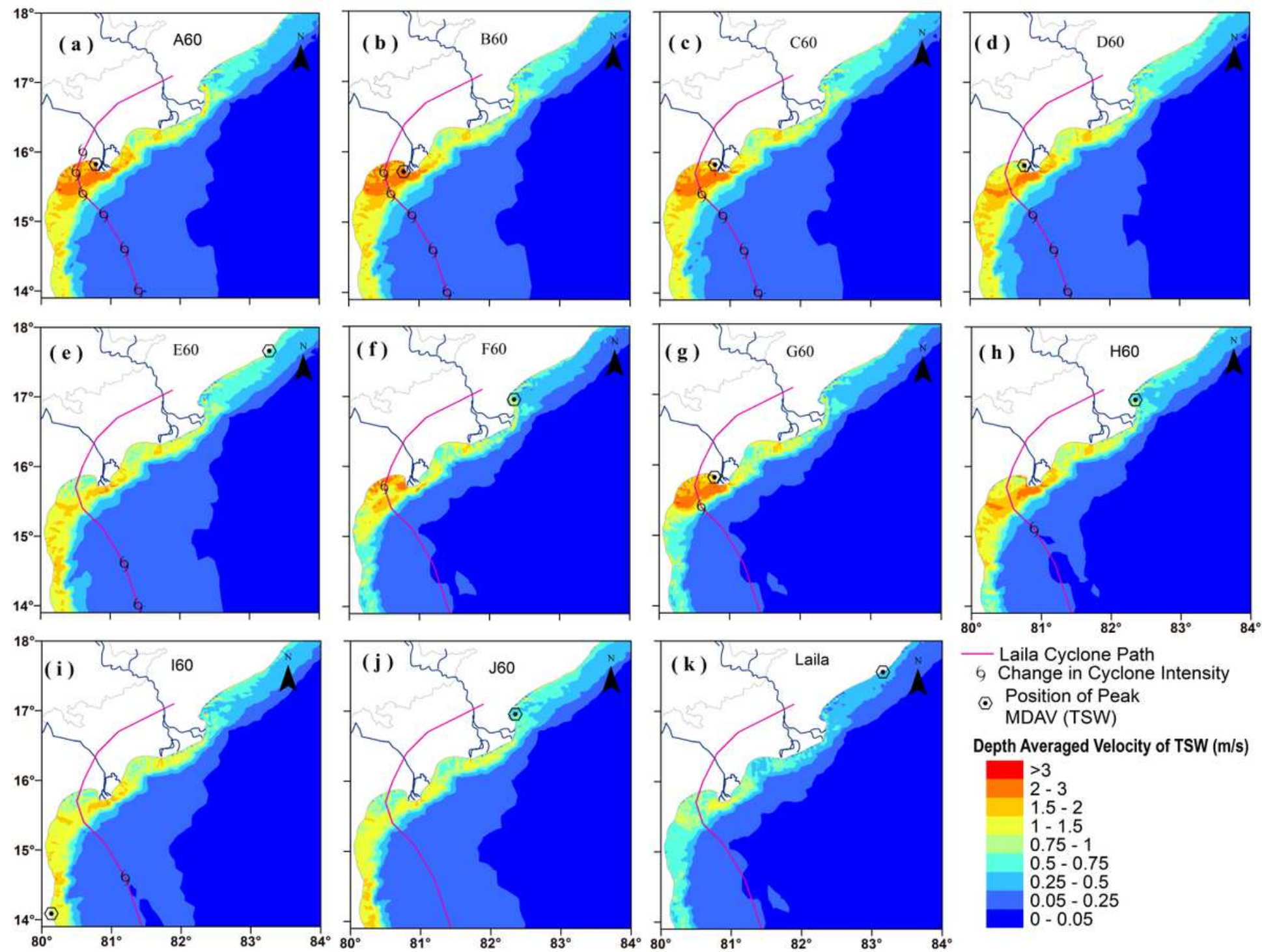

- Laila Cyclone Path

9 Change in Cyclone Intensity

- Position of Peak

MDAV (TSW)

Depth Averaged Velocity of TSW $(\mathrm{m} / \mathrm{s})$

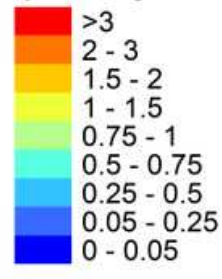

Figure 21

Spatial extent of Vavg_max with increasing wind speed by $30.86 \mathrm{~m} / \mathrm{s}$ (60 knots) for different durations considered for the study Note: The designations employed and the presentation of the material on this map do not imply the expression of any opinion whatsoever on the part of Research Square concerning the legal status of any country, territory, city or area or of its authorities, or concerning the delimitation of its frontiers or boundaries. This map has been provided by the authors. 


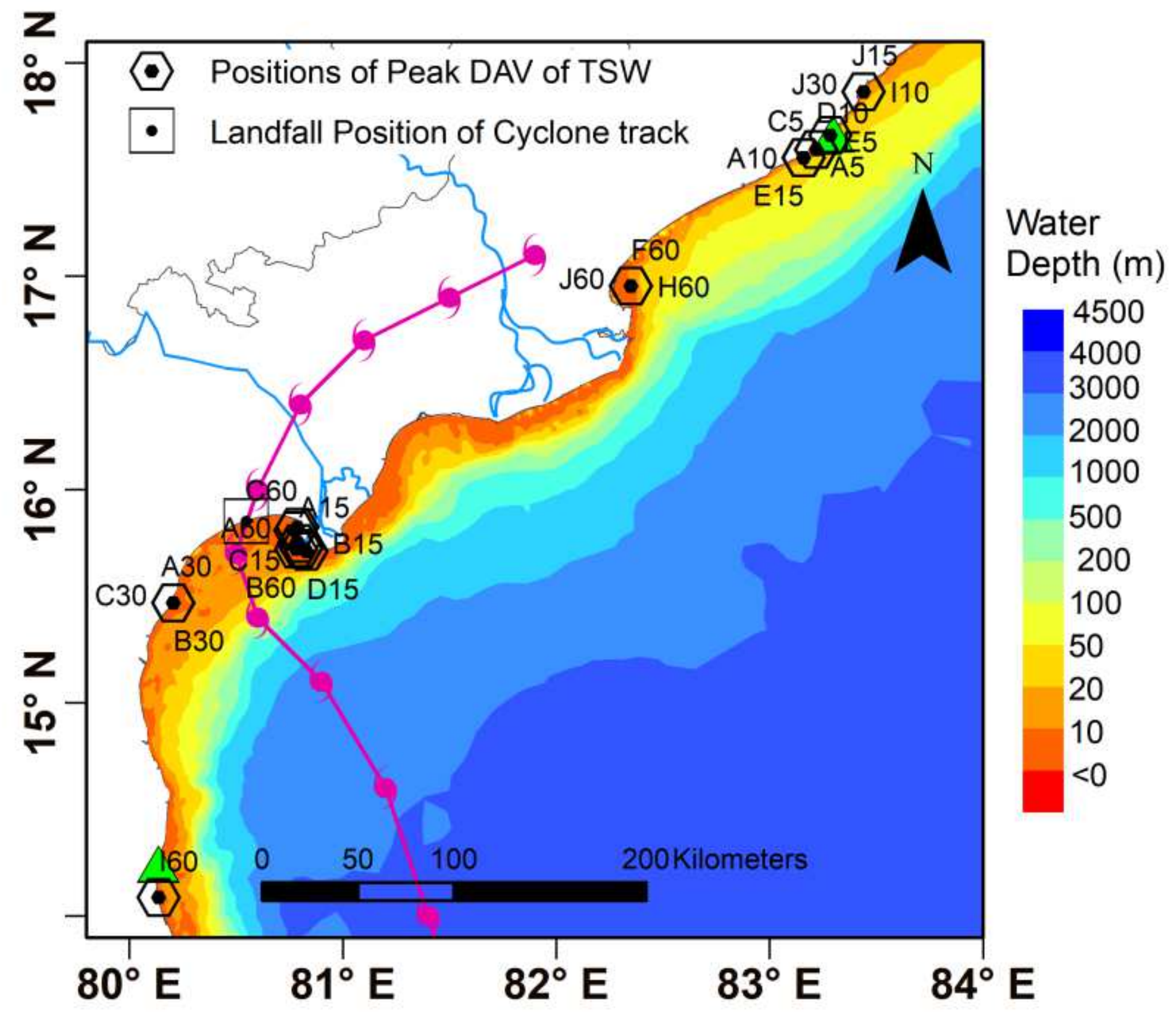

Figure 22

Locations of peak Vavg_max for all the scenarios Note: The designations employed and the presentation of the material on this map do not imply the expression of any opinion whatsoever on the part of Research Square concerning the legal status of any country, territory, city or area or of its authorities, or concerning the delimitation of its frontiers or boundaries. This map has been provided by the authors. 